\title{
Potential Alternate Smoldering Ignition Sources: Literature Review with Analysis
}

Amanda P. Robbins

Richard G. Gann

This publication is available free of charge from: https://doi.org/10.6028/NIST.TN.1710

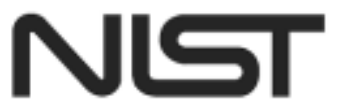

National Institute of

Standards and Technology

U.S. Department of Commerce 



\title{
Potential Alternate Smoldering Ignition Sources: Literature Review with Analysis
}

\author{
Amanda P. Robbins \\ BRANZ Ltd \\ Porirua, 5240, New Zealand \\ Richard G. Gann \\ Fire Research Division \\ Engineering Laboratory \\ Gaithersburg, MD 20899-8664
}

This publication is available free of charge from: https://doi.org/10.6028/NIST.TN.1710

October 2011

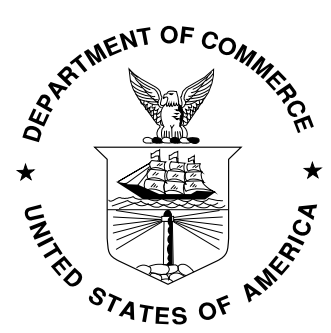

U.S. Department of Commerce

Rebecca M. Blank, Acting Secretary

National Institute of Standards and Technology

Patrick D. Gallagher, Under Secretary of Commerce for

Standards and Technology and Director 
National Institute of Standards and Technology Technical Note 1710 Natl. Inst. Stand. Technol. Tech. Note 1710, 108 pages (October 2011)

This publication is available free of charge from:

https://doi.org/10.6028/NIST.TN.1710 



\begin{abstract}
Existing and proposed U.S. flammability standards for soft furnishings such as mattresses and upholstered furniture specify a "standard" cigarette as the ignition source in smoldering resistance performance tests. With the introduction of reduced ignition propensity cigarettes into the marketplace, the specific conventional cigarette that has been widely used in testing for ignition resistance is no longer in production. A standard reference cigarette, SRM 1196, has been developed as a short-term replacement. However, to support furnishings manufacturers and testing organizations in product design and evaluation, and to assist regulators in the compliance evaluation process, a feasible and preferably non-agricultural ignition source with long-term availability is desirable. A key first step in establishing such a standard ignition source is examination of prior characterizations of smoldering ignition sources and the cigarette ignition process. This report documents a literature survey on these topics.
\end{abstract}

Keywords: cigarette; cigarette ignition resistance; fire; fire safety; fire test; ignition; ignition resistance; mattresses; smoldering; standard cigarette; upholstered furniture 


\section{DISCLAIMERS}

The research on reduced ignition propensity cigarettes conducted by NIST since 1984 was done in the interest of saving lives and protecting property from cigarette-induced fires. In no way does it lessen or negate the health hazards and addictive nature of smoking as determined by the Surgeon General or suggest that NIST and the Department of Commerce condone smoking.

Certain commercial equipment, instruments, or materials are identified in this report in order to specify the experimental procedure adequately. Such identification is not intended to imply recommendation or endorsement by the National Institute of Standards and Technology, nor is it intended to imply that the materials or equipment identified are necessarily the best available for the purpose.

Metric units are used throughout this document, except where standards are discussed that explicitly use non-metric units or where a commercial product is described in non-metric units.

This work was funded by the U.S. Consumer Product Safety Commission. The content of this publication has not been reviewed or approved by the Commission, and does not necessarily reflect the views of the Commission; similarly, mention of trade names, commercial products, or organizations does not imply endorsement by the Commission. 


\section{TABLE OF CONTENTS}

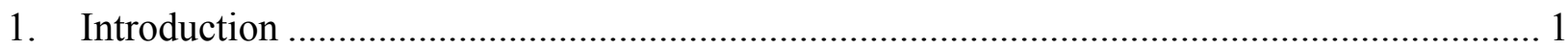

2. Categories of Replacement Standard Ignition Sources (SIS) .............................................. 5

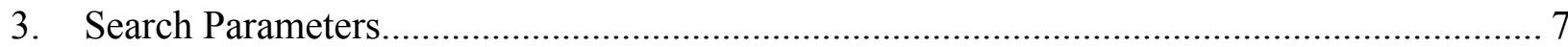

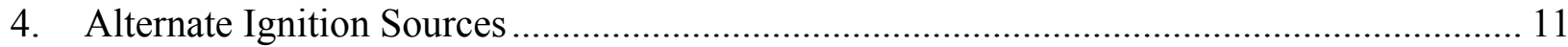

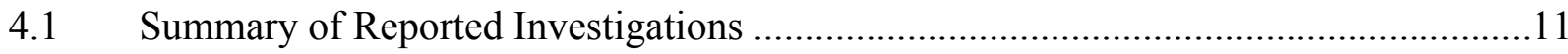

$4.2 \quad$ Electrically Powered Devices ............................................................................

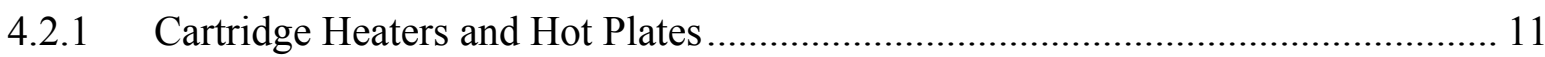

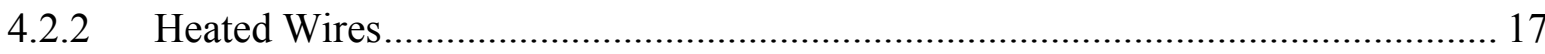

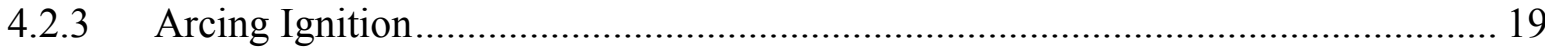

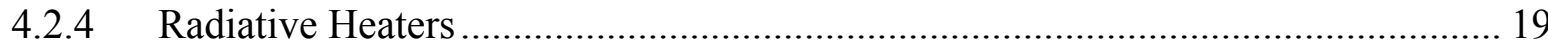

4.3 Non-Reactive Materials, Non-Electric Devices..........................................................22

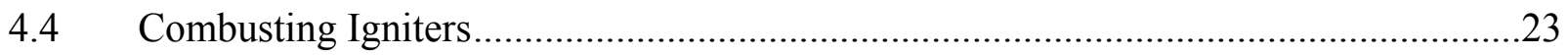

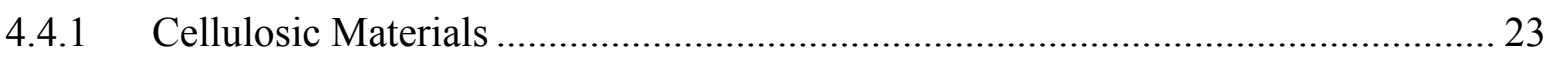

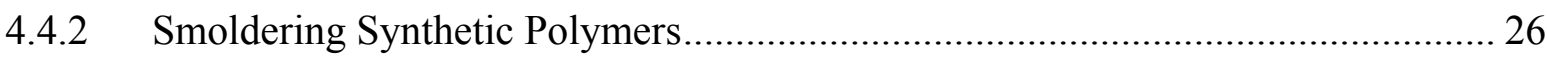

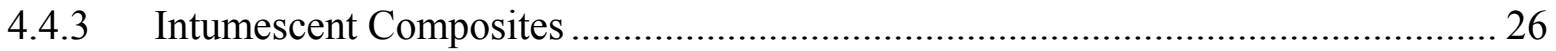

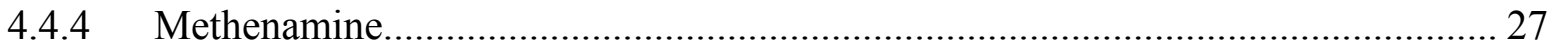

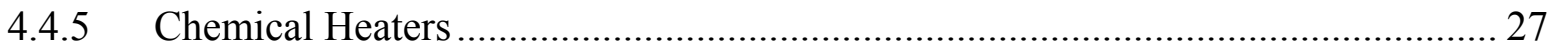

5. Thermal Characteristics of a Cigarette Burning on a Substrate ………………………....... 29

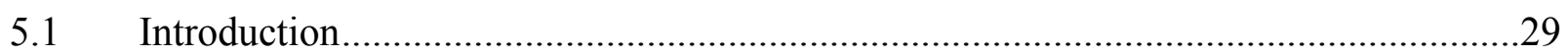

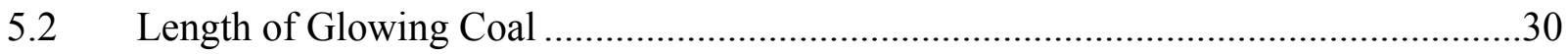

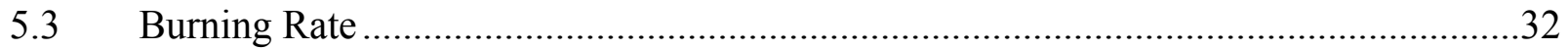

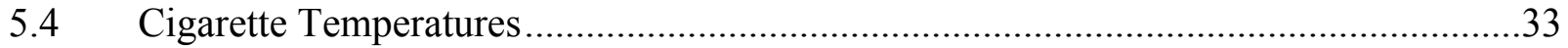

5.4.1 Temperature Measurement Devices ............................................................... 34

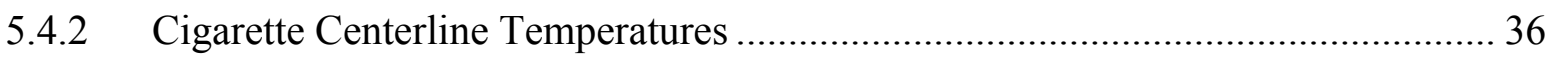

5.4.3 Cigarette Exterior and Substrate Temperatures ................................................... 38

5.4.4 Effect on Temperature of Covering a Cigarette on a Substrate .............................. 47

5.4.5 Infrared Measurements ............................................................................... 48 
5.4.6 Summary of Temperature Measurements .......................................................... 50

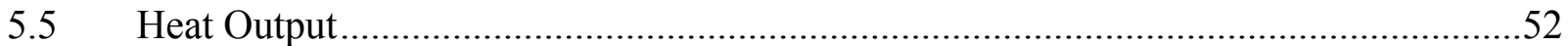

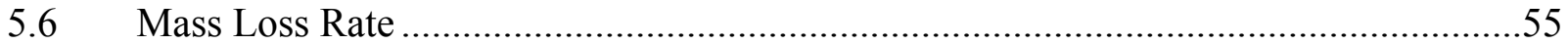

5.7 Potential Parameters for Determining Ignition Propensity ...........................................56

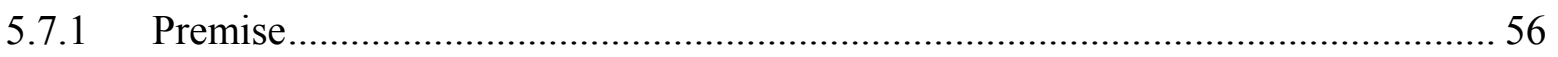

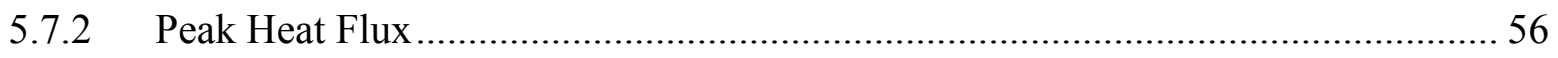

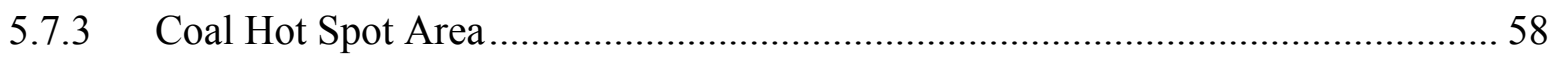

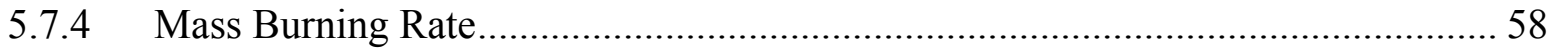

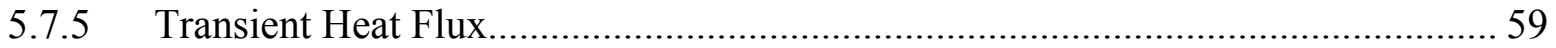

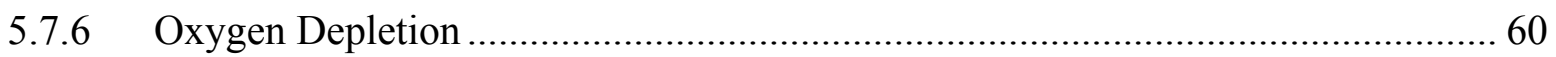

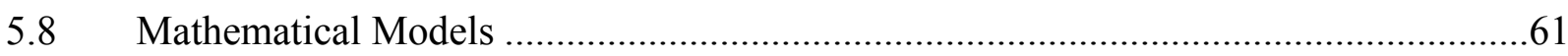

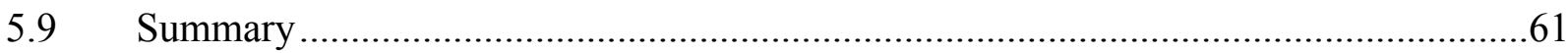

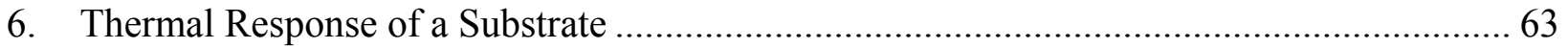

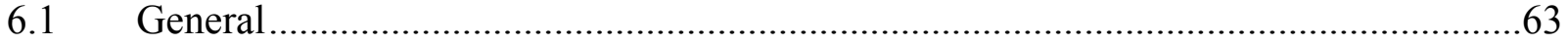

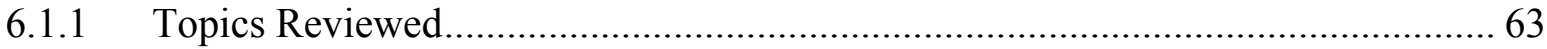

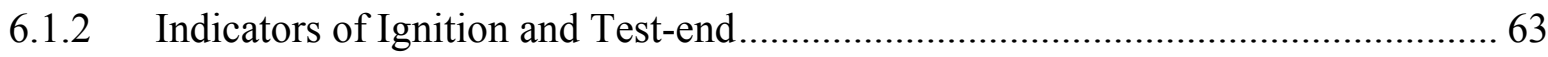

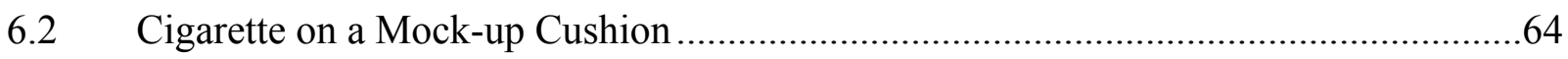

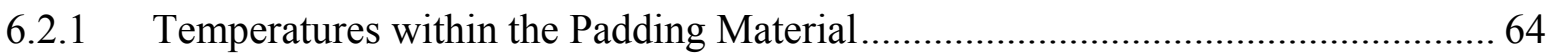

6.2.2 Temperatures on the Surface of the Substrate ………………………………..... 71

6.2.3 Inter-Bolt Fabric Variability ................................................................................ 73

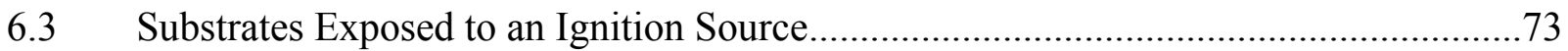

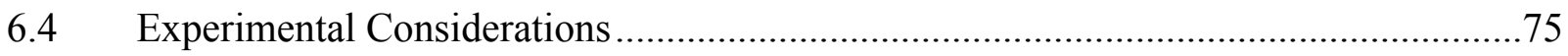

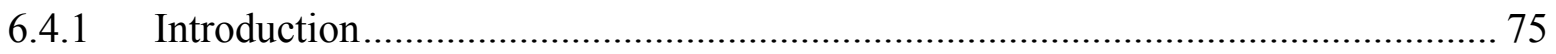

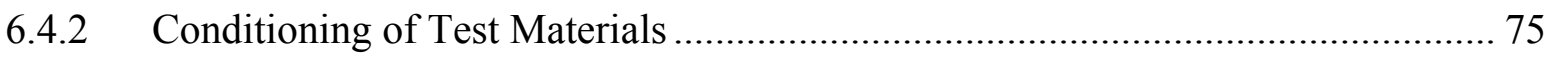

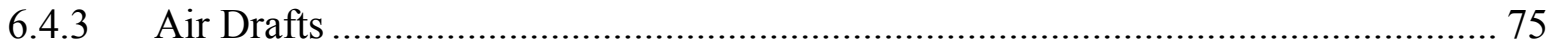

6.4.4 Influence of Substrate on Cigarette Burning ..................................................... 75

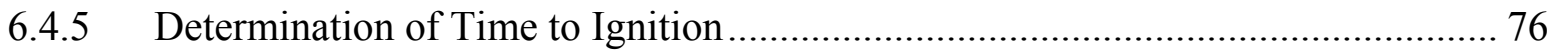

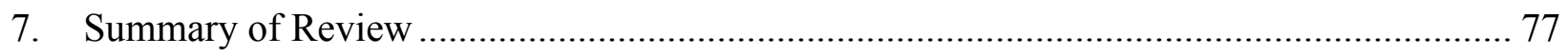

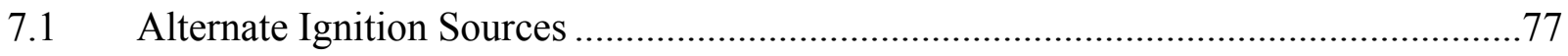




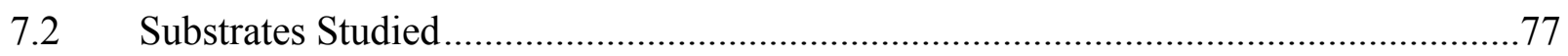

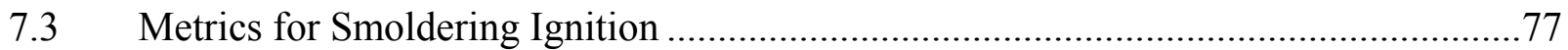

7.4 Other Considerations for Identifying and Qualifying Alternate Standard Ignition

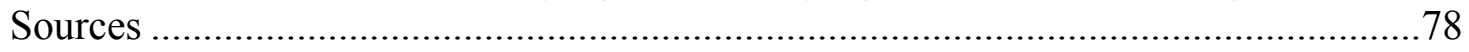

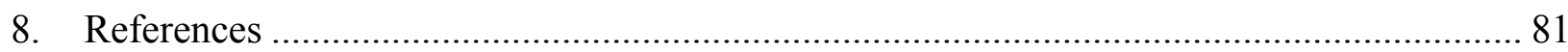


This page intentionally left blank.

viii 


\section{LIST OF FIGURES}

Figure 1. Cigarette Ignition of Soft Furnishings. [10] ....................................................... 2

Figure 2. Coal length for various cigarettes in various test configurations. [10]..................... 31

Figure 3. Smolder speed versus cigarette-substrate configuration. [10].................................. 32

Figure 4. Smolder speed for a cigarette on a fabric and foam mock-up versus smolder speed of a free-burning cigarette. [10] 33

Figure 5. Thermocouple temperatures on the centerline of a free-burning cigarette suspended in air. [30]

Figure 6. Thermocouple temperatures on the centerline of cigarettes, where one is a free-burning cigarette suspended in air and two others are located in the crevice of two upholstered cushions. [30] 37

Figure 7. Schematic of the test set up for cigarettes located in the crevice of two upholstered cushions. [30]..... 38

Figure 8. Schematic of the single cushion setup including thermocouple locations on the line of contact between the cigarette and substrate and within the foam directly under the initial location of the cigarette, where (a) one $80 \mathrm{~mm}$ cigarette was used, or (b) two $80 \mathrm{~mm}$ cigarettes were used in series to effectively form a $160 \mathrm{~mm}$ long cigarette. [30].....

Figure 9. Thermocouple temperatures located on the contact line between the bottom surface of a covered $80 \mathrm{~mm}$ cigarette and the substrate of Doblin fabric over polyurethane for (a) temperature versus time and (b) temperature versus thermocouple location. [30] 40

Figure 10. Thermocouple temperatures located on the contact line between the bottom surface of a covered $80 \mathrm{~mm}$ cigarette and the substrate of greige duck fabric over polyurethane for (a) temperature versus time and (b) temperature versus thermocouple location. [30]

Figure 11. Thermocouple temperatures located on the contact line between the bottom surface of a covered $160 \mathrm{~mm}$ cigarette and the substrate of duck dyed blue fabric over polyurethane for (a) temperature versus time and (b) temperature versus thermocouple location. [30]....

Figure 12. Thermocouple temperatures located on the contact line between the bottom surface of a covered $160 \mathrm{~mm}$ cigarette and the substrate of printcloth fabric over polyurethane for (a) temperature versus time and (b) temperature versus thermocouple location. [30]

Figure 13. Thermocouple temperatures on the centerline of cigarettes located in the crevice of two upholstered (printcloth fabric and polyurethane foam) cushions, where the cigarettes were either uncovered or covered with a square of printcloth fabric. [30].

Figure 14. Thermocouple temperature profile of a free-burning commercial cigarette as the Schmidt-Boelter gauge is scanned over the length. [10] 
Figure 15. Example of averaged heat flux gauge measurements for six scans during one test in three test configurations: (a) free-burning, (b) one-cushion mock-up and (c) two-cushion crevice mock-up. [10]......

Figure 16. Number of substrate ignitions versus average peak heat flux estimates for various cigarettes on a one-cushion mock-up. [10]

Figure 17. Peak temperature from a peripherally located thermocouple versus average peak flux for a cigarette on a one-cushion mock-up. [10] ..... 57

Figure 18. Estimated hot spot area and the number of substrate ignitions from one-cushion

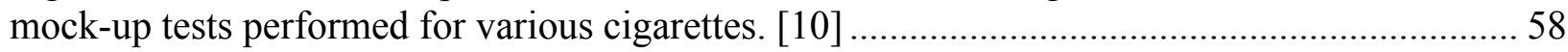

Figure 19. Mass burning rate and number of ignitions from all one-cushion mock-up tests. [10]

Figure 20. Mass burning rate versus coal length (from one-cushion mock-up tests using California fabric over 2024 polyurethane foam). [10] ............................................................ 59

Figure 21. Thermocouple temperatures versus (a) time and (b) location for TCs located in the foam at $25 \mathrm{~mm}$ directly below a covered $80 \mathrm{~mm}$ cigarette that is located on the substrate of Doblin fabric over a FPU foam. [30]

Figure 22. Thermocouple temperatures versus (a) time and (b) location for TCs located in the foam at $50 \mathrm{~mm}$ directly below a covered $80 \mathrm{~mm}$ cigarette that is located on the substrate of Doblin fabric over a FPU foam. [30]

Figure 23. Thermocouple temperatures versus (a) time and (b) location located in the foam $25 \mathrm{~mm}$ directly below a covered $80 \mathrm{~mm}$ cigarette that is located on the substrate of greige duck fabric over a FPU foam. [30]

Figure 24. Thermocouple temperatures versus (a) time and (b) location located in the foam $50 \mathrm{~mm}$ directly below a covered $80 \mathrm{~mm}$ cigarette that is located on the substrate of greige duck fabric over a FPU foam. [30]

Figure 25. Thermocouple temperatures versus (a) time and (b) location located in the foam $25 \mathrm{~mm}$ directly below a covered $80 \mathrm{~mm}$ cigarette that is located on the substrate of duck dyed blue fabric over a FPU foam. [30]

Figure 26. Thermocouple temperatures versus (a) time and (b) location located in the foam $50 \mathrm{~mm}$ directly below a covered $80 \mathrm{~mm}$ cigarette that is located on the substrate of duck dyed blue fabric over a FPU foam. [30]...

Figure 27. Thermocouple temperatures versus (a) time and (b) location located in the foam $25 \mathrm{~mm}$ directly below a covered $80 \mathrm{~mm}$ cigarette that is located on the substrate of printcloth fabric over a FPU foam. [30]. 
Figure 28. Thermocouple temperatures versus (a) time and (b) location located in the foam $50 \mathrm{~mm}$ directly below a covered $80 \mathrm{~mm}$ cigarette that is located on the substrate of printcloth

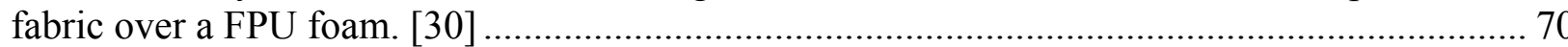

Figure 29. Isothermal contours on the top surface of a one-cushion mock-up after the cigarette had burnt $20 \mathrm{~mm}$ for (a) a relatively low ignition propensity cigarette, and (b) a relatively high ignition propensity cigarette. [10] 
This page intentionally left blank. 


\section{LIST OF TABLES}

Table 1. Reduction in U.S. cigarette-initiated fire losses following implementation of mitigating

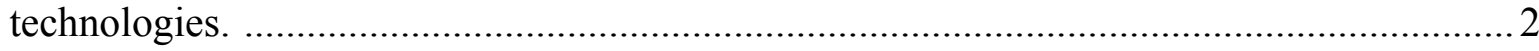

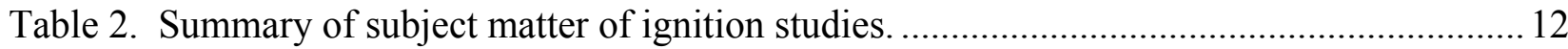

Table 3. Fabrics used and variables recorded for the Fabric Classification Test Method. ............. 24

Table 4. Thermocouple temperatures on the surface of a calcium silicate board under various

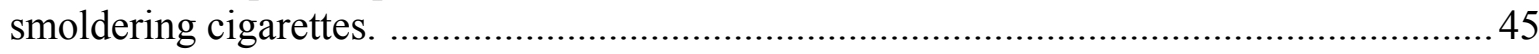

Table 5. Summary of measured maximum cigarette coal temperatures........................................51 
This page intentionally left blank. 


\section{INTRODUCTION}

As early as the 1960s, it was recognized that cigarette ignition of soft furnishings (upholstered furniture and mattresses) was a leading cause of fire deaths and a major contributor to fire losses in the United States. [1,2] Such fires typically occur when a lit cigarette is accidentally dropped onto a susceptible item, e.g., a chair or bed. The heat generated by the smoldering cigarette is transferred to the furnishing, raising its temperature locally. The surface fabric and/or the padding material is ignited, itself beginning to smolder and generating small, concentrated quantities of toxic gases in the immediate vicinity of the ignition. If the person who had been smoking the cigarette was still present, that person would then be inhaling concentrated toxicants (carbon monoxide, perhaps hydrogen cyanide, and others). Allowed to continue, this smoldering fire could be lethal. At some point, the smoldering fire might transition to a flaming fire. The burning rate would then rise sharply, and as the fire grows and develops, driving flames and toxic smoke throughout the building. People in other rooms would be exposed to the lifethreatening effluent from the fire.

Historically, mitigating this problem could have been achieved in multiple ways, including (in no particular order):

1. Reduction in the number of cigarettes smoked,

2. Alteration of the habits of smokers,

3. Improvements in and prevalence of fire detection and suppression systems,

4. Reducing the propensity of cigarettes to ignite soft furnishings;

5. Reducing the fire growth rate and peak heat release rate of ignited furnishings, and

6. Increasing the resistance of soft furnishings to cigarette ignition.

Considering the third and sixth of these approaches that were pursued, first, in the 1970s, research led to installation guidelines for residential fire smoke alarms. Today, these alarms are installed in nearly all American homes. [3] Second, test methods for characterizing the cigarette ignition resistance of upholstered furniture and mattresses were also developed also in the 1970s by the fire research community. Based on these, both the U.S. Consumer Product Safety Commission (CPSC) and the State of California have promulgated, or are in the process of promulgating, regulations that limit the susceptibility of these soft furnishings to ignition by a lit cigarette. [4-6] There are also standard tests for cigarette ignition resistance that are used by the soft furnishings industries. [7-9]

As noted in Table 1, these two concurrent activities contributed to a reduction in deaths from cigarette-initiated fires of approximately $60 \%$, injuries by $70 \%$, and property damage by over $40 \%$. [2,3] Nonetheless, cigarette ignition of upholstered furniture and mattresses continues to be the largest single cause of residential fire deaths in the United States. [3] 
Table 1. Reduction in U.S. cigarette-initiated fire losses following implementation of mitigating technologies. [3]

\begin{tabular}{|c|c|c|c|}
\hline Year & Deaths & Injuries & Property Damage \\
\hline 1980 & 1,820 & 5,280 & $\$ 1,305$ million \\
\hline 2003 & 780 & 1,610 & $\$ 737$ million \\
\hline
\end{tabular}

The ignition resistance test methods for both mattresses and upholstered furniture involve placing a lit cigarette on a substrate that is either the finished product or an assembly meant to be representative of the finished product. The hot coal of the cigarette moves along the substrate, transferring heat to the substrate materials, which themselves are transferring heat away from the point of contact. Should the thermal environment and the material chemistry combine appropriately, smoldering combustion begins. The process is depicted in Figure 1. A potential threat to life safety results if the smoldering continues to propagate outward from the ignition venue, with the potential for transitioning to flaming combustion.

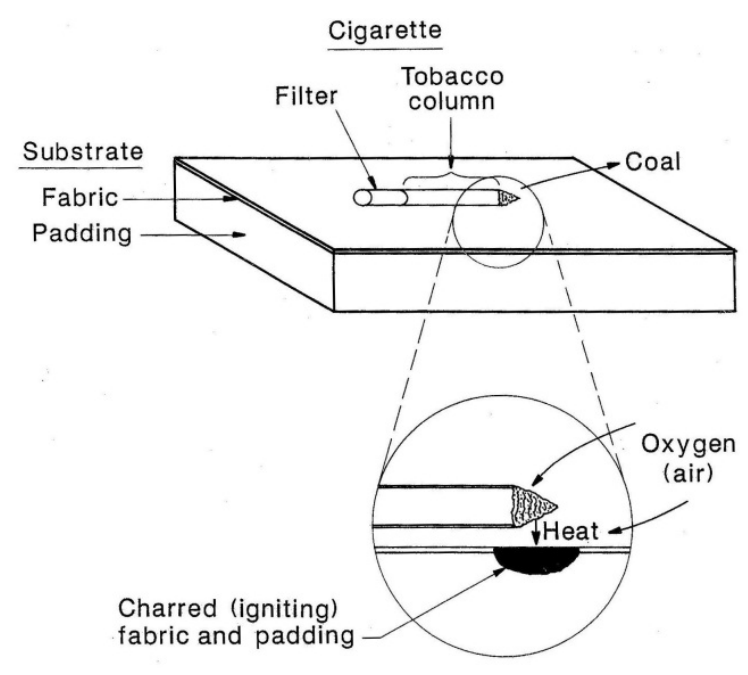

Figure 1. Cigarette Ignition of Soft Furnishings. [10]

In all these standard test methods (or flammability standards), the standard test cigarette is specified as a commercial product made from tobacco, nominally specified by its length ( $85 \mathrm{~mm}$ $\pm 2 \mathrm{~mm})^{\mathrm{i}}$, tobacco packing density $\left(0.270 \mathrm{~g} / \mathrm{cm}^{3} \pm 0.020 \mathrm{~g} / \mathrm{cm}^{3}\right)$, mass $(1.1 \mathrm{~g} \pm 0.1 \mathrm{~g})$, and the absence of a filter tip. This particular commercial cigarette had been selected because early data indicated that it had the highest ignition propensity of any of the cigarettes examined. [11,12] Over the more than three decades that these ignition susceptibility protocols have been in place, it is likely that this current test cigarette (CTC) had changed in formulation due to variations in the tobacco crop, changes in smoker preferences, etc. The ignition strength of the CTC had not been fully quantified at any time and is not specified in any of the test methods.

\footnotetext{
${ }^{\mathrm{i}}$ At some time prior to 1992, the manufacturer of this commercial cigarette decreased the length to approximately $83 \mathrm{~mm}$.
} 
In 2004, the first regulation of the ignition propensity of cigarettes went into effect in New York State. [13, 14] By July 2011, all 50 states and Canada were covered by similar regulations.

The result of this new activity was that furnishings were being tested for ignition resistance using a cigarette of high ignition propensity, while the marketplace was increasingly being filled with cigarettes of reduced ignition propensity.

The introduction of one regulation can potentially confound the success of another. In February 2008, the manufacturer of the CTC ceased its production, replacing the cigarette design with one that met the new reduced ignition propensity requirement. This made it imperative that a replacement for the CTC be developed. Working with the CPSC, the National Institute of Standards and Technology (NIST) developed a Standard Reference Material, SRM 1196, Standard Cigarette for Ignition Resistance Testing. [15] This SRM replicated the CTC physical properties and the ignition propensity of the most recent versions of the CTC. Sales of these SRM cigarettes indicate that they are already being used for testing furnishings.

The specifications of a SRM 1196 cigarette are:

- Length: $83 \mathrm{~mm} \pm 2 \mathrm{~mm}$

- Tobacco packing density: $0.270 \mathrm{~g} / \mathrm{cm}^{3} \pm 0.020 \mathrm{~g} / \mathrm{cm}^{3}$

- Mass: $1.1 \mathrm{~g} \pm 0.1 \mathrm{~g}$

- Ignition propensity: 70 percent full-length burns (PFLB) to 95 PFLB using the modified ASTM E 2187, as documented in NIST Technical Note 1627. [16] The actual value is 90.0 PFLB \pm 2.1 PFLB.

- No filter tip

- Unbanded paper

The cigarettes were manufactured of flue-cured tobacco. ${ }^{\text {ii }}$ The air permeability of the wrapping paper is nominally 33 CORESTA units. ${ }^{\mathrm{iii}}$

There is a finite quantity of SRM 1196 cigarettes available. Before this supply is exhausted, it will be necessary to either characterize a subsequent batch of cigarettes, i.e., SRM 1196a, and/or to develop a standard ignition source (SIS) that is not dependent on a tobacco-based cigarette manufacturer. It is not known whether the capacity or the willingness to create future supplies of SRM 1196 will exist when needed. Therefore, CPSC and NIST are collaborating on the latter approach.

The purpose of this report is to compile and analyze the content of a bibliography of prior research on:

\footnotetext{
ii From Wikipedia: Flue-cured tobacco is a type of cigarette tobacco that along with burley tobacco account for more than $90 \%$ of U.S. tobacco production.

iii A CORESTA unit is defined as the flow of air $\left(\mathrm{cm}^{3} / \mathrm{min}\right)$ through a sample of paper $1 \mathrm{~cm}^{2}$ in area when a pressure difference of $10 \mathrm{~cm}$ of water $(980 \mathrm{~Pa})$ is applied across the paper.
} 
- Alternative ignition sources used for examining the proclivity of materials to ignite to smoldering combustion (Section 4),

- Measurement of the thermal characteristics of a cigarette burning on a substrate (Section 5), and

- Measurement of the thermal response of the substrate (Section 6).

Section 7 summarizes the key findings of this review. 


\section{Categories of Replacement Standard Ignition Sources (SIS)}

As an aid in searching and interpreting the published literature, it is useful to have a vision of the potential alternates to SRM 1196. To ensure continuation of the same degree of cigarette ignition resistance shown by today's soft furnishings, the replacement (SIS) must be at least as potent as SRM 1196. A weaker SIS would allow more susceptible furnishing composites to enter the market, effectively weakening the existing and proposed flammability rules. For the SIS to be a "safety-neutral" replacement for SRM 1196, testing using the SIS should categorize all furnishing materials and composites in a manner that they are categorized when tested with SRM 1196. Arriving at a truly equivalent ignition source requires careful replication of the properties of SRM 1196 and/or enhanced knowledge of the physics of the ignition process.

In a cigarette-ignited fire, the heating of the composite substrate to the point of ignition is a function of:

0 the temperature of the burning cigarette coal,

0 the area of the burning coal,

0 the quality and area of the contact between the coal and the substrate surface,

0 the accessibility of air to this contact area,

0 the ambient temperature, relative humidity, and air velocity,

0 the rate of movement of the cigarette coal,

0 the duration of the cigarette's burning, and

o the susceptibility of the substrate to ignition (which includes such factors as the ignition temperature, thermal diffusivity, heat capacity, and density).

This list suggests that an ideal replacement for SRM 1196 as the ignition source in a test method needs to have mass and dimensions similar to SRM 1196 (for similar substrate contact) and a hot zone that is similar in size and temperature to the SRM 1196 coal. If the hot zone of the SIS does not move in a manner similar to that of SRM 1196, experimentation would be needed to determine the effect of a faster or slower speed on substrate ignition probability.

Practically, there are three approaches for developing a replacement for SRM 1196. Each presumes that reference data exist for the ignition performance of SRM 1196 on appropriate substrates.

1. Ensure continuing production of SRM 1196 (or its replacement) in perpetuity. This presumes that a vendor will be always available to manufacture a product for which the demand is steady, but modest relative to that for a mainstream commercial cigarette. It is recognized that:

a. Some batch-to-batch variation would continue as a result of annual variation in the tobacco crop, so it would be necessary to certify successive batches of cigarettes.

b. There is a risk that non-banded paper for wrapping the tobacco column might no longer be readily available. 
2. Develop a well-defined combustible material whose heat generation and heat transfer behavior can be characterized relative to SRM 1196.

3. Develop a heating device replacement for SRM 1196. This heating device would preferably be invariant over time. It is likely that it would be more complex to use than a cigarette. Possible approaches to such a device include:

a. Hot spot. The simplest source is a heated disk of diameter similar to that of a cigarette. Inexpensively and repeatably, this could capture all the thermal properties of the cigarette, including cooling by the substrate. However, it would not replicate the movement of the cigarette coal over the upholstery fabric and the resulting lengthening of the heated zone. Should lateral transfer of heat be as important as indepth heat transfer, this could give results different from the CTC.

b. Traveling hot spot. This would be similar to concept (a), but the disk would be moved mechanically or electronically over the surface of the substrate. This is potentially realistic, but means for preserving thermal contact during the movement would need to be developed.

A more sophisticated approach would be to develop a cylindrical host or channel within which a hot spot is moved mechanically or electronically. If the cylinder were of proper heat capacity and thermal conductivity, it would be possible to replicate the moving coal of the cigarette without moving the igniter itself.

c. Hot rod. A heatable rod of the same dimensions as the test cigarette would be almost as simple to construct and use as the heated disk. It too would replicate most of the features of the cigarette ignition process. However, heating would occur continuously along the full length of the rod, and the rod would be hottest near its middle. This steady heating of the full burn path might result in too high a frequency of ignitions for an appropriate rod temperature.

d. Radiant heater. Radiant energy would be imposed on a substrate location. The irradiated area could be fixed or movable. However the influence of the differences compared to a smoldering SRM1196 cigarette in the size of heated area of substrate, the changes in air flow due to the lack of a physical object in the buoyant area directly above the heated area, and potential changes in radiant flux due to attenuation by evolving products above the heated site would need to be considered.

This report is the first step in providing for pursuit of the second and third approaches. 


\section{SEARCh PARAmeters}

The intent of this literature survey is to locate information regarding as many diverse concepts and designs of smoldering ignition sources as possible. Of lesser concern was whether a reference was directly concerned with the ignition of furnishings. Thus, the sources and the keywords used reflected a diversity of types of ignition sources, beginning with those noted in the prior section of this report, and a variety of different items being heated, including furniture, beds, wire and cable, and various types of insulation. As the search progressed, it was noted that certain keywords and combinations would bring up citations from one bibliographic source, but not another. As a result, the search was extended to include some variants of the keywords.

The sources used in the search conducted for relevant published literature were:

- Web of Knowledge (includes Web of Science)

o http://apps.isiknowledge.com/

- Google Scholar

0 http://scholar.google.com/advanced_scholar_search?hl=en\&as_sdt=0,21

- NIST Fire Research Division publications

o www.nist.gov/manuscript-publication-search.cfm?pub_id=*

o fire.nist.gov/bfrlpubs/fire*/*.html

0 fire.nist.gov/bfrlpubs/build*/*.html

o fire.nist.gov/bfrlpubs/buildall/*.html

o fire.nist.gov/bfrlpubs/fireall/*.html

- United States Fire Administration publications

o www.usfa.dhs.gov/downloads/pdf/publications/*

o www.usfa.fema.gov/downloads/*

- SP Technical Research Institute of Sweden publications

o www-v2.sp.se/*

- VTT Technical Research Centre of Finland publications

o www.vtt.fi/inf/pdf/*

- BRANZ (New Zealand) publications

o www.branz.co.nz/cms_show_download.php?id=*

- U.S. Consumer Product Safety Commission publications

o www.cpsc.gov/cpscpub/pubs/*.html

o www.cpsc.gov/cpscpub/pubs/*.pdf

- National Research Council of Canada publications

o nparc.cisti-icist.nrc-cnrc.gc.ca/npsi/* 
O www.nrc-cnrc.gc.ca/obj/irc/doc/pubs/*

o irc.nrc-cnrc.gc.ca/pubs/*

- Federal Aviation Administration publications

$0 \quad$ www.fire.tc.faa.gov/pdf/*.pdf

o www.fire.tc.faa.gov/reports/listresults.asp?searchList=all\&listSubmit=Submit*

- National Technical Information Service

o www.ntis.gov/

- Inspec - Engineering Village

o www.engineeringvillage2.org/

- CSA Materials Research

- $\quad$ BRE (UK) Fire Research Notes

0 iafss.haifire.com/data/frs/Fire_Research_Notes/FRN-*.pdf

o iafss.haifire.com/html/frs/Fire_Research_Notes/abstracts/FRN_*.htm

- University of Edinburgh publications

o www.era.lib.ed.ac.uk/handle/*

o www.era.lib.ed.ac.uk/handle/1842/*

- International Association for Fire Safety Science, Fire Safety Symposia papers

o iafss.haifire.com/html/iafss/symposium/*/abstracts/*.htm

- Wiley journal publications

o www3.interscience.wiley.com/journal/*/abstract

- Springer journal publications

o www.springerlink.com/index/*

- Elsevier journal publications

o linkinghub.elsevier.com/*

- Sage journal publications

o jfe.sagepub.com/cgi/*

o jfs.sagepub.com/cgi/*

- Other Journals and Symposia

o iafss.haifire.com/html/aofst/symposium/*/abstracts/*.htm

o www.jstage.jst.go.jp/article/fst/*

o www.fire.uni-freiburg.de/iffn/*

o www.informaworld.com/smpp/content $\sim \mathrm{db}=\mathrm{all} \sim$ content*

o baywood.metapress.com/app/home/contribution.asp?*

o www.frmjournal.com/Journal+Archive/* 
o www.fireworld.com/ifw_articles/*

o www.hemmingfire.com/news/fullstory.php/*

o www.mdmpublishing.com/Archive/*

- DSpace
o www.dspace.org/*
o *.dspace.org/*

The key words and their combinations used in the literature search included:

- smouldering ignition source*

- smoldering ignition source*

- smouldering ignition

- smoldering ignition

- smouldering combustion

- smoldering combustion

- ignition source* AND (test* OR experiment* OR upholster*)

- ignit* AND cigarette*

- (alternate OR alternative) AND ignition source*

- sm*Ider AND (ignit* OR combust*)

- ignition equipment

- thermal ignit*

- ignit* AND smould*

- ignit* AND smold*

- "to initiate smoldering"

- "to initiate smouldering"

- "to initiate a smoldering"

- "to initiate a smouldering"

- Radiative, smoldering ignition

- intumescent material smolder ignition

- intumescing material smolder ignition

- cigarette* AND ignition*

- thermal AND cigarette

- thermal AND "heat source" AND ignition

- electric heater* AND ignit*

- electric heater* AND combusti* source

- ignit* AND (uphol* OR fabric* OR furniture OR household* OR mattress*) NOT fabricat*

- ignit* AND (cigarette* OR equipment) AND (alternate OR alternative)

- (alternate OR alternative) AND ignition source*

- cigarette* AND ignition* AND substrate

- thermal AND substrate AND cigarette

- Thermal AND substrate AND heat source

- thermal ignition AND (uphol* OR fabric* OR furniture OR bed* OR household* OR 
mattress*)

- $\quad$ ignit* AND (cigarette* OR (alternate OR alternative) OR equipment)

- thermal ignition AND (uphol* OR fabric* OR furniture OR bed* OR household* OR mattress*)

Since it is expected that not all literature may be listed in an accessible online database, references of relevant and related papers were intentionally checked for potential leads for other sources of information. 


\section{Alternate Ignition Sources}

\subsection{SUMMARY OF REPORTED INVESTIGATIONS}

Table 2 summarizes the manuscripts found in the literature search related to potential surrogate smoldering ignition sources. They are sorted by the type of ignition source and what was measured. The numbers in the cells of the table denote the references whose full citations appear at the end of this report. Some additional concepts are included, with blank cells indicating an absence of reports of prior examination related to aspects of interest here.

Although many different devices have been used to initiate smoldering combustion, the typical focus of previous investigations has been the smoldering properties of the ignited material or the result of a fire of a secondary item started from a smoldering item. Very few investigations have focused on the properties of the ignition source that affect its effectiveness at ignition of smoldering, and only one of these have compared the results to a particular type of cigarette used as an ignition source. CPSC's work by Tao [22] included a preliminary comparison of a particular cotton rope to the standard cigarette in standard test procedures.

There were some studies involving multiple aspects of smoldering combustion. In order to orient the reader, some redundant descriptive material has been included in each appearance of these studies.

\subsection{Electrically Powered Devices}

\subsubsection{Cartridge Heaters and Hot Plates}

Cleary $[17,18]$ initiated smoldering ignition in fabric-foam mock-ups using a $50 \mathrm{~W}$ cartridge heater (50 $\mathrm{mm}$ long, $10 \mathrm{~mm}$ diameter). The objective was to produce a reliable and repeatable smoldering fire for determining smoke alarm sensitivity. The furnishing mock-ups consisted of a seat and a back cushion made from combinations of one of two types of fabrics (a slow burning $100 \%$ cotton or a fast burning $100 \%$ polyester) and one of two types of polyurethane foam (low density, $21 \mathrm{~kg} / \mathrm{m}^{3}$, or high density, $29 \mathrm{~kg} / \mathrm{m}^{3}$ ). The cartridge heater was placed on top of a piece of cotton duck fabric (a heavy, plain woven fabric, $150 \mathrm{~mm}$ x $150 \mathrm{~mm}$ ), located on the seat cushion, to ensure a sustained smoldering fire. The electrical power to the heater was controlled such that the external temperature was sufficient to achieve sustained smoldering. The power applied or external device temperature required was not reported. The powered cartridge heater was located on the mock-up for approximately 6 min before being removed.

A team at the U.S. Naval Research Laboratory used a cartridge heater (500 W Vulcan, TB507A) to initiate various smoldering fuel packages during tests investigating the potential use of videobased fire detection technology for ship fires. [19] Power to the heater was controlled using a variable transformer. The smoldering fuel packages included bundles of cable, a bag of office trash, folded cotton clothing, a section of mattress with bedding, and a computer monitor. [20, 21] 
Table 2. Summary of subject matter of ignition studies.

\begin{tabular}{|c|c|c|c|c|c|c|}
\hline $\begin{array}{l}\text { Measurements Reported } \rightarrow \\
\text { Type of Igniter } \\
\downarrow\end{array}$ & $\stackrel{\text { 은 }}{\stackrel{ \pm}{\underline{5}}}$ & 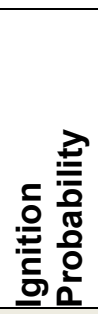 & 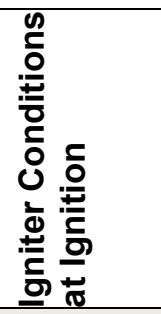 & 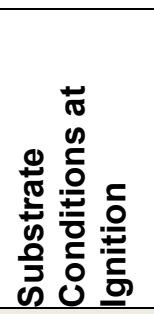 & 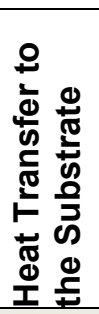 & 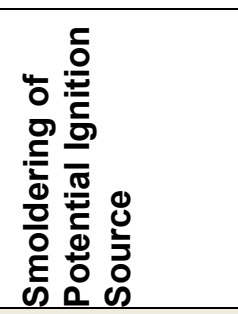 \\
\hline \multicolumn{7}{|l|}{ Electric Devices } \\
\hline $\begin{array}{l}\text { Heater Surface } \\
\text { (cartridge or plate) }\end{array}$ & $\begin{array}{l}\text { [17], [18], [19], } \\
{[20],[21],[22],} \\
{[23],[24],[25],} \\
{[26],[27],[28],} \\
{[29]}\end{array}$ & & $\begin{array}{l}\text { [20], [21], } \\
{[23],[24],} \\
{[30],[25],} \\
{[26],[28],} \\
{[29]}\end{array}$ & $\begin{array}{l}25], \\
{[28],} \\
{[29]}\end{array}$ & & \\
\hline Oven & [31] & & [31] & & & \\
\hline Heated Wire Mesh & [32] & & & & & \\
\hline Hot Wire & $\begin{array}{l}\text { [21], [33], [34], } \\
\text { [35], [36] }\end{array}$ & & [21], [35] & & & \\
\hline Arcing & [34], [37], [21] & & [37], [21] & & & \\
\hline Radiative Heater & $\begin{array}{l}\text { [23], [31], [32], } \\
\text { [38], [39], [40], } \\
\text { [41], [42], [43], } \\
\text { [44], [45], [46] }\end{array}$ & & $\begin{array}{l}\text { [31], [38], } \\
\text { [39], [41], } \\
\text { [42], [43], } \\
\text { [44], [46] }\end{array}$ & & & \\
\hline \multicolumn{7}{|l|}{$\begin{array}{l}\text { Non-Reactive, Non-Electric } \\
\text { Materials }\end{array}$} \\
\hline Heated Inert Slug & [31], [47] & & [31], [47] & & & \\
\hline \multicolumn{7}{|l|}{ Reactive Materials } \\
\hline Cellulosic & $\begin{array}{l}\text { [22], [42], [48], } \\
{[49],[50],[51],} \\
{[52],[53],[54],}\end{array}$ & & & & & \\
\hline $\begin{array}{l}\text { Powdered or Pulped } \\
\text { Material \& Binder }\end{array}$ & [32], [42] & & & & & $\begin{array}{l}\text { [22], [50], [55], } \\
\text { [56] }\end{array}$ \\
\hline $\begin{array}{l}\text { Smoldering Synthetic } \\
\text { Polymers }\end{array}$ & & & & & & $\begin{array}{l}\text { [57], [58], [59], } \\
{[60],[61],[62],} \\
{[63]}\end{array}$ \\
\hline Intumescent Composites & & & & & & [64] \\
\hline Methenamine & [65] & & & & & \\
\hline Chemical Heater & & & & & & \\
\hline
\end{tabular}


- The cable fuel source consisted of five pieces of $0.3 \mathrm{~m}$ long cable surrounding the cartridge heater. The heater was energized to $96 \mathrm{Vac}$.

- The bag of trash fuel source consisted of a bag (600 mm x $575 \mathrm{~mm}, 32.21$ in volume, and $15 \mu \mathrm{m}$ thick) filled with various office supplies (printer paper, paper towels, plastic, mailing packs, envelopes), all placed on top of the cartridge heater. The heater was located on top of a piece of gypsum board. The heater was energized to $120 \mathrm{Vac}$.

- The folded cotton clothing fuel source consisted of various items stacked one on top of another with the heater located in the middle of the pile. The heater was energized to 96 Vac.

- The mattress section and loose bedding fuel source was ignited by the cartridge heater located on the mattress ticking and under the bedding. The mattress section was from a Navy mattress (MIL-M-18351F(SH)) that had a $114 \mathrm{~mm}$ thick Safeguard polychloroprene foam core covered with a fire retardant cotton ticking. The bedding consisted of $0.6 \mathrm{~m} \times 0.6 \mathrm{~m}$ sections of various bedding components, including one polyester-batting quilted mattress pad (Volunteer Blind Industries, GS-07F-14865, DDDP-56E), one sheet (Federal Specification DDD-S-281), and one brown bed spread (Federal Specification DDD-B-151). The cartridge heater was energized to $120 \mathrm{Vac}$.

- The computer monitor fuel source was a CRT monitor with a $380 \mathrm{~mm}$ diagonal screen. The cartridge heater was inserted into the monitor through a $16 \mathrm{~mm}$ hole located at the bottom corner of the monitor, either located at the front or the back of the monitor. The heater was energized to 96 Vac.

Salig used a single coil of a heating element to ignite flexible polyurethane (FPU) foam cushions with various $100 \%$ cotton fabric covers. [30] The coil was embedded within the foam of the cushion. The coil was $40 \mathrm{~mm}$ in length and $6 \mathrm{~mm}$ in diameter. A constant heat flux was applied by the coil to the cushion for the duration of each test. Smoldering of the foam was observed in the tested samples when subjected to a continuous heat flux of at least $15.5 \mathrm{~kW} / \mathrm{m}^{2}$.

Damant and co-workers used a Calrod heater rod approximately the same size as a commercial cigarette and produced similar test results to those obtained when using the standard Pall Mall cigarette. [66] The heater was connected to a rheostat so that various heat fluxes could be investigated. Thermocouples were attached to the surface of the heater to measure the surface and heater-mattress interface temperatures. The heat along the length of the heater was relatively uniform. No difficulty was found for a test performed with a single device and one location. However, a disadvantage of the device was suggested to be the impracticality for a test performed with multiple devices across a mattress, because of the need for the wire connections to each device and the expense in terms of the additional time required to set up the devices for each test, as compared to the use of the Pall Mall cigarette. [66, 67]

Tao considered an electric heater in a previous preliminary investigation as a potential surrogate ignition source for the SRM 1196 cigarettes. [22] However, no details have been published.

Kellogg and co-workers [26] used cylindrical cartridge heaters (Watlow Electric Manufacturing Co.) in the testing of the heat flux and time combinations required in the ignition of cotton duck 
fabrics. The heaters were controlled using the applied voltage. Two methods of usage of the heaters were tested. One used the $6 \mathrm{~mm}$ diameter circular end of a $76 \mathrm{~mm}$ long $200 \mathrm{~W}, 120 \mathrm{~V}$ cartridge heater applied to a single piece of fabric held between two rings. The second used a $6 \mathrm{~mm}$ diameter, $26 \mathrm{~mm}$ long, $150 \mathrm{~W}, 120 \mathrm{~V}$ cartridge heater lying on the test fabric covering a polyurethane foam block. The heat flux applied to the sample was estimated using the electrical power applied to the heater divided by the surface area of the heater. The applied voltages between which ignition and no ignition were reported for each of the materials tested were reported. Ignitions were reported for cartridge heater fluxes from $1.5 \mathrm{~kW} / \mathrm{m}^{2}$ to $40 \mathrm{~kW} / \mathrm{m}^{2}$. The time to ignition for this range of fluxes was also reported. There were no ignitions for heat fluxes below about $15 \mathrm{~kW} / \mathrm{m}^{2}$. As the flux was increased toward approximately $30 \mathrm{~kW} / \mathrm{m}^{2}$, there was a sharp fall-off in the ignition time, and between $30 \mathrm{~kW} / \mathrm{m}^{2}$ and $40 \mathrm{~kW} / \mathrm{m}^{2}$, there was little further change in the time to ignition.

Pitts examined the smoldering ignition of cellulosic materials (shredded news print, cut grasses, pine needles, dry leaves and a mixture of grass and pine needles). [23] Ignition was by direct contact with a heated metal plate, representing heated mufflers and catalytic converters of outdoor power equipment. The focus of the investigation was to establish the range of ignition properties of the selection of forest materials subject to a range of air flows $(0 \mathrm{~m} / \mathrm{s}, 1.0 \mathrm{~m} / \mathrm{s}$, and $2.5 \mathrm{~m} / \mathrm{s}$ ) and heating element temperatures. Ignition by radiant heat flux was also considered in the study. Both smoldering and flaming ignition of the cellulosic samples were observed.

Time to ignition was reported to increase with decreasing heated element temperature. For all of the samples considered, ignition was observed within a few seconds for heated metal plate temperatures of $450{ }^{\circ} \mathrm{C}$ to $500{ }^{\circ} \mathrm{C}$. For temperatures below $450{ }^{\circ} \mathrm{C}$, the time to ignition was reported to increase more rapidly with decreasing plate temperature for all of the samples included in the investigation. Smoldering was reported for some samples exposed to plate temperatures down to approximately $300^{\circ} \mathrm{C}$. For the three wind conditions included in the investigation, wind speed was reported to have a strong influence on time to ignition. [23]

Although the substrate materials in this investigation were not the same as intended for testing with SRM 1196 cigarettes [23, 24], the range of temperatures reported to ignite the cellulosic samples are in the range of temperatures reported for the contact line between other various smoldering cigarettes and substrate combinations (e.g., similar to those reported by Salig [30]).

Hagen and co-workers used a hot plate to initiate smoldering in commercially-available, unbleached cotton batting samples $(0.15 \mathrm{~m} \times 0.15 \mathrm{~m} \times 0.15 \mathrm{~m})$ of various densities $(5.5,20,40$, 60,80 and 100) $\mathrm{kg} / \mathrm{m}^{3}$, produced by compressing the initial sample). [24] The ambient temperature was between $15^{\circ} \mathrm{C}$ and $25^{\circ} \mathrm{C}$, and the relative humidity was between $40 \%$ and $50 \%$ during the experiments. The moisture content of the samples was approximately $5 \%$ by weight. Maximum hot plate temperatures up to approximately $320{ }^{\circ} \mathrm{C}$ were used. Smoldering was reported for samples associated with maximum hot plate temperatures above approximately $305^{\circ} \mathrm{C}$, where the maximum hot plate temperature was achieved approximately 30 min from the start of each test.

Querol and co-workers used a hot plate apparatus to investigate the ignition temperature of different configurations of dust layers and cones. [27] Of interest is the reported difference in 
test results due to two different methods for controlling the heating element. The constant temperature control method utilized variable power to the hot plate to reach a steady temperature at the surface of the hot plate throughout a test. The constant power control method required the hot plate to reach equilibrium $( \pm 1 \mathrm{~K} / \mathrm{h})$ before the test specimen was placed on the plate. The two protocols led to different test results. As an example, for beech wood dust, the ignition temperature recorded for the power controlled apparatus was reported to be significantly lower than for the tests that utilized the constant temperature methodology. Conversely, the temperature-controlled methodology resulted in shorter times to ignition than for the powercontrolled methodology, e.g., 2 hours for the former compared to over 7 hours to 8 hours for the latter.

Ohlemiller and Rogers also used a hot plate in the investigation of the smoldering of commercial cellulose insulation made from shredded and milled waste paper (approximately $99 \%$ newsprint). [28, 29] The milled waste paper product was initially characterized in terms of heat release rate versus temperature in air and nitrogen atmospheres, using Thermogravimetric Analysis (TGA) and Differential Scanning Calorimetry (DSC). [68] Combinations of the cellulose insulation product and potential fire-retardant additives were tested.

Smoldering of the cellulose insulation product was first tested in an approximately onedimensional test arrangement, using a $300 \mathrm{~mm}$ square hot plate. [28] The hot plate was modified with a shelf and wire cage to hold the test material in place. The hot plate was temperature controlled. The temperature used for control was measured using a thermocouple of 30 gauge wire that was secured to the center of the hot plate with a brass screw. Two or three additional thermocouples (of $0.25 \mathrm{~mm}$ or $0.5 \mathrm{~mm}$ diameter Chromel-Alumel wire) were located $6 \mathrm{~mm}$ above the plate surface around the periphery of the heating element. These additional thermocouples were used to monitor the fuel temperature near the hot plate.

At the beginning of each test, the insulation was set on the hot plate while it was cold to ensure a uniform thickness. Insulation thicknesses of $30 \mathrm{~mm}$ to $70 \mathrm{~mm}$ were tested. The bulk density of the insulation product was $35 \mathrm{~kg} / \mathrm{m}^{3}$. The test temperature was set at the temperature controller of the hot plate, and then the hot plate was switched on. The temperature of the hot plate could be controlled to within $\pm 1{ }^{\circ} \mathrm{C}$. The hot plate would take up to $20 \mathrm{~min}$ to achieve the test temperature. The minimum plate temperature needed for ignition decreased monotonically as the layer thickness was increased.

Ohlemiller and Rogers also investigated commercial cellulose insulation with potential fireretarding additive combinations in a two-dimensional fuel arrangement using a rectangular wire basket (200 mm wide by $400 \mathrm{~mm}$ long and $250 \mathrm{~mm}$ deep). [28] The basket of fuel was ignited at one end using a specially shaped, electric heater cable. Details of the igniter were not reported. The wire basket holding the fuel was insulated on the bottom and sides using $25 \mathrm{~mm}$ thick ceramic fiber. This restricted the flow of air to the ends of the basket only. The ends of the basket were each covered with $50 \mathrm{~mm}$ thick layer of highly permeable fiberglass insulation to allow an air flow through the fuel. Three thermocouples of 36 gauge Chromel-Alumel wire were located centrally at mid-depth in the fuel at a spacing of approximately $100 \mathrm{~mm}$ along the length of the basket. The results from these thermocouples were used to estimate the average smolder propagation through the fuel in the basket. [28] 
Peak temperatures reported within the untreated cellulose insulation product were $623{ }^{\circ} \mathrm{C}$ $\pm 18{ }^{\circ} \mathrm{C}$, with an average smolder velocity of $0.046 \mathrm{~mm} / \mathrm{s} \pm 0.004 \mathrm{~mm} / \mathrm{s}$ at a layer height of approximately $150 \mathrm{~mm}$ and $0.065 \mathrm{~mm} / \mathrm{s} \pm 0.006 \mathrm{~mm} / \mathrm{s}$ at a layer height of approximately $200 \mathrm{~mm}$. The average smolder velocity values were each based on four to six tests. [28]

Ohlemiller investigated the commercial cellulose insulation in a three-dimensional fuel arrangement. [29] Eight heat source and insulation configurations were examined. The geometries of the heat sources tested represented idealized versions of an attic situation, including an electrical wire threaded through the insulation, a vertical chimney surface, and recessed light fixtures. Two configurations also were chosen that approximated one-dimensional heat flow through a horizontal layer of insulation. For each test the insulation was contained using $6 \mathrm{~mm}$ thick cement fiber boards. All the heating elements used a long, thin heating element. The planar heat source shapes were made by shaping the thin heating element into a raster-scan-like pattern. The temperature uniformity was reported to be $\pm 1{ }^{\circ} \mathrm{C}$ within $20 \mathrm{~mm}$ of the edges of the heat source. Test temperatures were achieved at the heat sources within approximately $12 \mathrm{~min}$ to $14 \mathrm{~min}$. The source temperatures reported for observed ignitions ranged from approximately $235^{\circ} \mathrm{C}$ to $290^{\circ} \mathrm{C}$ for all orientations, except for the orientation of the electrical wire threaded through the insulation that was approximately $380{ }^{\circ} \mathrm{C}$ to $390{ }^{\circ} \mathrm{C}$.

Beyler and co-workers used an $0.14 \mathrm{~m}^{3}$ oven to investigate potential self-heating of bundles of cotton towels treated with cerium nitrate solutions. [31] The oven was a Fisher Isotemp Programmable Oven, Model 851F that was controlled using a RS-232 interface. The heating method was forced convection, whereby hot air was drawn from the bottom of the oven and mixed with fresh air before being forced horizontally across the oven to heat the contents. The temperature distribution within the oven at $200{ }^{\circ} \mathrm{C}$ was $\pm 2{ }^{\circ} \mathrm{C}$. The oven control sensitivity was $\pm 0.25^{\circ} \mathrm{C}$, in accordance with ASTM E 145 . The temperature within the oven was increased by $1{ }^{\circ} \mathrm{C}$ per hour. For the sizes of bundles of towels tested, the critical temperature reported for which thermal runaway was observed was $385^{\circ} \mathrm{C}$ to $401{ }^{\circ} \mathrm{C}$.

Beyler and co-workers tested the same type of towel and cerium nitrate treatment for unpiloted ignition during cone calorimeter tests and ignition after application of hot object tests. [31] However, different sizes and packing geometry of each of the samples were used in the different types of tests.

Putzeys and co-workers used an infrared radiant strip heater (Research Inc. Model 4184) to heat the free surface of the sample and a ceramic honeycomb heater as an ignition source that was adjacent to the bottom surface of the sample in an investigation of piloted transition from smoldering to flaming for various FPU foams. [25, 69]

Sample blocks (50 $\mathrm{mm}$ x $50 \mathrm{~mm}$ by $125 \mathrm{~mm}$ long) of both a non-fire retarded (NFR) FPU and a fire retarded (FR) foam (Pyrell®) were used. The samples were located vertically in a wall of the test chamber, where the gas velocity was upward, past the free surface of the sample, through the chamber. The sample was located in a thin brass walled sample holder that was insulated on the back face. The outer surfaces of the back and side walls of the sample holder were maintained at $200{ }^{\circ} \mathrm{C}$, using guard heaters. [25] 
The free surface of the sample was exposed to a radiant heat flux (perpendicular to the free surface) from the infrared radiant strip heater. For the NFR FPU foam, the applied radiant heat flux was varied between $7.25 \mathrm{~kW} / \mathrm{m}^{2}$ and $8.75 \mathrm{~kW} / \mathrm{m}^{2}$. For the FR FPU foam, the applied radiant heat flux was varied between $4.5 \mathrm{~kW} / \mathrm{m}^{2}$ and $5.5 \mathrm{~kW} / \mathrm{m}^{2}$. The upper limit of the heat flux applied to each type of foam was determined by the minimum heat flux required to cause pyrolysis on the free surface of the samples. The lower limit of the range of heat fluxes applied to each type of foam was associated with the minimum heat flux at which a sustained smoldering reaction had been observed. [25]

The samples were ignited at the bottom end of the sample that was in contact with the $50 \mathrm{~mm} \mathrm{x}$ $50 \mathrm{~mm}$ ceramic honeycomb heater. The ceramic heater was set to a constant power to achieve smoldering ignition for each type of foam tested. For the non-fire retarded polyurethane foam, the power of the ceramic igniter was set to $23 \mathrm{~W}$. For the FR FPU foam, the power of the ceramic igniter was set to $115 \mathrm{~W}$. [25]

The oxygen concentration of the local atmosphere was varied between tests, from a mole fraction of 0.15 to 0.35 . The forced air velocity was $0.5 \mathrm{~m} / \mathrm{s}$ for the NFR FPU foam and $0.15 \mathrm{~m} / \mathrm{s}$ for the FR FPU foam. [25]

The smoldering velocity and peak smoldering temperature were reported to increase with oxygen concentration and applied heat flux. Oxygen concentration and applied heat flux were suggested to be the primary parameters needed to identify the transition between smoldering and flaming. [25]

Suuberg and co-workers used a heated wire mesh apparatus to investigate the transfer of tars within cellulose samples during charring. [32] The apparatus consisted of a piece of stainless steel wire gauze stretched between two brass electrodes. The sample was folded within the wire gauze. The intent of the experiments was to heat the sample such that pyrolysis volatiles would escape through the wire mesh and condense on the surrounding surfaces that were at ambient temperature. The heating rate of the sample was $60^{\circ} \mathrm{C} / \mathrm{min}$. A helium atmosphere was used within the apparatus to reduce the available oxygen.

\subsubsection{Heated Wires}

Bukowski and co-workers used a loop of Nichrome ${ }^{\mathrm{TM}}$ wire to effect reliable, sustained smoldering in furniture items (including mattresses and arm chairs) containing a FPU foam as the padding material. [33] The wire loop was located under the seat cushion or top layer of the mattress. A thermocouple was located on the top surface of each item, centered over the top of the location of the wire loop. This temperature was monitored to ensure smoldering was sustained. A test was terminated when flaming occurred. The igniter was constructed from $1.63 \mathrm{~mm}$ diameter (14 gage) Nichrome ${ }^{\mathrm{TM}}$ wire. The loop was approximately $130 \mathrm{~mm}$ in diameter, and the leads to the power source were encased in ceramic tubing. A variable transformer was used to control the power to the device, such that smoldering was initiated with a low current. The current was set to ensure sufficient heat to sustain the smoldering of the polyurethane foam. Too high a heating rate was avoided, since it resulted in either the foam melting and moving away from the smoldering region or in a transition from smoldering to 
flaming combustion. The transformer was controlled by an operator responding to visual cues from a live video feed of the test.

Collier and Whiting examined the use of a bare Nichrome ${ }^{\mathrm{TM}}$ wire wound around the outside of a ceramic tube as a potential device for ignition of upholstery mock-up specimens. [34] In order to protect the wire and reduce the potential for ignition of the mock-up cushion by arcing, the wound ceramic tube was placed in a glass test tube. The device was held in place on the top surface of mock-up cushions by a test tube clamp and stand. Two thermocouples were used, one located on the outside of the test tube and another located inside the test tube. The power was increased to the maximum available, such that the outer thermocouple was reading up to approximately $600{ }^{\circ} \mathrm{C}$. At the end of the attempts with the second device, the glass tube was visibly deformed, drooping downward at the end, which is consistent with the temperatures reported for the thermocouple located on the outside of the test tube. The mock-up would melt away but no ignition was observed. Both devices were held in place in the same way. Neither device could move or fall into the holes created in the mock-ups during heating. No thermal ignitions of the mock-ups were observed. (However, see Section 4.2.3 of this report.)

Grishin and co-workers used a coil of Nichrome ${ }^{\mathrm{TM}}$ wire as a reference ignition source for experiments investigating a range of ignition sources for natural forest floor materials. [35] The reference ignition source was used to compare results for other real sources of ignition, including a burning match, a smoldering twig, a burning twig and a smoldering cigarette. The $1.5 \mathrm{~mm}$ (outside) diameter coil was wound from a $20 \mathrm{~mm}$ length of $0.15 \mathrm{~mm}$ diameter Nichrome ${ }^{\mathrm{TM}}$, with a resistance of $23 \Omega$. The electrical supply was controlled to produce temperatures at the coil of $700 \mathrm{~K}$ to $1300 \mathrm{~K}$. For the experiments, the power of the reference ignition source of approximately $5.5 \mathrm{~W}$ to $7 \mathrm{~W}$ was chosen to approximate the cigarette ignition source considered for the set of experiments.

Lynch and co-workers used an insulated wire as a smoldering fuel package (i.e., the wire was heated to ignite the covering insulation) during tests investigating the potential use of videobased fire detection technology for ship fires. [21] Two $1 \mathrm{~m}$ lengths of wire were powered in parallel at $6 \mathrm{Vac}$, with no current limit, for $1 \mathrm{~min}$. The wire consisted of 10 strands of $0.1 \mathrm{~mm}$ diameter copper and PVC insulation with a radial thickness of $0.3 \mathrm{~mm}$ (with a cross-sectional area of $0.078 \mathrm{~mm}^{2}$ ). This approach was based on the British Code of Practice for fire protection for electronic equipment installations, BS 6266.

Walther and co-workers used a Nichrome ${ }^{\mathrm{TM}}$ wire between two $5 \mathrm{~mm}$ thick honeycomb ceramic disks as the ignition source for an investigation of the smoldering of an open-cell, NFR FPU foam in a forced oxidizer flow. [36] One ceramic disk was in contact with the foam sample surface. The ceramic discs were used to provide stability for the coiled wire and to diffuse the heat. The heater was used to supply sufficient power to ignite and sustain a smoldering reaction in the samples. A constant power was applied to the heater for a specified period of time, and then the resulting behavior of the sample was observed. Ignition was deemed to have been achieved when smoldering of the sample was observed after the heater had been de-energized.

The rectangular samples were vertically oriented. The samples had a $130 \mathrm{~mm}$ square crosssection and were $300 \mathrm{~mm}$ long. The test section walls were insulated with $3 \mathrm{~mm}$ thick ceramic 
fiber board in an aluminum frame, sealed with aluminum tape. Tests were conducted for atmospheres with oxygen mass fractions of 0.109 to 1.0. The local velocity of the gas in the test chamber was $0.1 \mathrm{~mm} / \mathrm{s}$ during the ignition period and $0.7 \mathrm{~mm} / \mathrm{s}$ or $3.0 \mathrm{~mm} / \mathrm{s}$ during the sample observation and potential self-sustained smoldering period. The following is an example of the results for the time to ignition for polyurethane foam samples for various applied heat fluxes in a range of oxygen mass fraction with an upward flow of $0.7 \mathrm{~mm} / \mathrm{s}$ and a downward burning orientation. The time to ignition decreased monotonically as the heat flux was increased from 20 $\mathrm{kW} / \mathrm{m}^{2}$ to $75 \mathrm{~kW} / \mathrm{m}^{2}$. Increasing the oxygen mass fraction from 0.233 to 0.329 had little effect on the times to ignition. (In an oxygen mass fraction of 1.0, the heat flux needed for ignition decreased by about $1 \mathrm{~kW} / \mathrm{m}^{2}$, from approximately $2.5 \mathrm{~kW} / \mathrm{m}^{2}$ to $1.5 \mathrm{~kW} / \mathrm{m}^{2}$.) [36]

It was reported that the igniter heater flux and application time were the primary parameters that defined well the smoldering ignition regime. It was suggested that these two parameters could be used to determine a minimum igniter-foam temperature and a minimum depth of smoldering propagation required for ignition to occur. [36]

\subsubsection{Arcing Ignition}

In the tests cited in the prior section, Collier and Whiting [34] observed some apparently nonthermal ignitions with the bare Nichrome ${ }^{\mathrm{TM}}$ wire. These coincided with observations of small flashes that might have been arcing or short-lived flaming of small particles.

Eckhoff found that very weak electric spark discharges, in the range $0.1 \mathrm{~mJ}$ to $1.0 \mathrm{~mJ}$, had the potential to initiate smoldering combustion in linen flax. [37]

Lynch and co-workers used a traveling arc to initiate smoldering of a printed circuit board (with a FR-4) substrate. This is a fire-retardant-treated glass reinforced epoxy laminate conforming to the requirements of military specification Mil P 13949 Type F, MIL-S-13949/04 GF/GFN/GFK and Mil I 24768/27 and is rated UL 94 V-O. The focus of the tests was investigation of the potential use of video-based fire detection technology for ship fires. The arc was created by applying $9 \mathrm{~V}, 8.5 \mathrm{~A}$ across two $1.27 \mathrm{~mm}$ copper tracks, spaced $1.27 \mathrm{~mm}$ apart. [21]

Aside from indicating electrical arcing as a potential source of smoldering ignition, these references comprise an alert to a possible unintentional ignition process when using electrical igniters.

\subsubsection{Radiative Heaters}

Olson and co-workers investigated smoldering ignition of smolder-promoted (potassium acetate doped) filter paper initiated in microgravity experiments using a focused beam from a nearinfrared tungsten/halogen lamp. [38] The ignition source intensity was $15.5 \mathrm{~W}$, with a Gaussian distribution over a radius of approximately $1 \mathrm{~cm}$ of the sample surface, and was applied for $10 \mathrm{~s}$. Fan-drawn air speeds of $0 \mathrm{~cm} / \mathrm{s}$ to $0.65 \mathrm{~cm} / \mathrm{s}$ over the surface of the sample were reported to have had a negligible effect on the ignition of the samples, although there were differences reported for the spread after ignition. 
Mitler and Walton used a heating element from an automobile cigarette lighter to investigate the thermal response of a substrate. $[39,40]$ The focus of the series of experiments was not to replicate a cigarette. Instead the intent was to subject substrates to a range of known heat fluxes, so that the response of the substrate could be measured. The element temperature could be varied from $500{ }^{\circ} \mathrm{C}$ to $900{ }^{\circ} \mathrm{C}$. The heater element was surrounded by a collar that had air passing through it. The air passed over the surface of the element and then normal to the element towards the substrate surface. The air jet was intended to purge the local area around the heater of volatiles, to reduce the likelihood of flaming combustion so that smoldering of the substrate could be investigated. The heat flux distribution was reported for a target at $5.4 \mathrm{~mm}$ vertically below the element, when the element was subjected to $7.0 \mathrm{~V}, 3.52 \mathrm{~A}$, and an air purge flow of nominally $0.5 \mathrm{~L} / \mathrm{min}$. The heat flux varied with the radius of the element, from approximately $11.5 \mathrm{~kW} / \mathrm{m}^{2}$ at $8 \mathrm{~mm}$ from the center of the element to $26 \mathrm{~kW} / \mathrm{m}^{2}$ directly below the center of the element. [39]

Anderson and co-workers used a cone calorimeter to test the smoldering properties of samples of a polyurethane foam. [41] Heat fluxes of $6.1 \mathrm{~kW} / \mathrm{m}^{2}$ to $6.8 \mathrm{~kW} / \mathrm{m}^{2}$ were reported to produce propagating smoldering ignition in the samples. Time to ignition was also reported to be weakly dependent on the external heat flux. A minimum temperature within the sample of approximately $300{ }^{\circ} \mathrm{C}$ to $325^{\circ} \mathrm{C}$ was reported as being needed for sustained smoldering to occur.

Daikoku and co-workers also used a cone calorimeter in the investigation of the pyrolysis of cellulosic samples, including pressed cellulose powder, Douglas fir particle board, and solid Douglas fir wood. Incident heat fluxes of $10 \mathrm{~kW} / \mathrm{m}^{2}$ to $50 \mathrm{~kW} / \mathrm{m}^{2}$ were applied. [42] Four $0.1 \mathrm{~mm}$ diameter Alumel-Chromel thermocouples were located through the depth of the center of the sample to record the response of the sample to the applied heat flux. The maximum temperature reported for the surface of a Douglas fir particle board sample subjected to an incident heat flux of $33.0 \mathrm{~kW} / \mathrm{m}^{2}$ was approximately $250{ }^{\circ} \mathrm{C}$ after $30 \mathrm{~s}$ of exposure and up to $580^{\circ} \mathrm{C}$ after $200 \mathrm{~s}$ of exposure. The surface temperature reported for the cast cellulose sample subjected to an incident heat flux of $30.0 \mathrm{~kW} / \mathrm{m}^{2}$ was approximately $330{ }^{\circ} \mathrm{C}$ after $41 \mathrm{~s}$ of exposure.

Similarly, Gratkowski and collogues investigated smoldering ignition of $18 \mathrm{~mm}$ thick maple plywood for cone calorimeter tests at radiant heat fluxes of $7.5 \mathrm{~kW} / \mathrm{m}^{2}$ and greater that were applied for up to 8 hours. [43] Similar situations of the onset of smoldering of cellulosic materials due to long duration, low level radiant sources have been previous investigated (e.g., as reported by Shaffer [45]), but the time frame for these types of situations is outside the scope relevant to the CTC.

Bilbao and co-workers used a truncated electrical cone to apply radiant heat fluxes of $10 \mathrm{~kW} / \mathrm{m}^{2}$ to $55 \mathrm{~kW} / \mathrm{m}^{2}$ at the surface of pine samples. [44] A range of heat fluxes and air velocities $(0 \mathrm{~m} / \mathrm{s}$ to $5 \mathrm{~m} / \mathrm{s}$ ), and either spontaneous or piloted ignition (with a propane flame or an electrical arc) were considered experimentally, and the times to smoldering and flaming were reported. Spontaneous smoldering ignition at no air flow was observed for radiant heat fluxes of approximately $24 \mathrm{~kW} / \mathrm{m}^{2}$ (applied for $110 \mathrm{~s}$ ) and above.

Pitts investigated the smoldering ignition of cellulosic materials (shredded news print, cut 
grasses, pine needles, dry leaves and a mixture of grass and pine needles) as initiated by the radiative heat flux from a heated metal plate, representing heated mufflers and catalytic converters of outdoor power equipment. [23] The focus of the investigation was to establish the range of ignition properties of the selection of forest materials subject to a range of air flows and heating element temperatures. A commercial cone calorimeter was also used, in the non-piloted mode, to challenge the various samples with known heat fluxes. In both variations of the radiative heat flux tests, both smoldering and flaming ignition of the cellulosic samples was observed. Pitts suggested that the results from the ignition tests using a radiative heat flux could be related to tests conducted for the same study using direct contact with a heated plate using the black body temperatures related to the radiative heat fluxes. [23]

Beyler and co-workers tested square $100 \mathrm{~mm} \times 100 \mathrm{~mm}$ samples of cotton towels treated with cerium nitrate solutions in stacks of three layers (19 mm thick) or five layers (32 mm thick) in a cone calorimeter. [31] The treated towels were the same as previous tests by Beyler and coworkers [31] using a forced convection oven and heated metal pieces. However, the sample configuration used in testing was different each time. Piloted and unpiloted tests were performed. Of the unpiloted tests, incident heat fluxes between $2.8 \mathrm{~kW} / \mathrm{m}^{2}$ and $10 \mathrm{~kW} / \mathrm{m}^{2}$ were tested. No ignitions were reported for two tests at $2.8 \mathrm{~kW} / \mathrm{m}^{2}$ after 1.5 hours and 2 hours. Ignitions were reported for heat fluxes of $3.0 \mathrm{~kW} / \mathrm{m}^{2}$ (at $874 \mathrm{~s}$ ) up to $10 \mathrm{~kW} / \mathrm{m}^{2}$ (at $11 \mathrm{~s}$ ).

Suuberg and co-workers used radiant quartz heaters to provide a constant incident heat flux of $20 \mathrm{~kW} / \mathrm{m}^{2}$ up to $100 \mathrm{~kW} / \mathrm{m}^{2}$ on high purity cotton (99\% alphacellulose, Whatman CF-11 Fibrous Cellulose Powder) samples and with other samples of pine (41 mm x $41 \mathrm{~mm}$ x $51 \mathrm{~mm}$ blocks), oak (20 mm thick blocks) and phenol-formaldehyde resin (powder), as part of an investigation into the mechanisms involved in the charring of cellulose. The intent of the experiments was to simulate fire conditions in a room with a burning wall. [32]

The radiant heaters used a tungsten filament. Two heaters were positioned to concentrate the radiant energy onto the vertical centerline of the sample. Aperture plates were used in front of the heaters to improve the uniformity of the heat flux on the sample and to minimize the radiative losses to other surfaces. Thermocouples were located at the front and back surface of each sample, pushed through the center of each sample from the back surface. Chromel-alumel $0.5 \mathrm{~mm}$ diameter thermocouples were used. The heaters were initially calibrated using a commercially calibrated heat flux meter and varying the voltage applied to the heaters to match the desired incident heat flux measured by the commercial heat flux meter. The samples were $38 \mathrm{~mm}$ in diameter and approximately $10 \mathrm{~mm}$ thick. They were either pressed (without any binders) in a die or cut from larger sized samples. Different densities of powdered materials were tested. The samples were located within an insulating ceramic holder. Samples were tested in a nitrogen purged environment intended to simulate a diffusion flame environment where there is little or no oxygen available at the surface of the sample. [32]

Similarly, Daikoku and co-workers also used quartz radiative heaters in the investigation of pyrolysis of cellulosic samples. Tests were performed with a 100\% nitrogen atmosphere and an air atmosphere (79\% nitrogen). [42] Samples of PMMA, Douglas fir particle board and cellulose were tested. The applied incident flux was $20 \mathrm{~kW} / \mathrm{m}^{2}$ to $60 \mathrm{~kW} / \mathrm{m}^{2}$. 
A carbon dioxide laser was used in autoignition and piloted ignition of PMMA and red oak samples. Incident fluxes of up to approximately $20 \mathrm{~kW} / \mathrm{m}^{2}$ were used. The laser was applied perpendicular to the sample surface. Strong attenuation of the incident laser radiation was reported. This attenuation was attributed to the gas phase decomposition products located directly above the sample surface. [46]

Considering the approach used in the investigation reported in the previous citation, it is clear that when using an optical ignition source, consideration must be given to attenuation of the incoming light beam by the specimen pyrolysis gases. Even for a light source of constant power, this will result in a different irradiance for each substrate and at different times in the test. Means to reduce this effect are directing the light source at an oblique angle to the substrate surface or reducing the length of path traversing the gas phase decomposition products directly above the area of heated material.

\subsection{Non-Reactive Materials, Non-Electric Devices}

Non-reactive, non-electric devices are potential ignition source surrogates that cannot chemically react with a substrate and do not use electrical control or equipment needed for electrical control while in contact with the substrate. They are typically heated prior to testing, removed from the heating device, and placed on the substrate with no attachments, e.g., heating wires.

In BS 4790, a hot metal nut is used to investigate the response of floor covering materials to a small point source ignition. [47] The test measures the radius of effect of a hexagonal M16 $30 \mathrm{~g}$ 304 stainless steel $[70,71]$ nut $(24.0 \mathrm{~mm}$ width across flat, $27.71 \mathrm{~mm}$ width across corners, $14.8 \mathrm{~mm}$ thick, with a $22.5 \mathrm{~mm}$ bearing face distance, $[72,73]$ ) when heated to $900{ }^{\circ} \mathrm{C}$ and placed on the flooring sample. A low radius of effect is considered less than $35 \mathrm{~mm}$. [74] To date, the hot metal nut test has not been used in the assessment of items other than floor coverings.

Beyler and co-workers used heated pieces of stainless steel sheet to investigate the potential ignition of four layers (yielding $25 \mathrm{~mm}$ ) of cotton towel squares $(100 \mathrm{~mm} \times 100 \mathrm{~mm})$ treated with cerium nitrate solutions. [31] The pieces of stainless steel sheet were approximately 8.5 $\mathrm{mm} \times 2.8 \mathrm{~mm} \times 1.9 \mathrm{~mm}$, with an average mass of $256 \mathrm{mg}$, with a standard deviation of $26.9 \mathrm{mg}$. The stainless steel pieces were heated using a hot plate controlled by a thermocouple welded to the surface of one piece of stainless steel. One to thirty metal pieces were used in each test. Once the thermocouple measured the desired temperature, then all the pieces of metal on the hot plate were assumed to be at the test temperature. These pieces of heated metal were applied to the towel samples in a pile.

The towel samples were tested using the heated pieces of metal by application of the heated pieces to the surface of the towel samples or location of the heated pieces between the layers of each sample. Some ignitions of the towel samples were reported for the metal pieces heated to $250{ }^{\circ} \mathrm{C}$ and above. In both the surface application and inter-layer application of heated metal pieces, the temperature of the applied heated object generally decreased for an increase in object mass. [31] 
In general, the concept of ignition by a slug of metal or other material that would act as a chemically inert igniter, with known thermal properties, heated to a uniform temperature throughout, has distinct appeal. There is also the opportunity for a wide degree of parametric variation of the mass, thermal properties, and substrate contact area. Consideration is needed of the degree of cooling of the slug between heating and positioning on the intended substrate for testing.

\subsection{COMBUSting IgNiters}

\subsubsection{Cellulosic Materials}

\subsubsection{Cotton Rope}

Tao investigated a cotton rope for its equivalence to the brand of the then-current test cigarette (CTC) used for ignition resistance testing. [22] The selection of this particular rope was based on prior screening experiments with ropes of various structures and linear mass densities.

The rope consisted of a diamond-braided cotton sheath around a core of cotton strands. The strands were removed prior to testing, leaving a hollow, braided structure. The rope, as purchased, was nominally $0.25 \mathrm{in}$. in diameter, had a tensile strength of nominally $125 \mathrm{~kg}$ $(275 \mathrm{lb})$, and had a nominal weight of $24.6 \mathrm{~kg} / \mathrm{m}(18 \mathrm{lb} / \mathrm{ft})$. It was tested in lengths of $85 \mathrm{~mm}$, $90 \mathrm{~mm}$, and $95 \mathrm{~mm}$. [75]

The tests were carried out on six fabric/foam substrates reflecting those used in qualifying fabrics for use in upholstered furniture (UFAC Fabric Classification Test Method [76], equivalent to References 7 and 8). ${ }^{\text {iv }}$ The fabrics are listed in Table 3; the foam was as specified in the UFAC Method. The testing consisted of three replicates for each combination of igniter, rope length, and fabric. Despite the small number of replicate tests, the agreement between the number of ignitions using the various lengths of rope and the CTC was encouraging. Among the results for the three rope lengths, the $90 \mathrm{~mm}$ specimens were reported as slightly superior.

The linear burn rates of the cigarettes and the rope were reported as nominally the same. The burning temperatures of the cigarettes and the ropes were reported to be close, although no definition of "burning temperature" and no data were provided.

\footnotetext{
iv The Fabric Classification Test Method: The mock-up consists of two 8 in. $(20.3 \mathrm{~cm})$ square pieces of 0.75 " $(1.9$ $\mathrm{cm}$ ) thick wood joined at a right angle at one edge. Fabric is placed over two pieces of FPU foam, and placed to cover the interior of the two pieces of wood. The ignition source is placed in the center of the crevice and covered by a sheet of unlaundered cotton fabric. The tests were conducted in a draft-preventative enclosure. The test is conducted in triplicate. If no test specimens ignite, or if no individual specimen yields a vertical char of $44 \mathrm{~mm}$ (1.75 in) or greater, the fabric is a UFAC Class I cover fabric. If the vertical char of any of the three test specimens is equal to or greater than $44 \mathrm{~mm}$ (1.75 in), the fabric is a UFAC Class II cover fabric. If an obvious ignition of the FPU substrate occurs on one of more test assemblies, the fabric is designated a UFAC Class II cover fabric.
} 
Table 3. Fabrics used and variables recorded for the Fabric Classification Test Method. [76]

\begin{tabular}{|c|c|c|}
\hline \multicolumn{2}{|r|}{ Fabric } & Variables Recorded \\
\hline \multirow[t]{2}{*}{ UFAC Class I } & Polyester/rayon/cotton, $10.1 \mathrm{oz} / \mathrm{yd}^{2}$ & \multirow{6}{*}{$\begin{array}{l}\text { Number of trials } \\
\text { Number of ignitions } \\
\text { Cigarette linear burn rate } \\
\text { Percentage of foam mass } \\
\text { loss }\end{array}$} \\
\hline & $100 \%$ cotton twill & \\
\hline \multirow{2}{*}{$\begin{array}{l}\text { UFAC 'borderline' } \\
\text { between Classes I and II }\end{array}$} & $100 \%$ cotton canvas & \\
\hline & $100 \%$ cotton denim & \\
\hline \multirow[t]{2}{*}{ UFAC Class II } & $100 \%$ cotton twill & \\
\hline & Cotton/rayon chenille & \\
\hline
\end{tabular}

Additional tests were performed on six commercial mattresses using the Federal test for cigarette ignition resistance [4]. For a quilted mattress surface, three cigarettes are placed on the tape edge, the smooth surface, and the quilted surface, for a total of nine cigarettes. For a smooth mattress surface, four cigarettes are placed on the smooth surface, and five cigarettes are placed on the tape edge. In both cases, an identically placed set of nine cigarettes are tested between two layers of cotton sheeting. The mattress passes the test for each type of location if none of the three cigarettes results in a char length more than $2.0 \mathrm{in} .(51 \mathrm{~mm})$ in any direction from the nearest point of the cigarette. A mattress fails if any one test location fails the test.

The testing was conducted with the CTC and $90 \mathrm{~mm}$ lengths of the braided cylinder of the cotton rope. Four mattresses passed with both ignition sources and two mattresses failed with both ignition sources. Again, despite the small number of tests, the results were encouraging. [75]

This rope has the advantages of being inexpensive and uniform in weight and dimensions, and of having a moving hot spot. These properties enable direct substitution for the CTC without changes to the overall procedure or the test equipment. The disadvantage is that the future availability of the rope is a function of the stability of the demand for it for its principal uses. The time needed to prepare each piece of rope (removing the core and cutting the sheath to length) would decrease the testing productivity. [75]

\subsubsection{Cylindrical Cotton Samples}

Ortiz Molina investigated the smoldering behavior of cylindrical samples of cotton thread, delineating the conditions associated with steadying smoldering and transition to flaming. [48] The cotton samples themselves were the focus of the study and were not used as an ignition source for a substrate. However, smoldering cylindrical cotton samples (e.g., dental wads) might be of interest as a surrogate SRM 1196 ignition source, similar to the cotton rope.

\subsubsection{Paper and Cardboard}

Kinbara and co-workers studied the downward propagation speed of smoldering through circular rods of rolled paper, strips of cardboard, and piles of cardboard tightly bound with thread. [49, 50] The results were summarized for the propagation speed in terms of the chamber temperature 
and sample dimensions, such as radius, thickness and breadth.

Paper and cardboard have been reported as ignition sources used in the testing of upholstered items, e.g., by Collier and Whiting [51], White and co-workers [52], Ohlemiller and Villa [53], and Zicherman and Allard [54]. In these studies, the application of this class of ignition source was to provide an ignition of the combustible item that was the focus of the investigations.

In general, the use of paper and cardboard as ignition sources to test the ignitability of a combustible item has not been reported in the literature. Furthermore, the fabrication of cellulosic material into an ignition source introduces a potentially high degree of variability. This is not a critical drawback if the material burns sufficiently vigorously to ensure ignition of a second item. However, if re-formed cellulosic materials were to be pursued as potential surrogate smoldering ignition sources, then the extent of ignition sensitivity to dimensions, mass, density, and material variability would need to be addressed.

\subsubsection{Powdered or Pulped Cellulosic Materials, with or without a Binder}

The types of potential ignition sources considered in this section are combinations of powder or granules of materials that are contained within a gum, resin, or other binding agent to provide form (e.g., a pellet or coating of a stick of bamboo or wire) and to control the rate of exposure of the bound particles. In some cases the material may be dry pressed, or formed or cast with a temporary binder that evaporates, such as water. The powder mixture typically includes a fuel (e.g., charcoal or wood) and oxidizer (e.g., sodium nitrate or potassium nitrate). Plant-based mucilaginous materials (including cellulose) are examples of binders.

Punk sticks are commonly used as manual lighters (similar to tapers) or as timed lighters (similar to fuses), such as for lighting fireworks, etc. The potential for using a punk stick as an ignition source with a burn rate that can be tuned using geometry and materials is of interest to this surrogate smoldering ignition source study.

Tao considered punk sticks as a surrogate smoldering ignition source and reported temperatures similar to those found with the standard cigarette. The suggested advantages of this surrogate were low cost and convenience of use. The disadvantages discussed included the non-uniformity of the mass and dimensions of the sticks, leading to high variability in the test results. [22]

Incense sticks have the same general composition as punk sticks. They might provide additional ranges of thermal properties, depending on the combination of bound materials, and physical characteristics, depending on manufacturing and demand specifications.

Kinbara, Edo and Sega measured the downward speed of propagation along vertical incense sticks. [50] They obtained propagation speeds as a function of the chamber temperature and sample radius. Similarly, Mukunda and co-workers studied the smolder rates of incense sticks as a function of the oxygen fraction in the air, the air speed, and the radius of the incense. [55]

Lin, Yang, and Chang determined the influence of the formulations of incense on the smoldering characteristics. [56] The incense sticks were lit using a propane burner. The flames were immediately quenched, and the sticks were allowed to continue to smolder. The concentrations 
of alkali metals in the incense were associated with changes in smoldering characteristics. The sticks were not used as an ignition source to ignite a potential fuel package; however, the influence of the chemical components on the smoldering characteristics may be of use.

Smoldering incense has been reported as a risk factor for accidental fires in housing. [77, 78] Incense has also been used for smoke generation in experiments. However, there were no reported studies of incense sticks being used as an ignition source in fire experiments.

Cellulose powder, without a binder, pressed into discs of various densities has been used in pyrolysis experiments in a number of different investigations. [32, 42] Daikoku and co-workers [42] used a slurry of cellulose powder and water to then cast the samples. Suuberg and coworkers [32] reported that pressing the powder, with the moisture content present in the commercial product, in a die produced samples of sufficient structural integrity to be used in testing. These samples were used for identification of species and amounts of pyrolysis products for various applied incident fluxes, rather than investigation of the thermal properties during smoldering of the samples as a potential ignition source for a second item.

Wood and wood products, such as particle board, have also been used in pyrolysis experiments. The non-uniformity of natural wood samples and samples formed from wood products has led to variability in test results and lack of reproducible data. [42] Daikoku and co-workers suggested that a standard preparation method of the samples would reduce the variability in test results. Similar to the cellulose powder, the samples discussed here were used for identification of species and amounts of pyrolysis products, rather than investigation of the thermal properties during smoldering of the samples as a potential ignition source of an adjacent item.

\subsubsection{Smoldering Synthetic Polymers}

Self-sustained smoldering of foams has been reported in the literature, e.g., for polyurethane foams [57-59] and other organic polymers [60,61]. Shredded FPU foams, in the forms of filling for pillows and parts of furniture items [62, 63], have been used in previous investigations as all or part of experiment fuel packages. Chao and Wang [59] reported steady state smoldering temperatures for a FR FPU foam near $400{ }^{\circ} \mathrm{C}$, similar to temperatures near a cigarette coal.

Although self-sustained smoldering foams have not been reported as being investigated for use as an intentional ignition source, there may be the possibility that a foam or other forms of polymer could be engineered to produce required smoldering temperatures and burn rates associated with a potential surrogate ignition source for the SRM 1196 cigarette.

\subsubsection{Intumescent Composites}

The characteristics of intumescent materials used as protective coatings of steel substrates or other fire protection applications in the event of fire exposure have been investigated extensively. [79-81] These materials expand when heated, forming a thick surface layer that reduces the transfer of radiant flame energy to the underlying combustible and forms a barrier to the transport of pyrolyzed fuel to where it can mix with air and react. Experiments have demonstrated reduced peak heat release rate, decreased total heat release, and increased time to 
ignition. $[55,58,59]$

Of interest to this review is the potential for the use of a mixture of a fuel and an intumescent material as an ignition source. Examples of such formulations are "black snake fireworks" or "glow worms," where the commercial mixtures comprise of soda, nitrated napthalenes and linseed oil and amateur versions may contain sugar or ammonium nitrate and alcohol, fuel oil, or lighter fluid. [82, 83]

There have been no studies of this use of intumescent materials reported in the scientific literature. Nonetheless, such a mixture may serve as a potential moving heat source that is fully described by a smoldering front within the igniter material.

\subsubsection{Methenamine}

The methenamine pill or tablet [65] is routinely used to qualify the resistance of floor covering materials to a small point potential ignition source. [84] The procedure is standardized in ASTM D2859 [65] and in the analogous CPSC regulations, 16 CFR parts 1630 and 1631. In this sense, the test is similar to the hot metal nut test. [47] However, the methenamine pill is a flaming ignition source. It might be possible to wrap the pill in a tube, converting it to a source of conductive heat. If the contact temperatures were too high, it might be possible to reduce the heat release rate using inert fillers.

\subsubsection{Chemical Heaters}

This heading encompasses chemical systems that generate heat in a manner other than by classic combustion reactions. Were such chemicals to come in contact with the substrate, they would likely change the substrate degradation chemistry in a manner different from the way a cigarette would. For this reason, a nonreactive material would be used as a chemical separator and thermal interface between the chemical reaction and the substrate (e.g., as found in packs to heat pre-prepared food, in survival heat packs, and in hand warmers).

Devices involving irreversible exothermic reactions to produce heat utilize cellulose, iron and water, activated carbon, vermiculite, charcoal, lighter fluid or liquid petroleum gas and may include catalysts such as salt or platinum. [82, 85]

Other types of small heating devices generate energy through crystallization of supersaturated solutions, and may also be reusable. Such devices may utilize sodium acetate that has a latent heat of fusion of approximately $264 \mathrm{~kJ} / \mathrm{kg}$ to $289 \mathrm{~kJ} / \mathrm{kg}$ that can be released when a nucleation center is formed within a room temperature supersaturated aqueous solution. Sodium acetate heat packs can be reactivated by boiling to re-dissolve the crystals. Ideally, these packs can be reused indefinitely. [82, 85]

There were no references to the use of these chemical systems as igniters. It would take some effort to tune such a system to generate appropriate temperatures and durations. However, once accomplished, the result would be an igniter that is based on common materials and could thus be reproduced without limitation. 
This page intentionally left blank. 


\section{Thermal Characteristics of a Cigarette Burning on a Substrate}

\subsection{INTRODUCTION}

Since the SRM 1196 cigarettes have only recently become available, there has been little published literature pertaining to their effectiveness as an ignition source. Gann and Hnetkovsky established a modification to the ASTM E 2187 test method, with a standard substrate of two pieces of filter paper over a $6.35 \mathrm{~mm} \pm 0.05 \mathrm{~mm}$ thick brass plate, for measuring the ignition propensity of the CTC and SRM 1196. [16] Additional work established the ignition propensity value for SRM 1196 that appears in Section 1 of this report. However, this work did not include any other information regarding the thermal characteristics of the cigarette or of a substrate when in contact with each other during a test.

In the following sections, studies that produced such data for other types of cigarettes are included. The specific values of the thermal response parameters are not necessarily the same as for SRM 1196 cigarettes, but they do provide some insight into the effects of varying one or both of the combustible "partners." The parameter value ranges for SRM 1196 cigarettes will need to be determined in a later task of this investigation.

Processes involved in cigarette combustion and smoldering ignition of substrates include [10, 61 , 86, 87]:

- oxidation and thermal degradation of the tobacco and the paper wrapper at the thermal front (the coal or ember) of the cigarette,

- heating of the substrate by the smoldering cigarette,

- heat transfer within the surrounding substrate, and

- oxygen transport to the combustion front at the surface of the substrate and within the substrate.

There are a number of parameters associated with these processes, including:

- heat release rate, temperature, movement speed, geometry and duration of the burning cigarette coal,

- ignition temperature, geometry, contact roughness, thermal energy transfer characteristics, heat capacity, density, heat of oxidation in the condensed phase of the substrate,

- area of contact between the coal and substrate, condensation on the substrate surface of pyrolysis and combustion products from the cigarette and/or the substrate,

- ventilation, and

- local environmental conditions.

Not all of these parameters have been fully measured and reported in the published literature, nor has a comprehensive model of a burning cigarette on a susceptible substrate been developed and made available. Therefore, there may be additional cigarette, substrate, and cigarette-substrate interactive parameters to be added to this list. 
The following are aspects of a cigarette burning on a substrate that have been reported in the available published literature:

- length of the visible glowing coal,

- burning rate (in terms of either mass or length),

- temperature peaks and profiles within the cigarette and at the interface between the cigarette and substrate,

- heat transfer to the substrate,

- temperature profiles within the substrate, and

- mass loss rates of cigarette and substrate combinations.

Reports of measurements of these aspects are summarized in the following sections. Details of the experiments and results are included where information germane to the current project was available. Also presented are any results resulting from variations in the testing situation, such as cigarettes smoldering while uncovered and covered with a section of cotton fabric, and the use of different types of measuring equipment.

\subsection{Length of Glowing CoAL}

Salig reported observations of increases in the length of the glowing portion of a smoldering cigarette when placed on certain fabric-foam combinations. [30] The cigarettes used in the investigation were Pall Mall king size without filter tips ( $80 \mathrm{~mm}$ length, $8 \mathrm{~mm}$ diameter). One type of FPU foam and five types of $100 \%$ cotton fabrics were used in the testing.

Thermocouples were located along the centerline of each test cigarette, and the cigarettes were studied either while suspended in air or while located on a substrate. The length of the glowing coal was determined visually.

When suspended in air, the glowing zone of the cigarette was measured and found to be approximately $10 \mathrm{~mm}$ at the times when one-half, three-quarters, and almost all of the cigarette was consumed. When the lit cigarette was placed on a substrate (printcloth upholstery fabric over a FPU foam) and covered by a piece of fabric (printcloth), the glowing zone of the cigarette was found to be approximately $15 \mathrm{~mm}$ when one-half of the cigarette was consumed, increasing to $20 \mathrm{~mm}$ when three-fourths of the cigarette was consumed, and to $25 \mathrm{~mm}$ just before the end of the test. For a different cover fabric (a bleached and scoured cotton duck), the measured glowing region was consistently longer. The reported length was approximately $20 \mathrm{~mm}$ when one-half of the cigarette was consumed, increasing to $25 \mathrm{~mm}$ when three-fourths of the cigarette was consumed and, to $30 \mathrm{~mm}$ just before the end of the test. No replicate testing was reported in this study [30], so the repeatability was not quantified.

Gann and co-workers reported coal lengths for various experimental cigarettes for three test configurations: free-burning, centrally located on a horizontal fabric/FPU foam mock-up and in the crevice of a two-cushion mock-up, as shown in Figure 2. [10] The experimental cigarettes were all $100 \mathrm{~mm}$ in length, with a tobacco column length of approximately $72 \mathrm{~mm}$ and the 
remaining length being that of the filter tip. The alphabetized designations in the figure (using the form: abcd-e), and in subsequent figures and text, indicate properties of the cigarettes that were systematically varied for that study:
a. Tobacco type:
F: flue cured, B: Burley
b. Prevalence of expanded tobacco:
E: nominally all, N: nominally none
c. Air permeability of the wrapping paper:
H: high, L: low
d. Alkali metal citrate added to the wrapping paper:
$\mathrm{C}$ : added, N: none
e. Cigarette circumference in $\mathrm{mm}$

For the free-burning configuration, the length of the coal varied from approximately $5 \mathrm{~mm}$ to $11 \mathrm{~mm}$, depending on the type of cigarette. For each cigarette type tested, a small increase in coal length was reported for the horizontal mock-up configuration compared to the free-burning configuration. A greater increase was observed for the two-cushion mock-up configuration, where the coal length varied from approximately $6 \mathrm{~mm}$ to $17 \mathrm{~mm}$ with cigarette type.

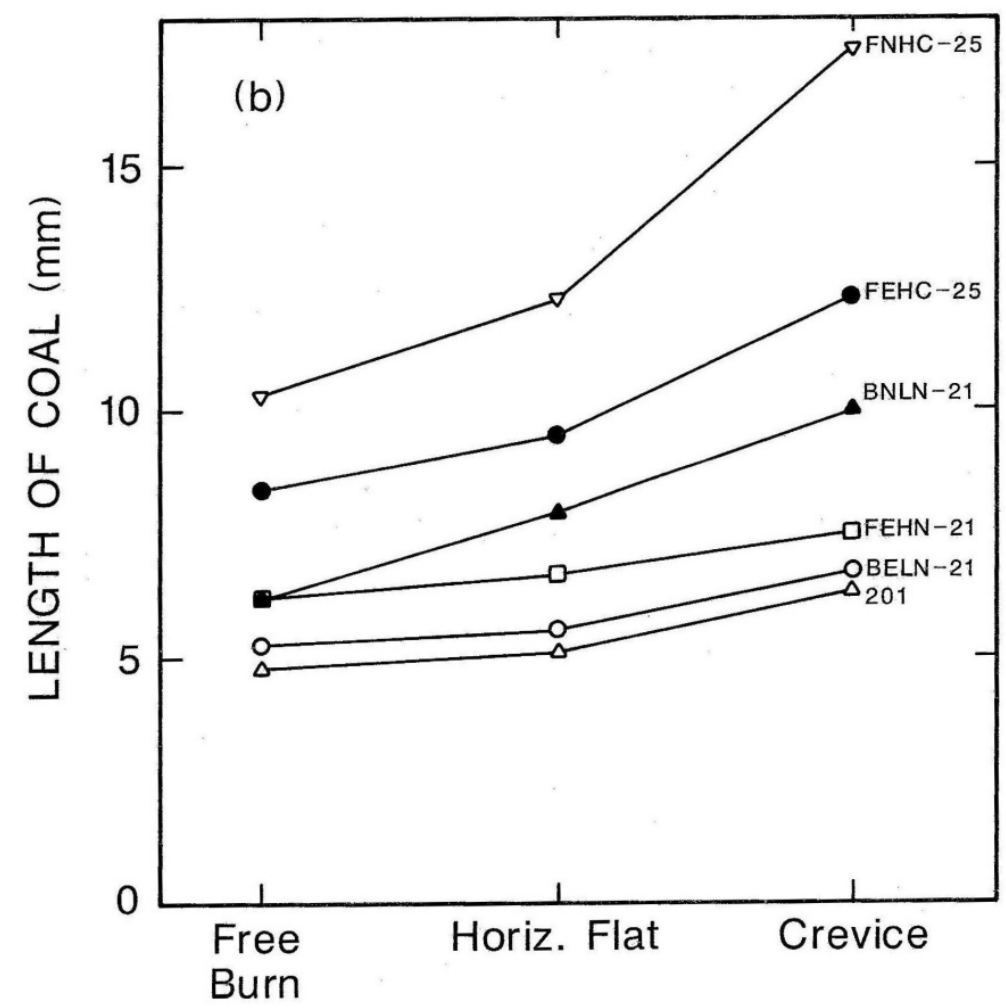

Figure 2. Coal length for various cigarettes in various test configurations. [10]

Of the six cigarettes in Figure 2, the composition of the FNHC-25 cigarettes is the closest to the SRM 1196 cigarettes. However, even there, the tobaccos are from different crop years, the SRM 1196 paper permeability is lower than that of the FNHC cigarettes, and there is no filter tip on a SRM 1196 cigarette. The variation in coal length with cigarette type highlights that burning properties of SRM 1196 cigarettes need to be measured in order to relate the findings of studies such as this. Moreover, the reported variations in coal length with substrate materials and 
configuration suggest that the SRM 1196 thermal properties will need to be determined on multiple substrates to characterize the cigarette-substrate interaction.

\subsection{Burning RAte}

Salig reported that the rate of smoldering along the length of the cigarette was faster for a freeburning cigarette, compared to the same type of cigarette lying on a foam-fabric substrate. The rate of smoldering was also reported to differ for the two types of fabric considered. [30]

Gann and co-workers reported smolder speeds of various cigarettes in various cigarette-substrate configurations (Figure 3). They also presented free-burning cigarette smolder speed versus the smolder speed of a cigarette on a California fabric and FPU horizontal or crevice mock-up for various cigarettes (Figure 4). [10] The reported smolder rates for free-burning cigarettes and cigarettes on substrates (Figure 4) indicated that some of the types of cigarette shared a common dependence on the type of test configuration, whereas other types of cigarette had a different interaction with the substrates and configurations.

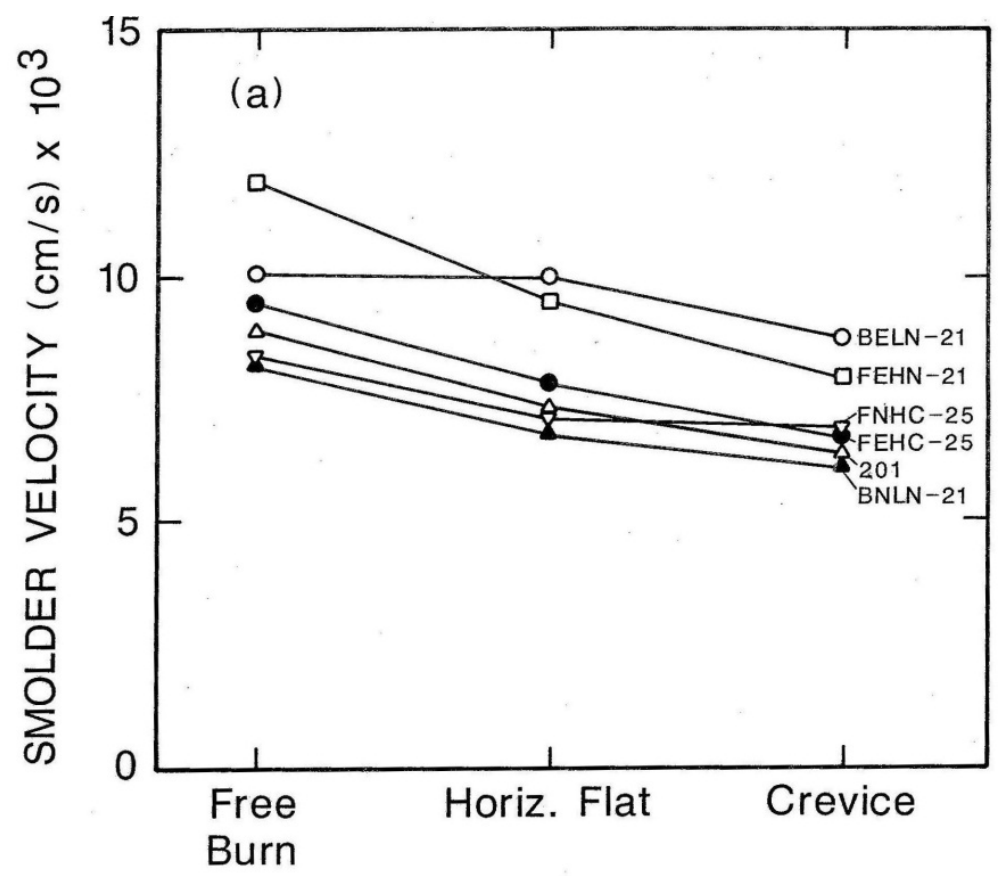

Figure 3. Smolder speed versus cigarette-substrate configuration. [10]

Waymack and co-workers reported mass burn rates for various cigarette designs tested to be linear with time. [88] They also found that the coal size was proportional to the mass burn rate of a free-burning cigarette, for a variety of experimental cigarette designs. This coal size was measured after extinguishment, by manually dipping the cigarette into water, after 5 minutes of free-burning smoldering that was counted from the time the initial $15 \mathrm{~mm}$ length of the cigarette was burnt. Additional findings were that the mass burn rate was proportional to the heat output for this selection of cigarette designs and that tobacco packing density (varied by changing the ratio of expanded to non-expanded tobacco) had little influence on the mass burn rate of a cigarette, when all other design parameters remained the same. 


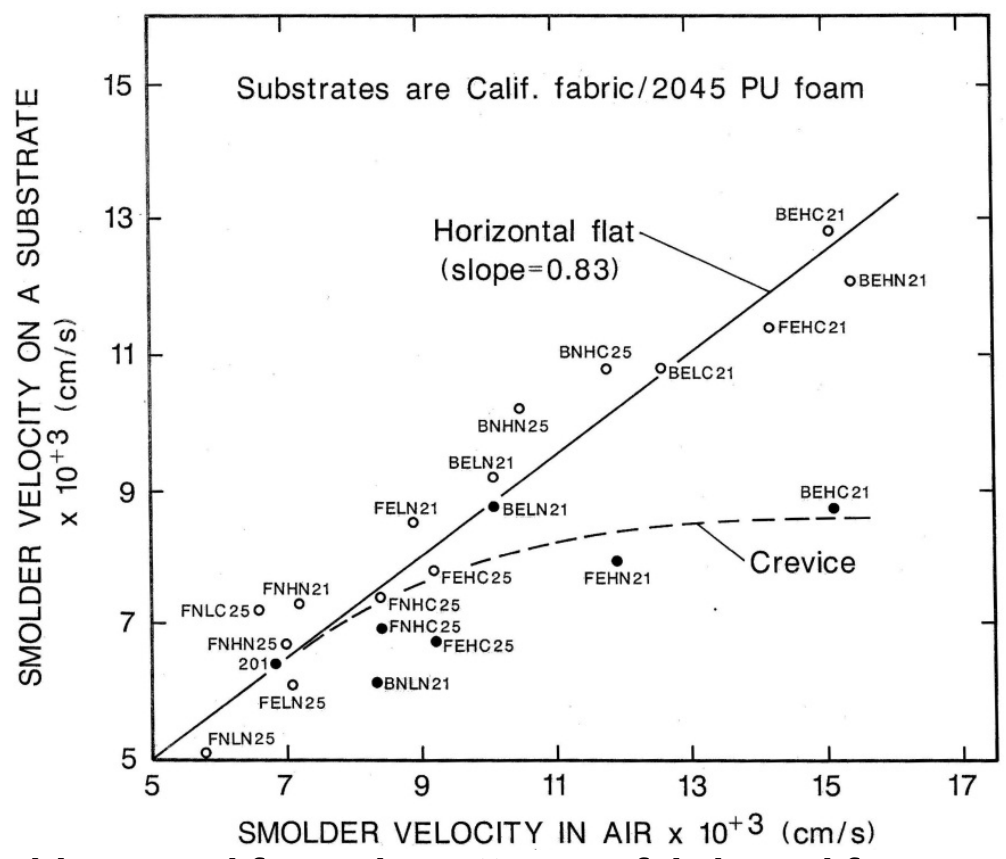

Figure 4. Smolder speed for a cigarette on a fabric and foam mock-up versus smolder speed of a free-burning cigarette. [10]

\subsection{CigaretTE TEMPERATURES}

The locations of temperature measurements of systems involving cigarettes and substrates discussed in the literature are described as:

- Centerline of the cigarette, where the temperature measurement device is threaded into the longitudinal axis of the cigarette.

- Surface of the cigarette, where the temperature measurement device is located on the outside surface of the cigarette, or the measurement focus of the (optical) device is directed at the surface of the cigarette.

- In contact with both the cigarette and substrate.

- On the surface of the substrate around the location of the cigarette, where the temperature measurement device is located on the surface of the substrate, or the measurement focus of the device of is directed at the surface of the substrate.

- Within the substrate, where the temperature measurement device is located at a specified depth below the substrate surface and at a distance relative to the location of the cigarette (such as distance from the centerline of the cigarette and distance from the non-lit end). 


\subsubsection{Temperature Measurement Devices}

\subsubsection{Thermocouples}

By far, thermocouples have been the most commonly used devices to measure temperatures within and around lit cigarettes. They are inexpensive and easy to monitor.

It is well known that the diameters of the thermocouple bead and the thermocouple wires can affect the accuracy of the measured temperature. This is especially true for an item of low thermal mass, such as a cigarette, where the thermocouple is an unintended heat sink. Finer thermocouples can provide minimal thermal disturbance of the cigarette/substrate system, but at the cost of fragility.

For the most part, the diameters of the thermocouples used in the experiments were not reported. Typically only the thermocouple type and location were included in the published documents (e.g., Salig [30], Krasny and co-workers [89], etc.). In other cases, the diameter was reported but the influence of the size on the test results was not investigated (e.g., as included in previously published summaries $[87,90])$. Available information on the thermocouples used in the testing of cigarettes is summarized here.

Lam [91] used thermocouples of $0.2 \mathrm{~mm}$ diameter wire to measure temperatures within the smoldering tobacco of cigarettes, cigars and pipes. However, the influence of the thermocouple wire diameter was not investigated.

Laszlo and Watson [90] reviewed various experiments that considered the influence of thermocouple size used in cigarette smoldering tests. They reported the following:

- A decrease in thermocouple wire diameter from $0.100 \mathrm{~mm}$ to $0.025 \mathrm{~mm}$, for the same test set up, was associated with an increase of $127^{\circ} \mathrm{C}$ in the measured peak temperatures within the cigarette; and

- A decrease in thermocouple wire diameter from $0.20 \mathrm{~mm}$ to $0.05 \mathrm{~mm}$, was associated with an increase in the measured peak temperatures within the cigarette of $156^{\circ} \mathrm{C}$ (from $656^{\circ} \mathrm{C}$ to $812^{\circ} \mathrm{C}$ ). No further increases in peak temperatures were reported for tests in which the thermocouple diameter was further reduced to $0.03 \mathrm{~mm}$.

These values were based on single tests, so the repeatability associated with these measurements was not established.

Krasny [87] suggested that thermocouples no larger than $0.025 \mathrm{~mm}$ in diameter be used in the measurements within or on cigarette coals. He also acknowledged that the contact between the thermocouple and the cigarette or the substrate has a large degree of uncontrollable variability. This is particularly perceptible when shrinkage and movement occurs during charring, a phenomenon observed with cigarettes and with cellulosic substrates.

\subsubsection{Infrared Devices}

Infrared cameras collect the thermal emission from an object and translate it into a value on 
either a grey or colored scale that is then analyzed to estimate of the surface temperature. The general assumption is that the hot object radiates as a black body (following the MaxwellBoltzmann radiation equation, with unit emissivity), or at least a nearly black, gray body (with emissivity only moderately less than unity). Errors are introduced when these assumptions are not the case or when the camera is not focused on an area of uniform temperature. It should also be noted that different cigarettes were used in most of the studies cited here.

Reported surface temperatures of free-burning non-banded cigarettes estimated using infrared camera analysis have ranged from approximately $620^{\circ} \mathrm{C}$ to $680{ }^{\circ} \mathrm{C}$, as reported by Waymack and co-workers [88], and approximately $590^{\circ} \mathrm{C}$, as reported by Sherwood and co-workers [92].

Liu and Woodcock [93] used an infrared camera (AGEMA THV570 from AGEMA Infrared Systems, Sweden) with a resolution of approximately $0.2 \mathrm{~mm}$ x $0.2 \mathrm{~mm}$ at 8-bit (256-color) and $50 \mathrm{~Hz}$, and a response of $0.04 \mathrm{~s}$ at approximately $780^{\circ} \mathrm{C}$, to measure the peripheral temperatures of a puffed cigarette. Tobacco shreds near the coal surface were suggested to cause localized transient events, where the temperature was approximately $200{ }^{\circ} \mathrm{C}$ to $250{ }^{\circ} \mathrm{C}$ higher than the average peripheral temperature of the cigarette. It was suggested that these localized high temperature occurrences were significantly less likely during free-burning smolder.

Average higher temperatures than those reported for free-burning cigarettes are expected to be associated with puffed cigarettes. For example, temperatures of up to $900{ }^{\circ} \mathrm{C}$ have been reported for situations simulating a smoker taking one last draw before discarding a cigarette. [94] However, these values are from the center of the coal rather than the tobacco shreds at the coal surface discussed by Liu and Woodcock.

Although these free-burn temperatures and localized transient results associated with a puffed cigarette do not directly apply to the situation of interest for this study, they provide valuable information regarding the precision, the spatial and temporal resolution, and the repeatability of measurements using infrared devices.

Lendvay and Laszlo used infrared photometry to estimate the surface temperature of a freeburning commercial cigarette where the ash was in place (approximately $550{ }^{\circ} \mathrm{C}$ to $600{ }^{\circ} \mathrm{C}$ ) and then the ash was removed (approximately $700{ }^{\circ} \mathrm{C}$ to $790{ }^{\circ} \mathrm{C}$ ). [95]

Baker used a combination of an infrared probe to measure solid phase temperatures and thermocouples to measure the gas phase temperatures of a free-burning cigarette. [96] He found little difference between the two measurement methods at any one point (and a maximum temperature in coal of $775^{\circ} \mathrm{C}$ and at the periphery of $500^{\circ} \mathrm{C}$ ).

\subsubsection{A Novel Method}

Egerton and co-workers used X-ray scanning of beads with different melting temperatures embedded in the sample cigarettes. They reported maximum free-burning commercial cigarette temperatures of $820^{\circ} \mathrm{C}$ at the core and $616^{\circ} \mathrm{C}$ on the periphery. [97] 


\subsubsection{Cigarette Centerline Temperatures}

Loftus [12] reported centerline temperatures of cigarettes burning on non-combusting (asbestos board) surfaces using $0.05 \mathrm{~mm}$ diameter Chromel-Alumel thermocouples located at $3.2 \mathrm{~mm}$ from the butt end for both filter-type cigarettes and non-filter-type cigarettes. The range of peak temperatures reported for the 26 filter cigarettes was $601{ }^{\circ} \mathrm{C}$ to $711^{\circ} \mathrm{C}$, with an average of $659^{\circ} \mathrm{C}$. The range of peak temperatures reported for the six non-filter cigarettes was $627^{\circ} \mathrm{C}$ to $722^{\circ} \mathrm{C}$, with an average of $695^{\circ} \mathrm{C} .[12,87]$

Behnke presented centerline temperatures of cigarettes also tested on other non-combusting surfaces, such as $0.075 \mathrm{~mm}$ thick copper sheet, using $0.25 \mathrm{~mm}$ diameter Chromel-Alumel thermocouples to the ASTM D.13 committee in 1969. The work was reported elsewhere. [10, 87] The temperature change of the copper substrate was also used to estimate the heat flux from the sample cigarettes. The average centerline thermocouple temperature was [87]:

- $490{ }^{\circ} \mathrm{C}$, with a standard deviation of $35^{\circ} \mathrm{C}$ for cigarettes dried (at $110{ }^{\circ} \mathrm{C}$ for 16 hours, followed by desiccating at room temperature for 8 hours); and

- $492{ }^{\circ} \mathrm{C}$, with a standard deviation of $45^{\circ} \mathrm{C}$ for cigarettes that were dried then conditioned (at $24^{\circ} \mathrm{C}$ and $65 \%$ relative humidity for 8 hours).

The negligible difference between the temperatures for the dried and the conditioned cigarettes may have been influenced by:

- the type of cigarette;

- the initial drying, which may have removed volatiles or denatured chemical sites that may have been hydroscopic, reducing or eliminating the effect of the conditioning; and

- the diameter of the thermocouple beads, which may have had a damping effect on the thermocouple temperatures achievable.

Krasny [87] summarized that substrate ignitions were observed for tests where cigarette centerline temperatures were up to $250^{\circ} \mathrm{C}$ lower for the substrate scenario compared to the same cigarette during a free-burning scenario.

Salig [30] reported higher maximum thermocouple measurements located on the center axis of a burning cigarette for free-burning than the same cigarette located on a potentially smolder-prone substrate. He also reported maximum thermocouple measurements within a cigarette smoldering while suspended on a wire through the centerline to be approximately $710{ }^{\circ} \mathrm{C}$ to $780{ }^{\circ} \mathrm{C}$ (Figure $\left.5^{\vee}\right)$. This range is in agreement with other published values for free-burning commercial cigarettes, as summarized elsewhere [87]. Maximum thermocouple measurements within the same type of cigarette on a substrate (located in a crevice orientation, as shown in the schematic of Figure 7) were reported in the range of $580^{\circ} \mathrm{C}$ to $720^{\circ} \mathrm{C}$ (Figure 6). The time from ignition of each cigarette to each maximum thermocouple temperature located on the centerline of the cigarette was shortest for the free-burning cigarette (Figure 5), compared to each of the foamfabric combinations considered (Figure 6).

${ }^{\mathrm{v}}$ All figures from Reference 30 are used with permission of the Massachusetts Institute of Technology. 


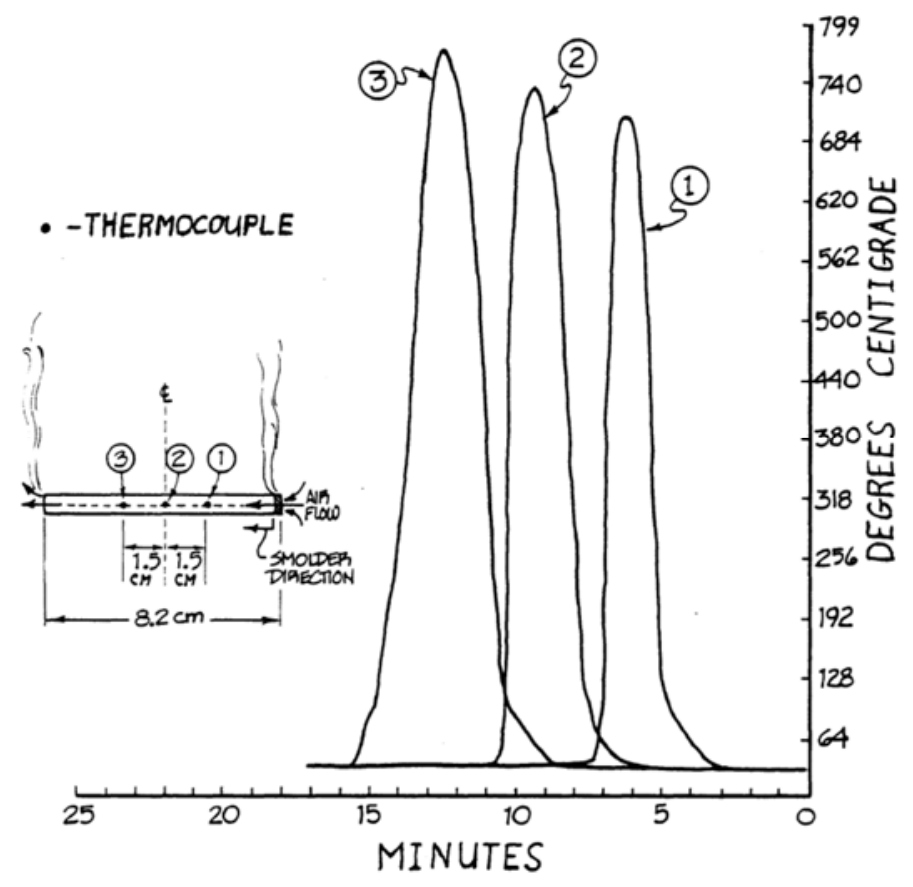

Figure 5. Thermocouple temperatures on the centerline of a free-burning cigarette suspended in air. [30]

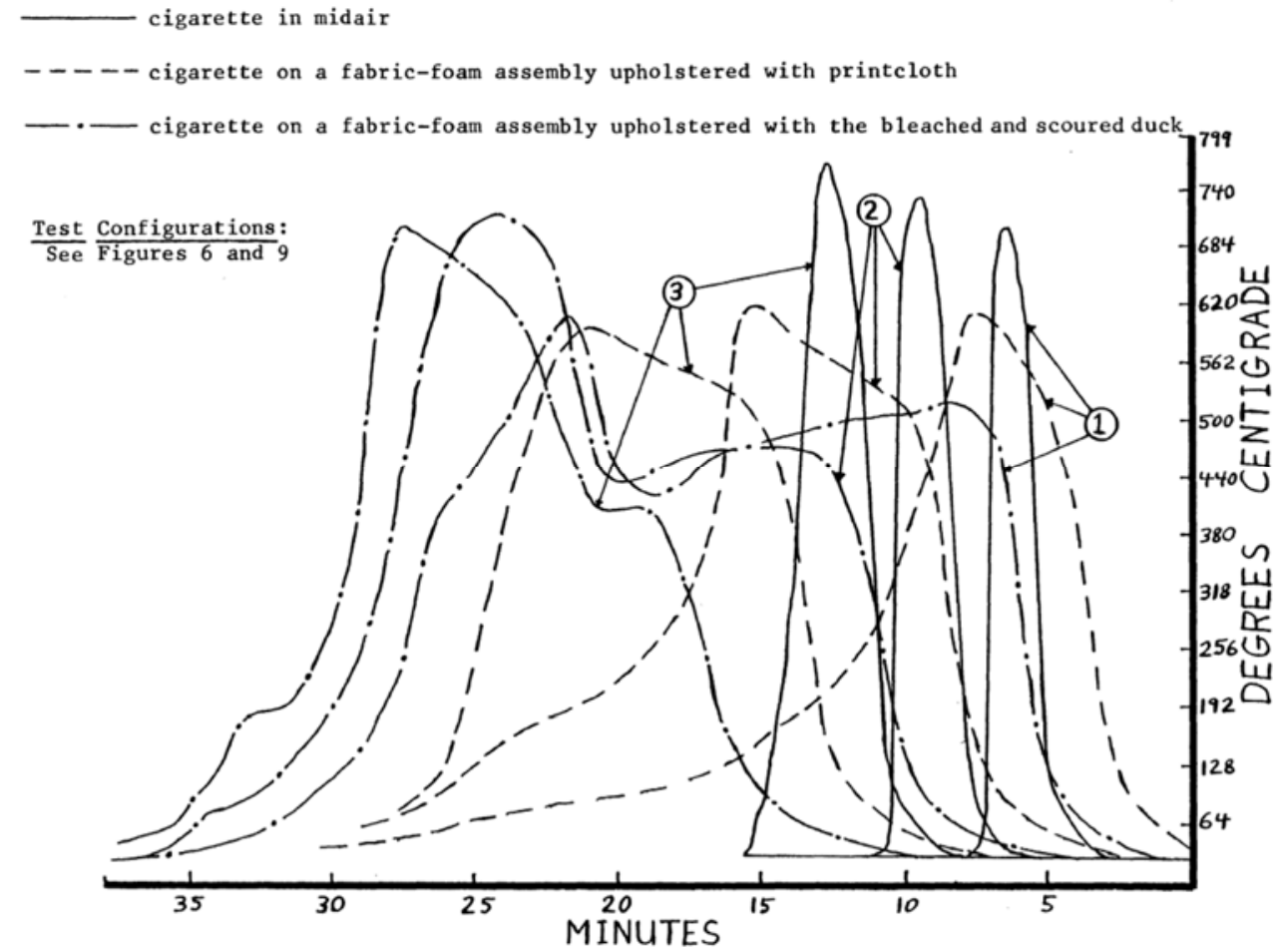

Figure 6. Thermocouple temperatures on the centerline of cigarettes, where one is a free-burning cigarette suspended in air and two others are located in the crevice of two upholstered cushions. [30] 


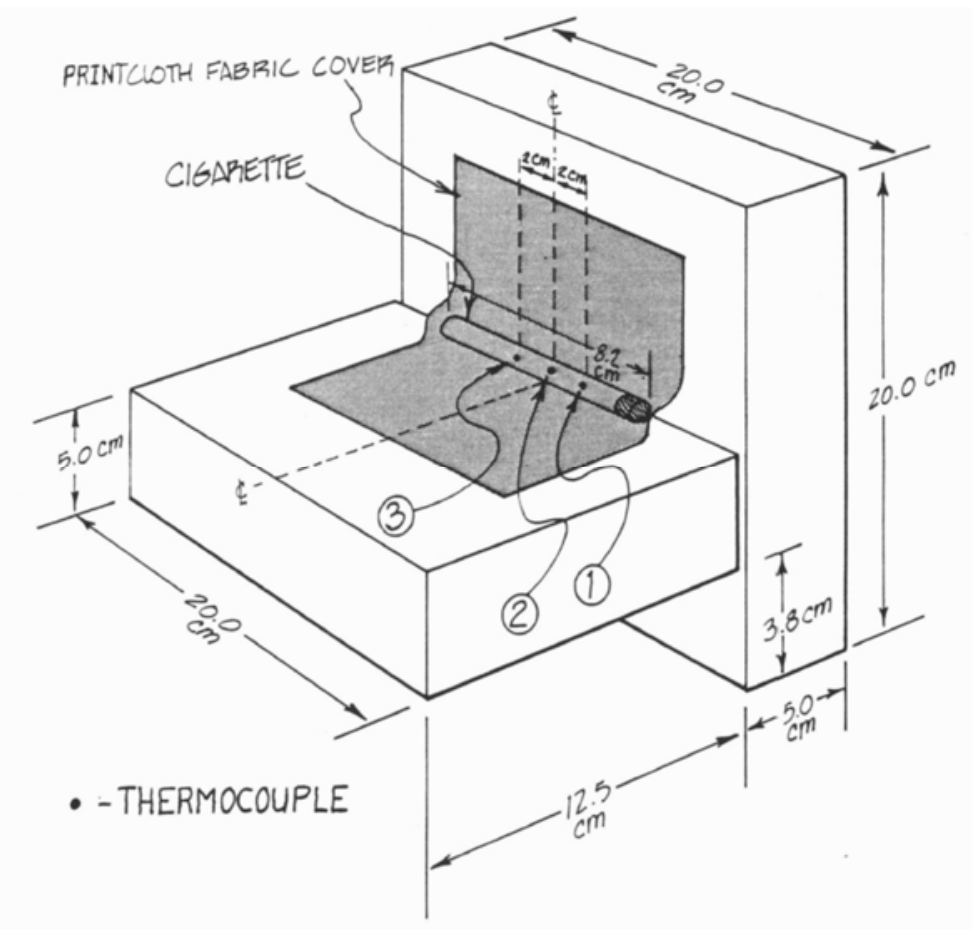

\section{Figure 7. Schematic of the test set up for cigarettes located in the crevice of two upholstered cushions. [30]}

Other estimates of maximum internal cigarette coal temperatures have also been reported. Results of peak coal temperatures of free-burning, non-banded cigarettes were summarized from a 1977 Department of Health, Education and Welfare (DHEW), National Institute of Health (NIH) study to be approximately $780^{\circ} \mathrm{C}$ to $840^{\circ} \mathrm{C}$, after $15 \mathrm{~mm}$ of the length of the cigarettes had burnt, and approximately $770{ }^{\circ} \mathrm{C}$ to $840^{\circ} \mathrm{C}$, after $55 \mathrm{~mm}$ of the length of the cigarettes had burnt. [89] A maximum temperature in the coal of $775^{\circ} \mathrm{C}$ and at the periphery of $500{ }^{\circ} \mathrm{C}$ was reported by Baker, who used an infrared probe in the solid phase of a free-burning cigarette. [96] Temperatures between puffs of a burning cigarette were estimated to be approximately $770{ }^{\circ} \mathrm{C}$ to $790{ }^{\circ} \mathrm{C}$ when the ash was partially removed from the coal, as reported by Lendvay and Laszlo, who used infrared photometry to estimate the surface temperatures. [95] A maximum freeburning commercial cigarette temperature of $820^{\circ} \mathrm{C}$ at the center was reported by Egerton and co-workers, who used an X-ray scanning technique. [97]

\subsubsection{Cigarette Exterior and Substrate Temperatures}

Salig [30] reported maximum thermocouple temperatures located along the line of contact between the bottom of a cigarette and the top of a fabric covered FPU foam cushion. A schematic of the test setup is shown in Figure 8(a) for an $80 \mathrm{~mm}$ long cigarette and Figure 8(b) for two such cigarettes placed end to end, the equivalent of a $160 \mathrm{~mm}$ long cigarette.

Four types of fabric were used in the testing: Doblin (diamond weave), greige duck (untreated), duck (bleached and scoured), duck dyed blue, and a printcloth. Self-sustained smolder was initiated with a lit uncovered cigarette in approximately $1 \mathrm{~min}$ for the Doblin and greige duck fabrics. Only the Doblin upholstered cushion was observed to have initiation of foam smolder. 
Using covered cigarettes, the Doblin and greige duck-covered cushions were observed to initiate self-sustained smolder that completely consumed the cushions. The times to self-sustained smolder were 12 min for the Doblin upholstered cushion and 16 min for the greige duck upholstered cushion.

When configurations of two cigarettes in series were used, the duck dyed blue and printcloth upholstered cushions were both observed to ignite to self-sustained smolder and both cushions were completely consumed. The times to self-sustained smolder were 17 min for the duck dyed blue upholstered cushion and $43 \mathrm{~min}$ for the greige duck upholstered cushion.

When using a $80 \mathrm{~mm}$ long cigarette, the maximum thermocouple temperatures measured at the interface between the bottom of the cigarette and the top of the substrate were approximately $360{ }^{\circ} \mathrm{C}$ to $560^{\circ} \mathrm{C}$ (Figure 9) for the Doblin fabric and $320^{\circ} \mathrm{C}$ to $500{ }^{\circ} \mathrm{C}$ (Figure 10) for the greige duck fabric. When using a $160 \mathrm{~mm}$ long cigarette, the maximum thermocouple temperatures measured at the interface between the bottom of the cigarette and the top of the substrate were approximately $310{ }^{\circ} \mathrm{C}$ to $450{ }^{\circ} \mathrm{C}$ (Figure 11) for the duck (dyed blue) fabric and $380{ }^{\circ} \mathrm{C}$ to $450{ }^{\circ} \mathrm{C}$ (Figure 12) for the printcloth fabric.

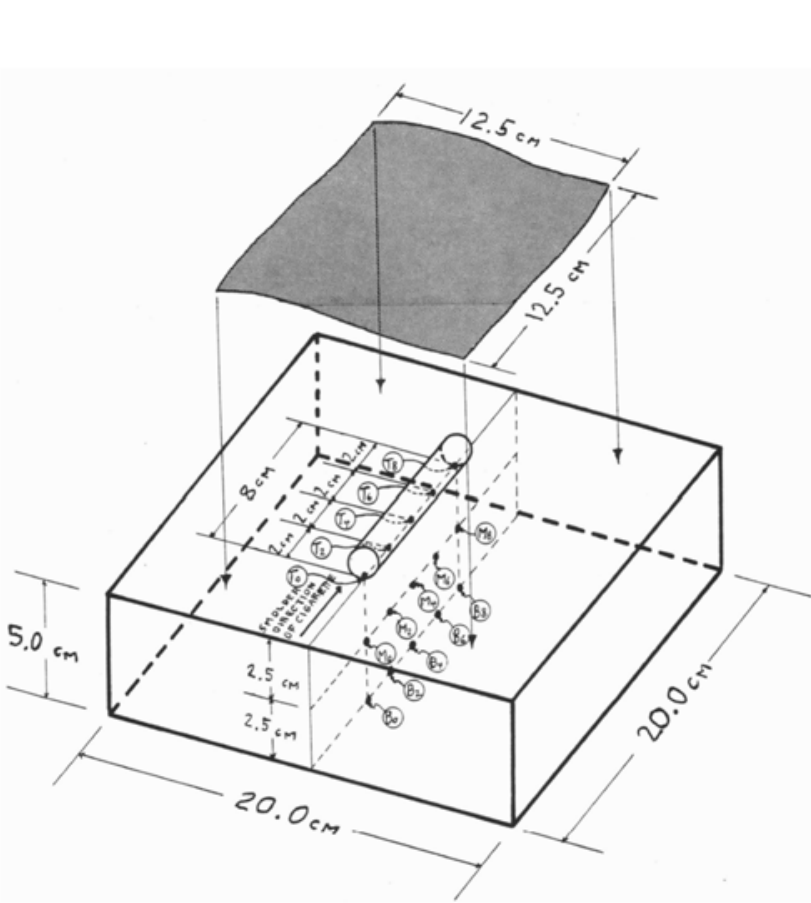

(a)

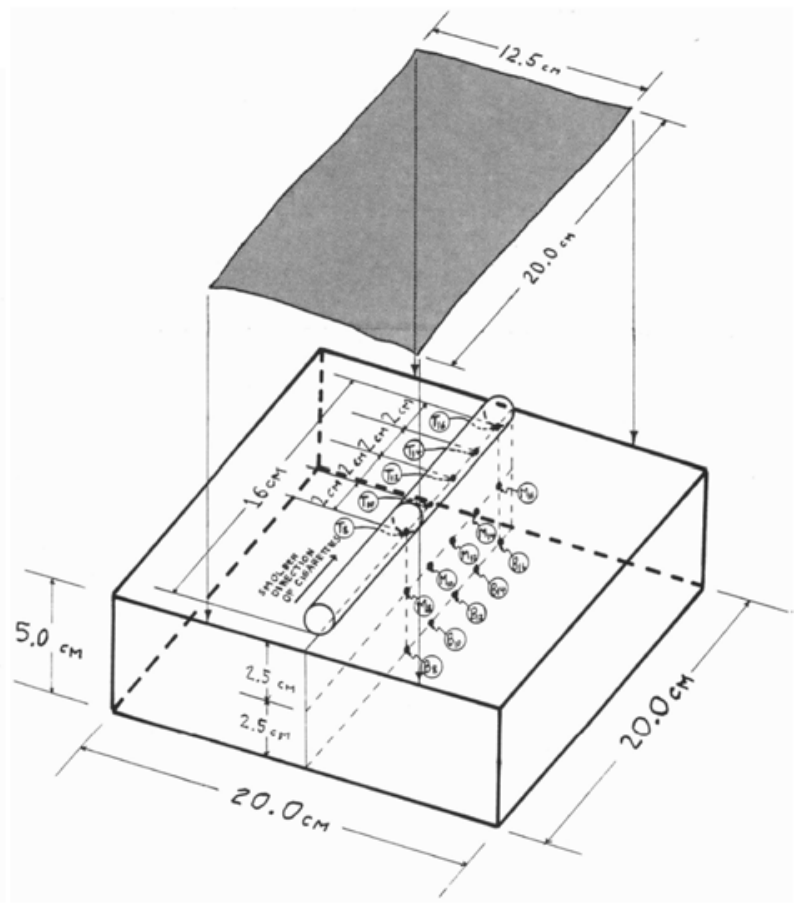

(b)

Figure 8. Schematic of the single cushion setup including thermocouple locations on the line of contact between the cigarette and substrate and within the foam directly under the initial location of the cigarette, where (a) one $80 \mathrm{~mm}$ cigarette was used, or (b) two $80 \mathrm{~mm}$ cigarettes were used in series to effectively form a $160 \mathrm{~mm}$ long cigarette. [30] 


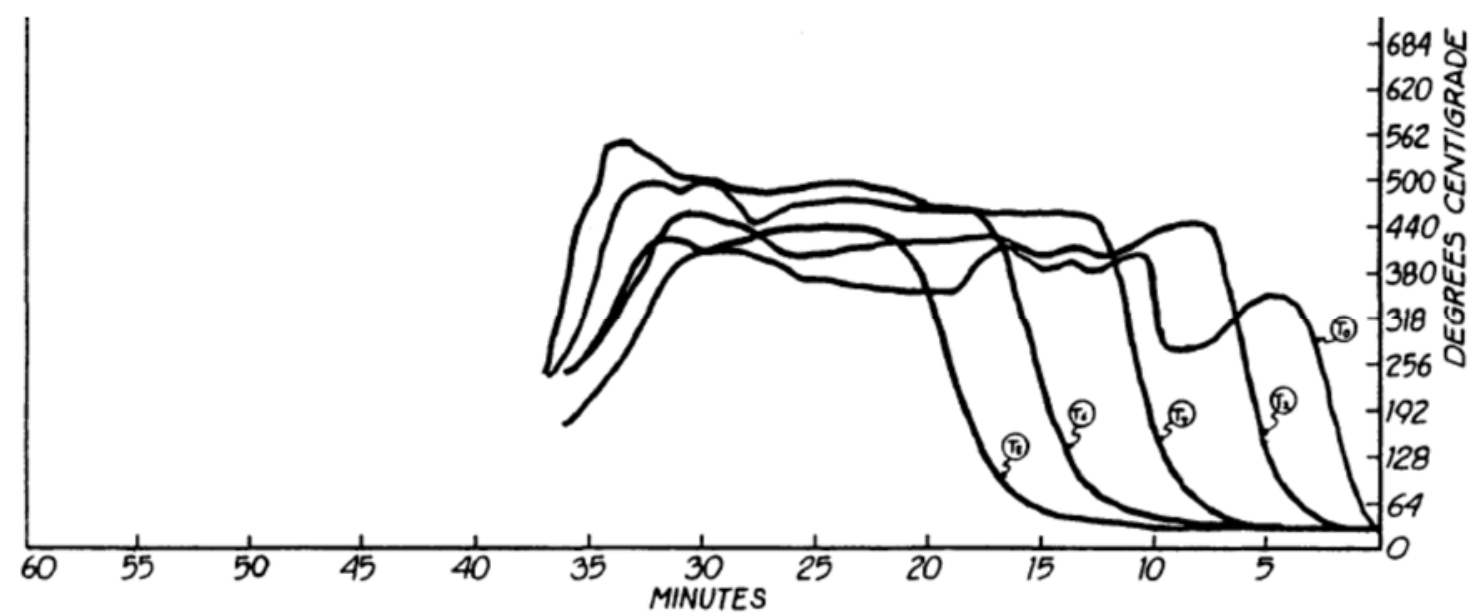

(a)

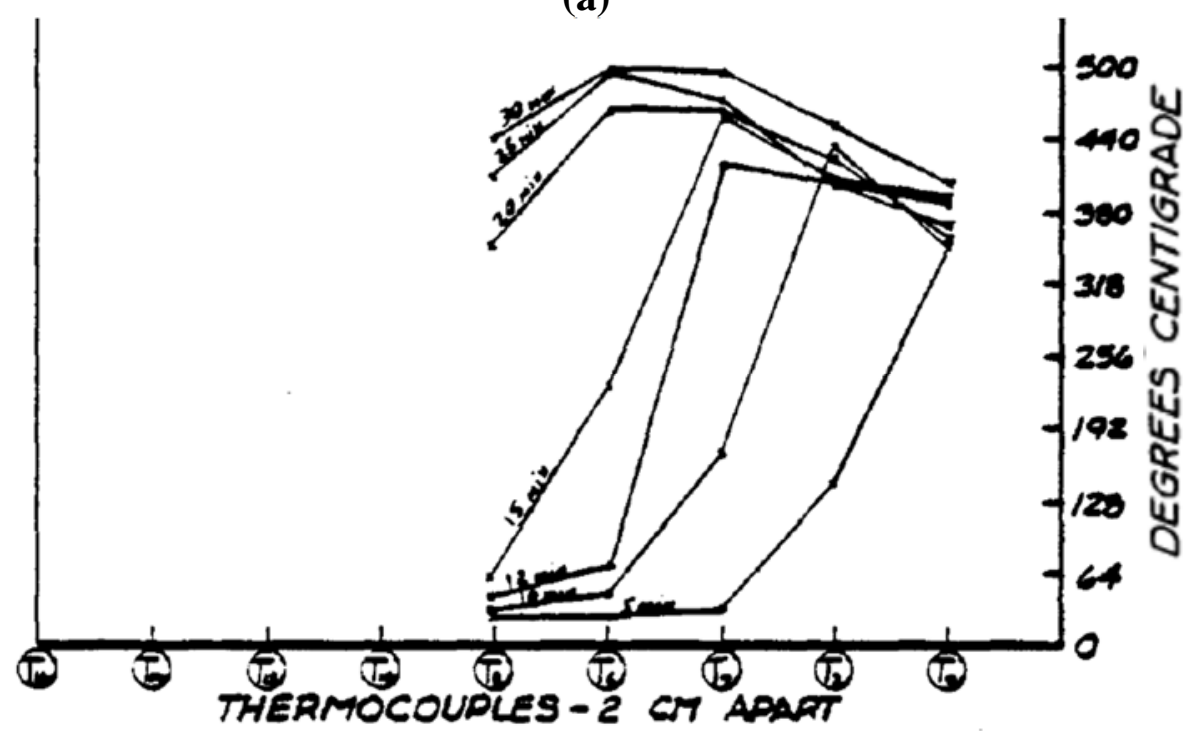

(b)

Figure 9. Thermocouple temperatures located on the contact line between the bottom surface of a covered $80 \mathrm{~mm}$ cigarette and the substrate of Doblin fabric over polyurethane for (a) temperature versus time and (b) temperature versus thermocouple location. [30] 


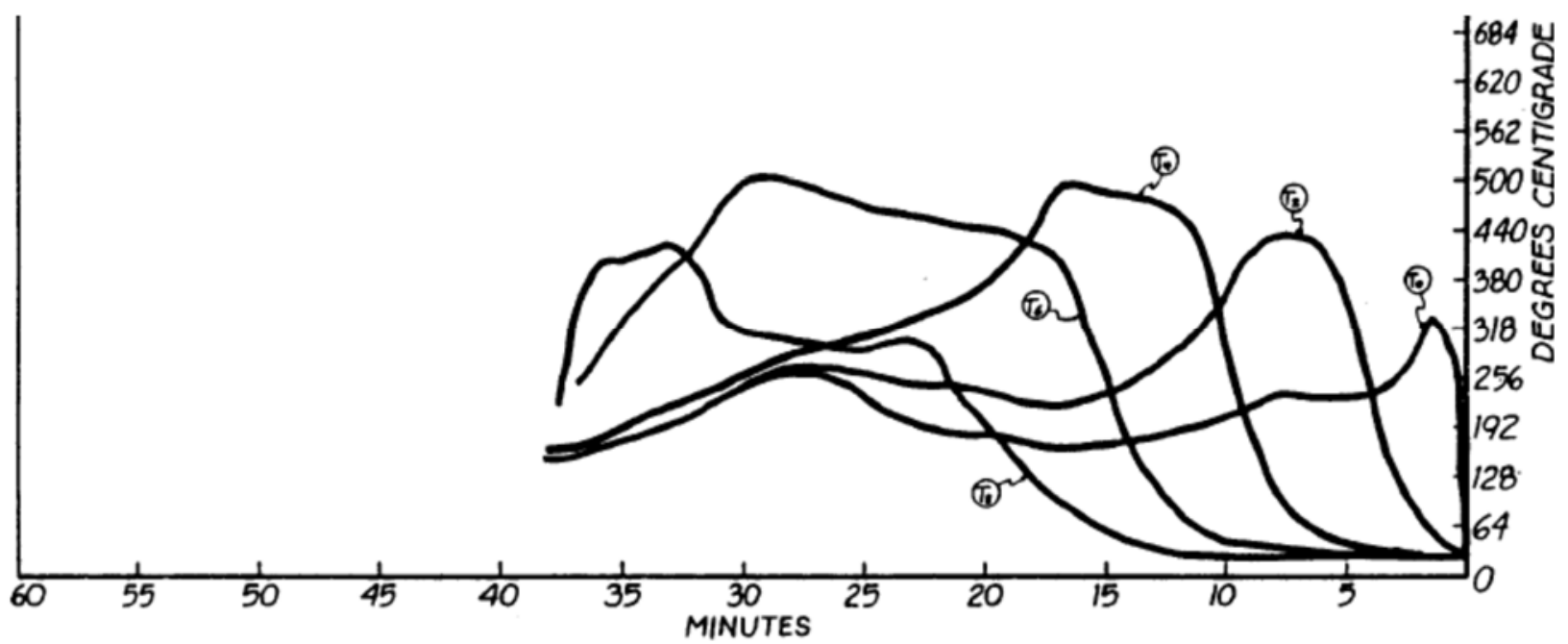

(a)

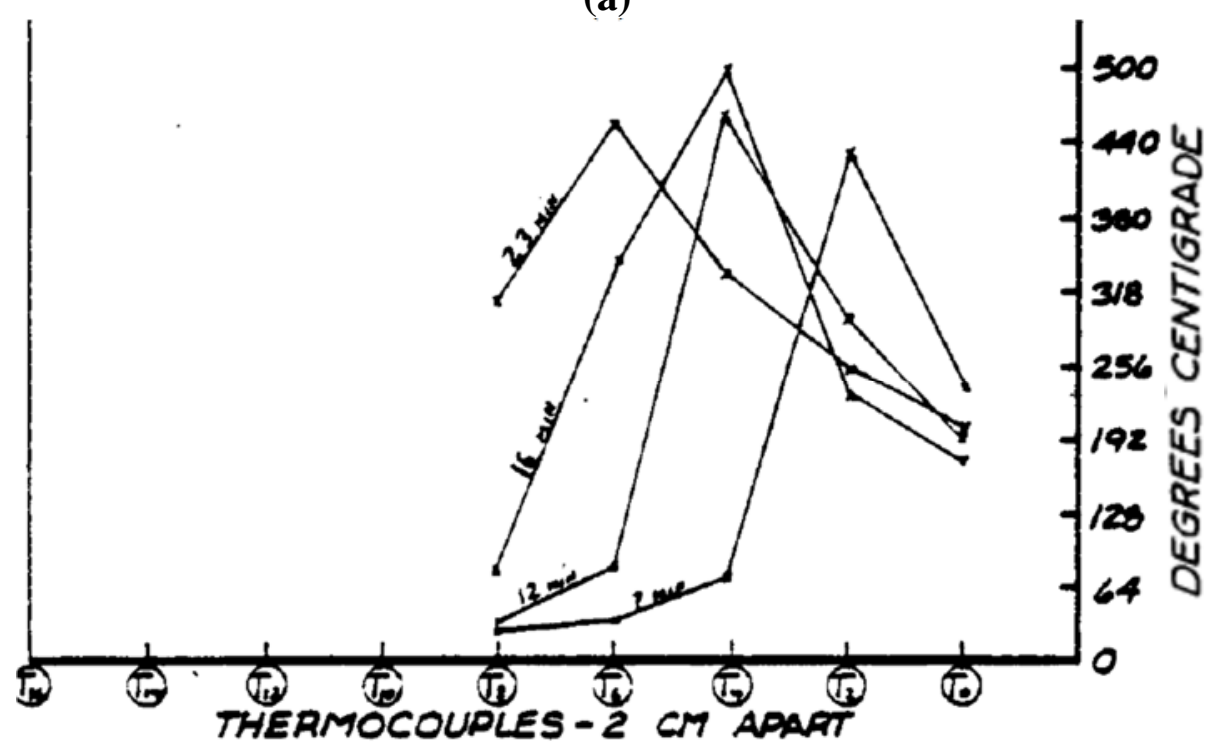

(b)

Figure 10. Thermocouple temperatures located on the contact line between the bottom surface of a covered $80 \mathrm{~mm}$ cigarette and the substrate of greige duck fabric over polyurethane for (a) temperature versus time and (b) temperature versus thermocouple location. [30] 

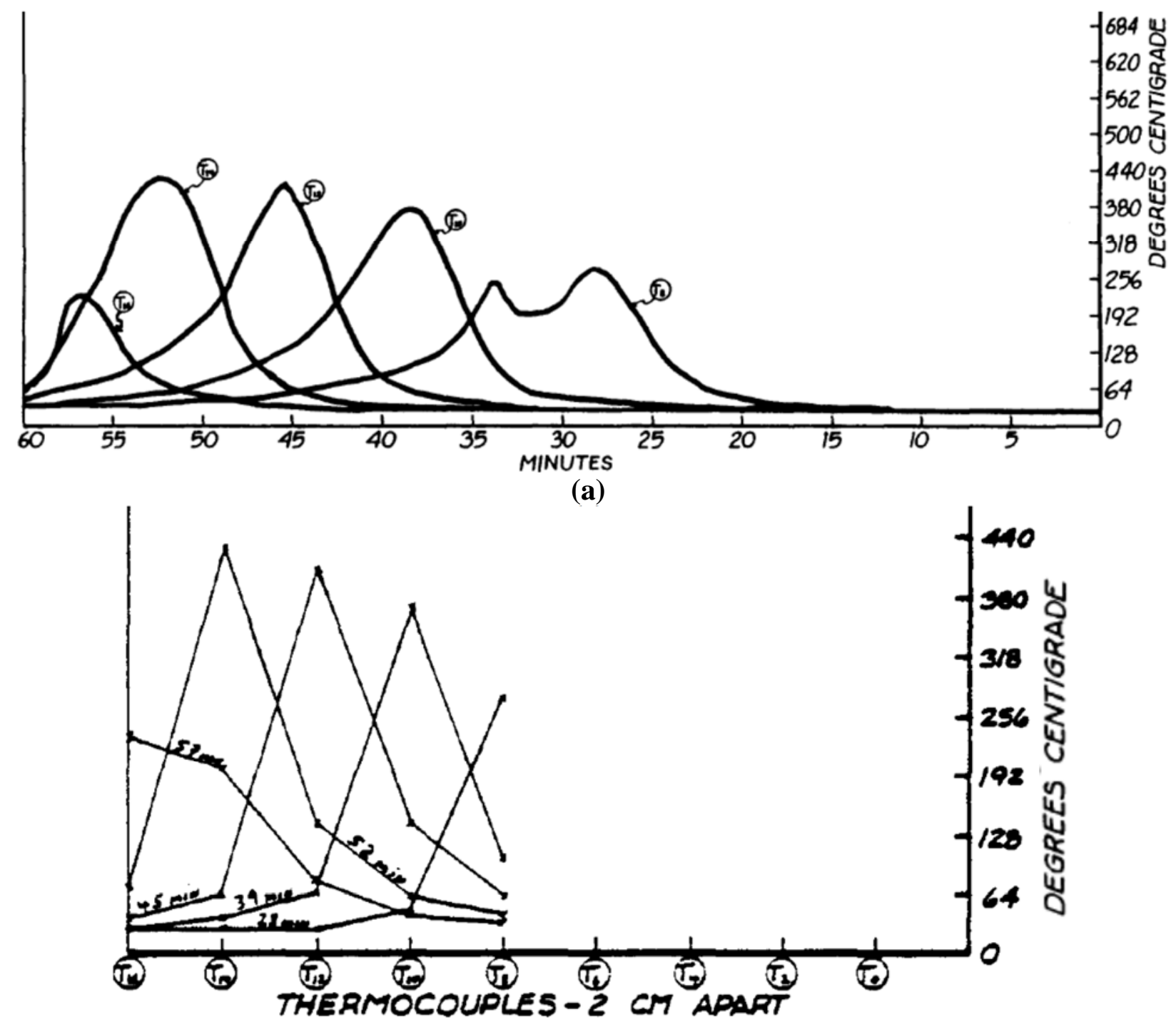

(b)

Figure 11. Thermocouple temperatures located on the contact line between the bottom surface of a covered $160 \mathrm{~mm}$ cigarette and the substrate of duck dyed blue fabric over polyurethane for (a) temperature versus time and (b) temperature versus thermocouple location. [30] 


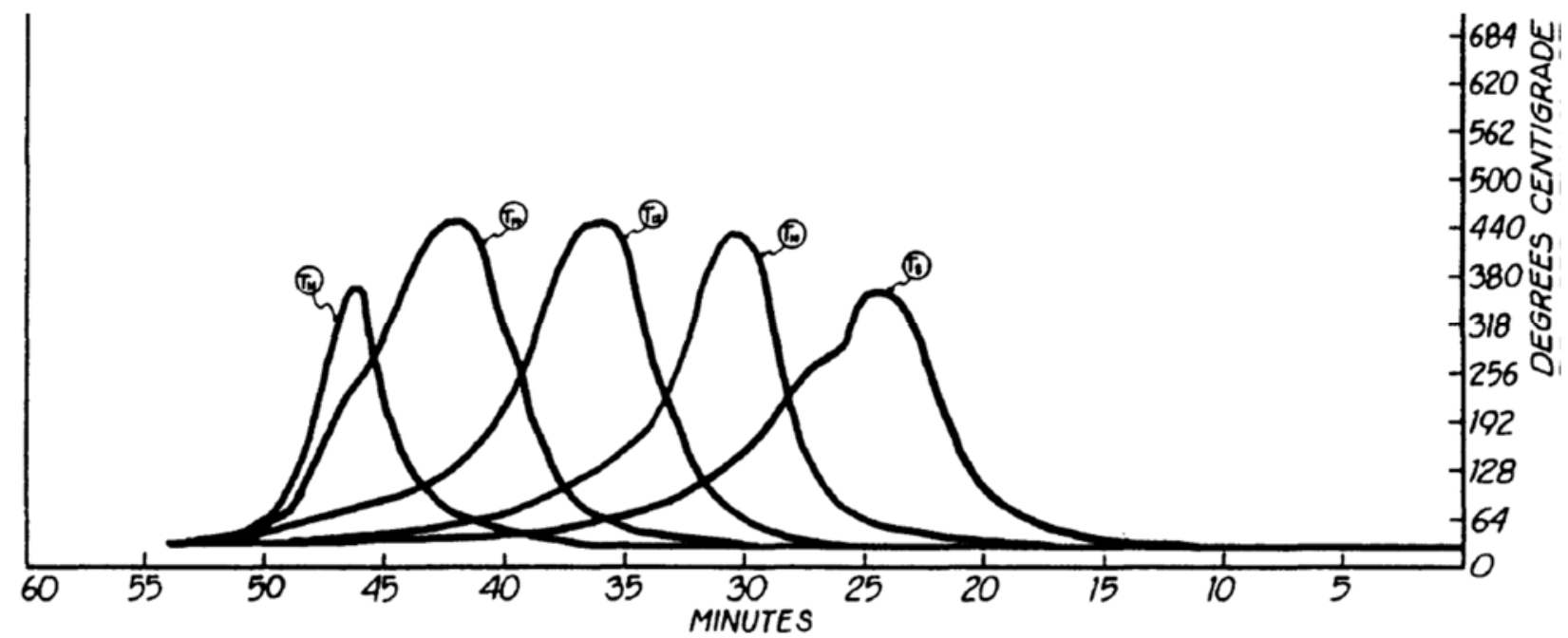

(a)

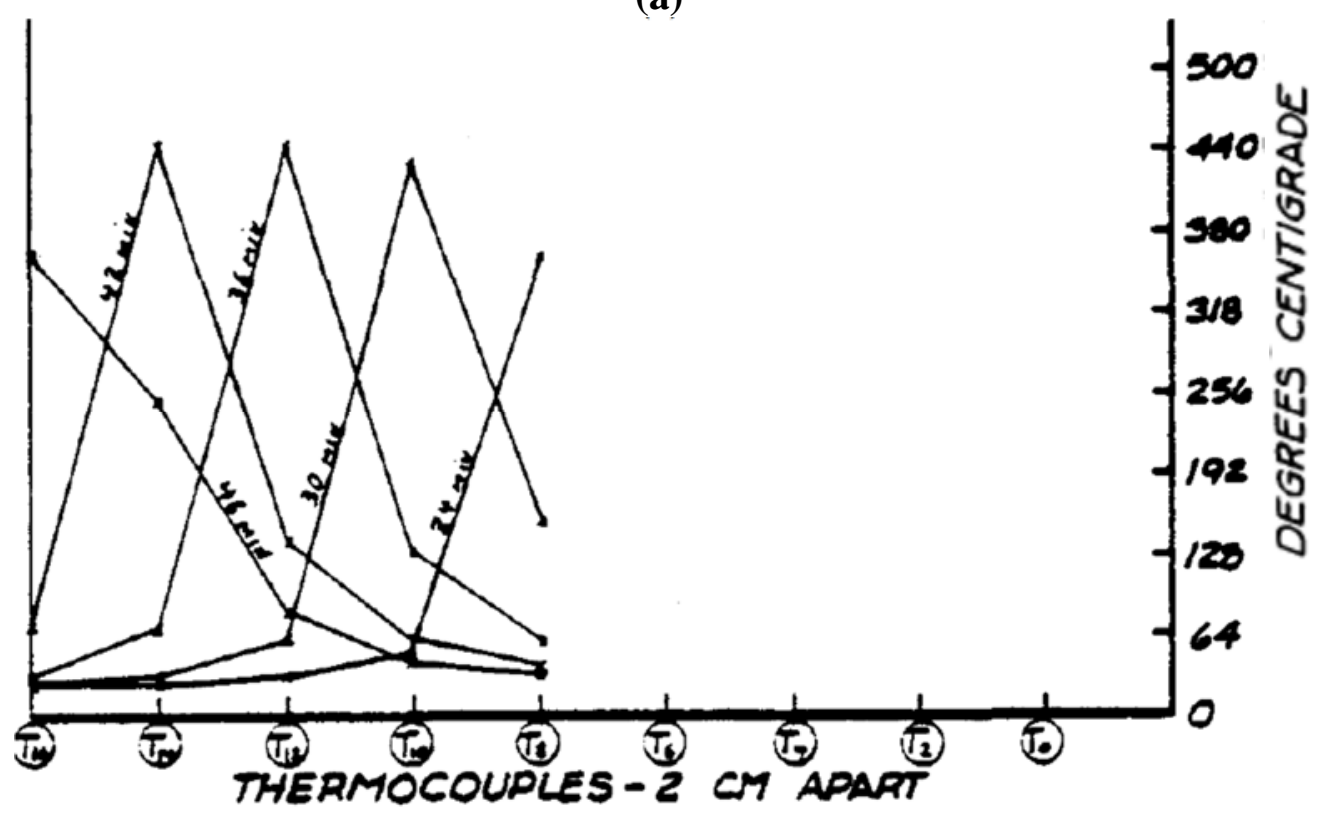

(b)

Figure 12. Thermocouple temperatures located on the contact line between the bottom surface of a covered $160 \mathrm{~mm}$ cigarette and the substrate of printcloth fabric over polyurethane for (a) temperature versus time and (b) temperature versus thermocouple location. [30]

Gann and co-workers conducted a series of experiments to determine the thermal characteristics of a lit cigarette. [10] In addition to the coal length and burning rate measurements cited in previous sections of this report, the team also measured:

- cigarette surface temperatures when the cigarette was located in air and on inert and combustible surfaces,

- the heat flux from the cigarettes,

- the number of ignitions of differing substrates, and 
- oxygen depletion beneath the fabric in the substrates.

These data sets were collected for cigarettes of differing diameter and composition. The studies were used to clarify the relation between the cigarette and the smoldering ignition process it induces in upholstered substrates. The findings form a useful basis for sorting the thermal parameters that need to be considered for the various categories of possible successors to SRM 1196.

It was apparent that, even before any rapid exothermic reactions begin in the upholstery fabric, there are multiple interactions that affect the values of the thermal properties of the cigarette, from the analysis of results including [10]:

- The cigarette coal length and smolder speed were altered by the proximity of a substrate, as shown earlier in Figure 2, and Figure 3 and Figure 4, respectively.

- The heat flux from the cigarette to the substrate surface varied with the geometric configuration of the adjacent substrate. The heat flux was higher when the cigarette was on a flat surface than when it was in a crevice. This was explained on the basis of adjustments the cigarette coal made to its rate of oxygen supply. Heat losses appeared to interact with these adjustments.

- The design parameters of the tested cigarettes had little effect on their peak coal surface temperatures and hence on their peak heat flux. There was no statistically significant correlation between peak heat flux and ignition propensity, although there is good physical reason to believe that variation over a wider range would show such a relationship.

- Cigarette design did substantially affect the smolder velocity and the coal length. These two parameters combined to influence the total heat input from a moving cigarette coal to a fixed point on a substrate surface. However, the total heat input correlated only approximately with substrate ignition tendency, indicating that other factors were involved.

- The best correlation (though by no means perfect) was found between a measure of coal area and ignition tendency; a related correlation was found between mass burning rate and ignition tendency. The partial correlation with coal area implies that the threedimensional nature of the heat flow in a substrate in response to local heating by a cigarette coal is a major factor in determining whether the fabric beneath the cigarette coal will become hot enough to smolder.

- There was significant oxygen depletion below the fabric during its heating by a cigarette coal, and this could be sufficient to raise the smoldering ignition temperature a few tens of degrees.

- The variation in oxygen depletion for tests with cigarettes of differing design was not sufficient to explain their differing ignition propensities.

Some useful temperatures for comparison with other collated data sets are summarized here from the work reported by Gann and co-workers [10]. For example, temperatures from two $(0.5 \mathrm{~mm}$ Chromel-Alumel) thermocouples embedded in the surface of a calcium silicate board $10 \mathrm{~mm}$ 
apart along the major axis of the cigarette were reported for four types of cigarette. The average thermocouple temperature when the burn line in the cigarette paper passed the first thermocouple was between $355^{\circ} \mathrm{C}$ and $417^{\circ} \mathrm{C}$, based on two tests of each cigarette type. The average peak temperature reported for the first thermocouple was from $372{ }^{\circ} \mathrm{C}$ to $470{ }^{\circ} \mathrm{C}$ and for the second thermocouple was from $389{ }^{\circ} \mathrm{C}$ to $434{ }^{\circ} \mathrm{C}$. The thermocouple temperature difference between the two thermocouples when the burn line of the cigarette paper passed over the first thermocouple ranged from $314{ }^{\circ} \mathrm{C}$ to $378{ }^{\circ} \mathrm{C}$. The total number of ignitions reported for one-cushion mock up tests using various foam and fabric combinations were reported to increase for each type of cigarette with increasing thermocouple temperature at the time of the burn line in the cigarette paper passed the thermocouple, and average peak temperatures of both of the thermocouples. However no correlation was found between the temperature differences between the thermocouples at the time when the burn line in the cigarette paper passed the first thermocouple. The temperature difference between the two thermocouples was reported to not appear to provide a good measure of the width of the flux distribution in the substrate. The results are summarized in Table 4.

\section{Table 4. Thermocouple temperatures on the surface of a calcium silicate board under various smoldering cigarettes. [10]}

\begin{tabular}{|l|c|c|c|c|c|}
\hline Cigarette & $\begin{array}{c}\text { Total No. } \\
\text { of Ignitions } \\
\text { on All One- } \\
\text { Cushion } \\
\text { Mock-ups }\end{array}$ & $\begin{array}{c}\text { Temperature } \\
\text { of TC1 when } \\
\text { Burn Line in } \\
\text { Paper Passed } \\
\left({ }^{\circ} \mathbf{C}\right)\end{array}$ & $\begin{array}{c}\text { Average } \\
\text { Peak } \\
\text { Temperature } \\
\text { at TC1 } \\
\left({ }^{\circ} \mathbf{C}\right)\end{array}$ & $\begin{array}{c}\text { Average } \\
\text { Peak } \\
\text { Temperature } \\
\text { at TC2 } \\
\left({ }^{\circ} \mathbf{C}\right)\end{array}$ & $\begin{array}{c}\text { Average } \\
\text { Temperature } \\
\text { Difference } \\
\text { between TC1 } \\
\text { and TC2 at } \\
\text { Passing of Burn } \\
\text { Line } \\
\left.\text { ( }{ }^{\circ} \mathbf{C}\right)\end{array}$ \\
\hline FNHC-25 & 20 & $417 \pm 12$ & $470 \pm 10$ & $434 \pm 10$ & 366 \\
\hline BNLN-21 & 12 & $418 \pm 12$ & $460 \pm 8$ & $457 \pm 9$ & 378 \\
\hline FEHN-21 & 12 & $380 \pm 12$ & $420 \pm 14$ & $432 \pm 16$ & 343 \\
\hline BELN-21 & 1 & $355 \pm 18$ & $372 \pm 18$ & $389 \pm 28$ & 314 \\
\hline
\end{tabular}

The reported temperature difference between the two embedded thermocouples may not have related to a measure of the width of the flux distribution in the substrate, depending on whether the temperature at the second thermocouple was increasing or decreasing. In addition, the results were based on two tests of each scenario and the numbers of ignitions were based on 5 tests of 4 types of cushion mock-up. Therefore, a statistically significant amount of variation would be expected if more tests had been conducted.

Justice investigated the potential ignition of various cellulose substrates by hand-rolled cigarettes. [98] The hand-rolled cigarettes consisted of a combination of tobacco and cannabis. The paper was "Rizla Green." The cigarettes were rolled using a rolling device designed for use with hand rolling tobacco or rolled between the fingers. The finished diameter was approximately $6 \mathrm{~mm}$ to $7 \mathrm{~mm}$. In one set of 10 tests, the lit hand-rolled cigarette was placed on a cotton pad where the tip of the coal was located on a thermocouple. The cotton pads were commercially available cotton wool facial pads that had been conditioned at $100{ }^{\circ} \mathrm{C}$ for $10 \mathrm{~min}$. The maximum temperature reported for this set of tests was $389^{\circ} \mathrm{C}$. The range of maximum 
temperatures was approximately $160{ }^{\circ} \mathrm{C}$ to $390{ }^{\circ} \mathrm{C}$. No ignitions of the substrate were reported. [98]

In a second set of tests, the lit hand-rolled cigarettes were placed in one of three orientations using cotton tissue. In the first orientation, four layers of tissue were placed on a glass test plate. The lit cigarette was located in the center of the tissue and then one half of the tissue was folded over the lit cigarette. The disposable cotton tissue was a commercially available brand (Kleenex ${ }^{\circledR}$ ) that had been conditioned at $100^{\circ} \mathrm{C}$ for $10 \mathrm{~min}$. A single thermocouple was used in each test. The thermocouple was located at the center of the initial four layers of tissue, and the lit cigarette was located on the tissue substrate over the top of the thermocouple. The maximum temperature reported for this set of tests was $356{ }^{\circ} \mathrm{C}$. The range of maximum temperatures was approximately $110^{\circ} \mathrm{C}$ to $360^{\circ} \mathrm{C}$. No ignitions of the substrate were reported. [98]

The second orientation of cotton tissue tests consisted of two crumpled tissues. Nine tests were conducted. The crumpled tissues were located on a glass test plate. The smoldering hand-rolled cigarette was placed on top of one crumpled tissue. A second crumpled tissue was placed on top of the cigarette. A single thermocouple was used in each test. This was located under the coal of the cigarette. The maximum temperature reported for this set of tests was $356{ }^{\circ} \mathrm{C}$. The range of maximum temperatures was approximately $90^{\circ} \mathrm{C}$ to $360^{\circ} \mathrm{C}$. Two tests were reported to have observations of glowing of the crumpled tissue. No flaming was reported. [98]

The third orientation of cotton tissue tests consisted of a tissue tightly wrapped around a smoldering cigarette. Twenty-five tests were conducted in which a hand rolled cigarette was lit and allowed to start smoldering before being wrapped tightly in a single tissue. The wrapped tissue was clamped around the cigarette using a clothes peg (clothespin). For 19 of the tests, the assembled test sample was then placed horizontally on a glass test plate. For six of the tests, the assembled test sample was held vertically (coal upwards) by a test tube clamp and stand. A single thermocouple, located under the coal of the cigarette, was used in each test. The range of maximum temperatures in the reported vertical tests was approximately $200{ }^{\circ} \mathrm{C}$ to $393{ }^{\circ} \mathrm{C}$. Ten horizontal tests and all six vertical tests were reported to have observations of glowing of the crumpled tissue. No flaming was reported. [98]

Justice investigated a third type of cellulose substrate: a piece of a $100 \%$ cotton bed sheet that had been washed and dried five times. The pieces of fabric were then conditioned at $100{ }^{\circ} \mathrm{C}$ for $10 \mathrm{~min}$. The cotton fabric was tested in orientations similar to the cotton tissue tests. [98]

The first fabric orientation was a single layer of fabric with the smoldering hand rolled cigarette placed in the center of the piece of fabric, and then the fabric was folded over the top of the cigarette. Eight tests were conducted. No glowing of the substrate was observed. The second fabric orientation was a single layer of fabric with the smoldering hand rolled cigarette wrapped tightly in the fabric, and then the assembled test sample was located horizontally on a glass plate. Four tests were conducted. No glowing of the substrate was observed. The third fabric orientation was a single layer of fabric with the smoldering hand rolled cigarette wrapped tightly in the fabric. The assembled test sample was held vertically using a test tube clamp and stand. Six tests were conducted. The range of maximum temperatures in the reported vertical tests was approximately less than $100{ }^{\circ} \mathrm{C}$ to $584^{\circ} \mathrm{C}$. No observations of a glowing substrate were 
reported. [98]

The fourth fabric orientation was a single layer of fabric and a layer of tissue with the smoldering hand rolled cigarette wrapped tightly in the fabric and tissue. The assembled test sample was held vertically using a test tube clamp and stand. Fourteen tests were conducted. The range of maximum temperatures in the reported vertical tests was approximately $160^{\circ} \mathrm{C}$ to $614^{\circ} \mathrm{C}$. Observations of a glowing substrate during four of the tests were reported. [98]

Maximum cigarette surface temperatures have also been reported during other studies. Maximum reported surface temperatures of free-burning non-banded cigarettes have ranged from approximately $620^{\circ} \mathrm{C}$ to $680^{\circ} \mathrm{C}$, as reported by Waymack and co-workers [88], and approximately $590^{\circ} \mathrm{C}$, as reported by Sherwood and co-workers [92], where both sets of studies estimated surface temperatures based on infrared camera analysis. A maximum temperature at the periphery of a free burning cigarette of $500{ }^{\circ} \mathrm{C}$ was reported by Baker, who used an infrared probe in the solid phase of a free-burning cigarette. [96] Temperatures between puffs of a burning cigarette were estimated to be approximately $550{ }^{\circ} \mathrm{C}$ to $600{ }^{\circ} \mathrm{C}$ when the ash was attached, as reported by Lendvay and Laszlo, who used infrared photometry to estimate the surface temperatures. [95]

Time based profiles of thermocouple temperatures instead of average peak values may potentially prove more useful in the intended thermal characterization of SRM 1196 cigarettes.

\subsubsection{Effect on Temperature of Covering a Cigarette on a Substrate}

Salig [30] reported slower cigarette smolder rates, lower maximum cigarette temperatures, longer duration smoldering of the cigarettes and higher maximum substrate temperatures for tests performed with a covered cigarette compared to an uncovered cigarette for the same substrate. Crevice tests were performed on polyurethane cushions upholstered with printcloth fabric, where the cigarettes were covered (with a square of printcloth fabric) and uncovered (as shown in the schematic included in Figure 13). Three thermocouples were located between the cigarette and the upright cushion. An additional thermocouple was located within the foam of the cushion, $20 \mathrm{~mm}$ below the location of the cigarette. For the covered cigarette tests, the temperatures between the cigarette and the substrate were approximately $30^{\circ} \mathrm{C}$ to $50{ }^{\circ} \mathrm{C}$ lower and the duration of the elevated temperatures was approximately twice as long as those measured in the uncovered cigarette tests. The glowing oxidation zone of the cigarette was also approximately twice the length for the covered cigarette than for the uncovered cigarette. The thermocouple temperature located within the foam was approximately $100^{\circ} \mathrm{C}$ higher for the covered cigarette test than the uncovered cigarette test. Self-sustained smolder of the substrate did not occur during any of these tests. Therefore, the higher maximum temperature recorded within the foam was attributed to the longer smoldering duration of the covered cigarette compared to the uncovered cigarette. Other potential influencing parameters were not discussed.

It appears that further examination of the effect of a cover fabric would be valuable in determining whether future testing of soft furnishings with an uncovered cigarette is necessary. 


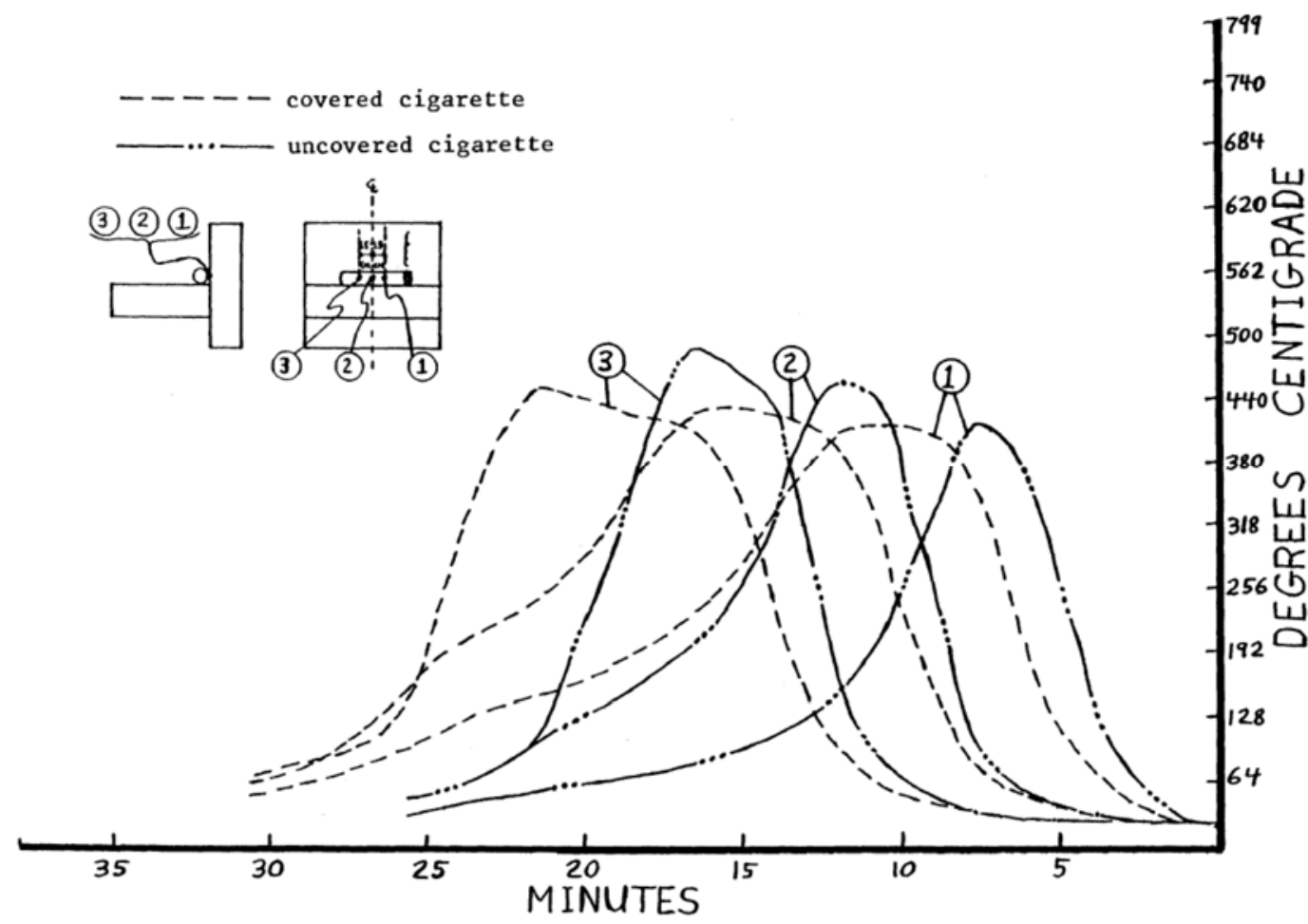

Figure 13. Thermocouple temperatures on the centerline of cigarettes located in the crevice of two upholstered (printcloth fabric and polyurethane foam) cushions, where the cigarettes were either uncovered or covered with a square of printcloth fabric. [30]

\subsubsection{Infrared Measurements}

Infrared detection devices have been used for estimating surface temperatures associated with cigarette on substrate testing. Examples of such devices have been either infrared cameras, as used by Sherwood and co-workers [92], or infrared thermometers, as used by Ohlemiller [99].

Sherwood and co-workers compared results from infrared imaging of free-burning cigarettes (of one set of 40 cigarettes) with the average percentages of full length burns (of 4 sets of 40 cigarettes) on 7 and 10 sheets of Whatman No. 2 filter paper, based on the ASTM E2187-02b test. These tests were conducted using forty-eight cigarette designs. Their objective was to estimate the characteristic coal power and investigate the relationship to extinguishment thresholds for various cigarette designs. [92]

The infrared imaging apparatus was located beside the free-burning cigarettes such that the length of the cigarette was in full view. It was assumed that the full surface area of a burning cigarette could be measured using two infrared imaging cameras located directly opposite each other, with the cigarette located centrally on a horizontal plane between them. One pixel represented approximately $0.5 \mathrm{~mm}$ at the vertical plane that dissected the sample cigarette along its centerline. 
A relative radiant power of the coal was estimated using the average pixel temperature and pixel area from each of the two-dimensional left and right-side images and an assumed coal emissivity of 1 . The authors noted that this estimate for the radiant power of the coal was only a relative measure and not an absolute measure. [92] The coal location and size were estimated using the assumption that $350{ }^{\circ} \mathrm{C}$, as indicated empirically from analysis of the infrared results, would account for the zone where pyrolysis and combustion occurred (estimated as greater than $400{ }^{\circ} \mathrm{C}$ ). The area reported for the coals of non-banded cigarettes as "of the order of $100 \mathrm{~mm}^{2}$ or 400 pixels." [92] This led to an approximate range of coal lengths of $12 \mathrm{~mm}$ to $18 \mathrm{~mm}$ for the range of diameters $(5.6 \mathrm{~mm}$ to $8.1 \mathrm{~mm})$ of the cigarette designs tested in the study. The uncertainty of \pm 1 pixel led to an approximate uncertainty of $\pm 5 \%$ in the coal length. The peak free-burning temperature for all the cigarettes, banded or non-banded, was approximately $590{ }^{\circ} \mathrm{C}$.

Sherwood and co-workers [92] also estimated an effective characteristic coal power of each type of cigarette using a cumulative histogram from the free-burning infrared results for each of the sample sets. An effective extinguishment threshold was estimated using the minimum effective characteristic coal power in combination with the average percentages of full length burn. The hypothesis was that the effective characteristic coal power could be used to predict the likelihood of a full length burn/extinguishment in tests, using 10 or 7 layers of paper, based on ASTM E2187-02b. The estimated radiant coal power of the non-banded cigarettes was $2.0 \mathrm{~W}$ to $2.8 \mathrm{~W}$.

Ohlemiller [99] used the peak temperature reading from an infrared thermometer as one marker in experiments investigating the potential of other measurements for use as an end of test criteria for the 16 CFR 1632 bench-scale test method. Two commercial infrared thermometers were used in the testing; an Omega Engineering Model OS534E and a Fluke Model 572. Both units had a reported accuracy of $\pm 5^{\circ} \mathrm{C}$ for a $300^{\circ} \mathrm{C}$ blackbody. The location for which a temperature was being estimated and the surface indicated by the instrument could differ by up to $20 \mathrm{~mm}$ to $30 \mathrm{~mm}$. Both devices viewed an area that was wider than the width of a cigarette coal. The temperature recorded by each device is the average temperature of the circular viewing area. The time response of the devices was reported to be approximately one-half second or less. Therefore, the area of possible combustion was scanned slowly for approximately $12 \mathrm{~s}$ to $14 \mathrm{~s}$.

Ohlemiller [99] also suggested a potential marker for determining whether or not combustion was continuing or had ceased in bench scale upholstered tests, based on sequential average surface temperature estimates using the infrared thermometers. His premise for estimating the cessation of combustion was the observation of a trend of decreasing temperatures (e.g., at least $100^{\circ} \mathrm{C}$ difference, 2 min apart), along with a conservative approach to estimate the average temperatures.

The average cigarette surface temperatures reported for this testing varied from $200{ }^{\circ} \mathrm{C}$ to over $400{ }^{\circ} \mathrm{C}$. This range of temperatures was expected, since the peak fee-burning coal surface temperature was expected to be above $500^{\circ} \mathrm{C}$ and these tests were conducted with the cigarette located on a substrate, with the measured values being averaged over the device view area. [99]

Lendvay and Laszlo [95] used infrared photometry to estimate the surface temperature of a freeburning commercial cigarette where the ash was in place (approximately $550{ }^{\circ} \mathrm{C}$ to $600{ }^{\circ} \mathrm{C}$ ) and then the ash was removed (approximately $700^{\circ} \mathrm{C}$ ). 
Ohlemiller [99] discussed the accuracy and applicability of the estimates of the average surface temperatures using the infrared thermometer, and suggested that such measurements could be of value if the limitations and correct use were constantly borne in mind during both testing and analysis. On the other hand, the repeatability and reproducibility of the estimated radiant coal power were not discussed by Sherwood and co-workers [92] for the values and applicability of the results using an infrared camera to estimate surface temperatures.

The results of these studies demonstrate that radiant power is a useful measure to correlate to cigarette ignition and self-extinguishment. However the value of such measurements lies in the correct use of the infrared devices and respecting the limitations during both testing and analysis.

\subsubsection{Summary of Temperature Measurements}

There are relatively few publications that contain temperature measurements of cigarettes, either suspended or on a substrate. Indicative data for the reported maximum cigarette temperatures are summarized in Table 5.

There are significant differences among the studies. For example, some temperature measurements were taken between puffs; others during smoldering-only tests for free-burning. It is unlikely that the same cigarettes were used in any of the studies. The substrates varied considerably in their thermal properties. There are also considerable uncertainties associated with the temperature measurements beyond their simple repeatability. For example, Liu and Woodcock [93] observed that tobacco shreds near the coal surface experienced localized, transient heating to temperatures that were approximately $200^{\circ} \mathrm{C}$ to $250^{\circ} \mathrm{C}$ higher than the average peripheral temperature of the cigarette.

Nonetheless, there are a few summary observations from the published results that can be used as points of departure for research to identify alternate ignition sources.

- Peak centerline temperatures of lit, free burning cigarettes that are unpuffed or between puffs are approximately $700{ }^{\circ} \mathrm{C} \pm 100^{\circ} \mathrm{C}$.

- Maximum surface temperatures of free burning cigarettes are approximately $100{ }^{\circ} \mathrm{C}$ lower than peak centerline temperatures.

- The peak centerline temperature in a cigarette burning on a substrate varies considerably with the nature of the substrate. On a substrate consisting of a fabric over a FPU foam, this temperature might be as little as $50^{\circ} \mathrm{C}$ lower than the centerline temperature of a free burning cigarette.

- The peak temperature at the cigarette-substrate interface varies considerably with (at least) the nature of the cigarette and the cover fabric. 
Table 5. Summary of measured maximum cigarette coal temperatures.

\begin{tabular}{|c|c|c|c|c|}
\hline $\begin{array}{c}\text { Location of } \\
\text { Temperature } \\
\text { Measurement }\end{array}$ & Technique & $\begin{array}{c}\text { Maximum } \\
\text { Temperature } \\
\left({ }^{\circ} \mathrm{C}\right)\end{array}$ & Notes & Ref. \\
\hline \multirow{7}{*}{$\begin{array}{l}\text { Centerline } \\
\text { temperature: } \\
\text { free burning } \\
\text { cigarette }\end{array}$} & \multirow[t]{2}{*}{ Infrared Device } & 775 & & {$[96]$} \\
\hline & & 770 to 790 & $\begin{array}{l}\text { Ash partially removed; between puffs } \\
\text { on smoking machine }\end{array}$ & {$[95]$} \\
\hline & \multirow[t]{4}{*}{ Thermocouple } & 710 to 780 & $\begin{array}{l}\text { Non-filter cigarettes suspended on a } \\
\text { wire }\end{array}$ & {$[30]$} \\
\hline & & 627 to 722 & Non-filter cigarettes & {$[12]$} \\
\hline & & 770 to 840 & & {$[89]$} \\
\hline & & 656 and 812 & $\begin{array}{l}\text { Thermocouple wire diameter } 0.20 \\
\mathrm{~mm} \text { and } 0.05 \mathrm{~mm}\end{array}$ & {$[90]$} \\
\hline & Novel Device & 820 & & {$[97]$} \\
\hline \multirow{6}{*}{$\begin{array}{l}\text { Surface } \\
\text { temperature: } \\
\text { free burning } \\
\text { cigarette }\end{array}$} & \multirow[t]{5}{*}{ Infrared Device } & 620 to 680 & & {$[88]$} \\
\hline & & 590 & & {$[92]$} \\
\hline & & 500 & & {$[96]$} \\
\hline & & 550 to 600 & $\begin{array}{l}\text { Ash still attached; between puffs on } \\
\text { smoking machine }\end{array}$ & {$[95]$} \\
\hline & & 700 to 790 & Ash partially removed & {$[89]$} \\
\hline & Novel Device & 616 & & {$[97]$} \\
\hline \multirow{5}{*}{$\begin{array}{l}\text { Centerline } \\
\text { temperature: } \\
\text { cigarette on a } \\
\text { substrate }\end{array}$} & \multirow[t]{5}{*}{ Thermocouple } & $490(35)$ & $\begin{array}{l}\text { Thin copper sheet substrate; dried } \\
\text { cigarettes; (standard deviation) }\end{array}$ & {$[87]$} \\
\hline & & $492(45)$ & $\begin{array}{l}\text { Thin copper sheet substrate; dried \& } \\
\text { conditioned cigarettes; (standard } \\
\text { deviation) }\end{array}$ & {$[87]$} \\
\hline & & 601 to 711 & $\begin{array}{l}\text { Non-combusting (asbestos board) } \\
\text { substrate; filter cigarettes }\end{array}$ & {$[12]$} \\
\hline & & 627 to 722 & $\begin{array}{l}\text { Non-combusting (asbestos board) } \\
\text { substrate; non-filter cigarettes }\end{array}$ & {$[12]$} \\
\hline & & 580 to 720 & FPU foam/fabric crevice substrate & {$[30]$} \\
\hline \multirow{4}{*}{$\begin{array}{l}\text { Temperature } \\
\text { between cigarette } \\
\text { and substrate }\end{array}$} & \multirow[t]{3}{*}{ Thermocouple } & 310 to 560 & Various fabrics over FPU foam & {$[30]$} \\
\hline & & 355 to 470 & Ceramic fiberboard substrate & {$[10]$} \\
\hline & & 90 to 614 & $\begin{array}{l}100 \% \text { cotton pads, tissues, bed sheet; } \\
\text { hand rolled cigarettes }\end{array}$ & {$[98]$} \\
\hline & Infrared Device & 200 to 500 & Foam/fabric crevice substrate & [99] \\
\hline
\end{tabular}




\subsection{HeAt OUtPut}

Behnke investigated the heat flux from a cigarette as it was placed on a thin copper sheet and reported his findings to the ASTM D.13 committee in 1969. [10,87] The apparatus used a $0.075 \mathrm{~mm}$ thick copper sheet and $0.25 \mathrm{~mm}$ diameter Chromel-Alumel thermocouples. The temperature change of the copper substrate was used to estimate the heat flux of the sample cigarettes, which was found to be $42 \mathrm{~kW} / \mathrm{m}^{2}$ with a standard deviation of $8 \mathrm{~kW} / \mathrm{m}^{2}$. [10]

Gann and co-workers determined the heat flux from a cigarette lying on a substrate during the time period prior to ignition of the substrate. [10] A low ignition risk mock-up was used, consisting of the standard California fabric (soaked twice in distilled water, air dried, and ironed) over FPU foam. Three smoldering configurations were examined:

1. a free-burning cigarette,

2. a smoldering cigarette on the center of a mock-up cushion, and

3. a smoldering cigarette in the crevice of a two-cushion mock-up.

The device used to measure the heat output from the cigarette coal was a Schmidt-Boelter type heat flux gauge: a water-cooled Medtherm Model 20321, modified thermopile, with a $1.6 \mathrm{~mm}$ diameter blackened sensor. The response time was approximately $100 \mathrm{~ms}$. The gauge was used to scan past the surface of the cigarette coal (at $2.7 \mathrm{~mm} / \mathrm{s}$ ) to provide an estimate of the total flux profile along the direction of the scan. It was expected that the scanning method would flatten the flux profile slightly, thus providing an underestimate of the peak flux. In order for the gauge to be in contact with the bottom surface of the smoldering cigarette, a $1.6 \mathrm{~mm}$ slit was cut through the top $12.7 \mathrm{~mm}$ of the California fabric and FPU foam of the mock-up cushion. [10]

The influence of this disturbance of the substrate on the cigarette/substrate system was estimated using thermocouple measurements for the same cigarette (FLNL-21) located on the substrate with and without the slit. The thermocouple was placed at the location designated for the slit. When no slit was present, the peak temperature was $682^{\circ} \mathrm{C} \pm 18^{\circ} \mathrm{C}$. When a slit was present, the peak temperature was slightly lower, $649^{\circ} \mathrm{C} \pm 14^{\circ} \mathrm{C}$. The reduced temperature associated with the slit cushion was estimated to cause a $5 \%$ to $13 \%$ decrease in the peak heat flux measured by the flux gage. The underestimate of the peak flux measurement for a horizontal substrate (associated with these tests) was $25 \%$ to $30 \%$. [10]

Peripheral thermocouple temperatures were used to provide an estimate of the disturbance caused by introducing the gauge to a smoldering commercial cigarette. A $0.050 \mathrm{~mm}$ thermocouple was embedded under the cigarette paper and located on the scanning path of the gage. An example of the thermocouple temperature profile for a free-burning cigarette subjected to two scans by the flux gauge is shown in Figure 14. Based on 12 replicate tests, the flux gauge was estimated to produce an average temperature drop of $70^{\circ} \mathrm{C}$. The peak flux was estimated to have been reduced by approximately $15 \%$ to $20 \%$ by the introduction of the gauge to the smoldering cigarette. [10] Likely variation of this interaction with cigarette properties was not investigated. 


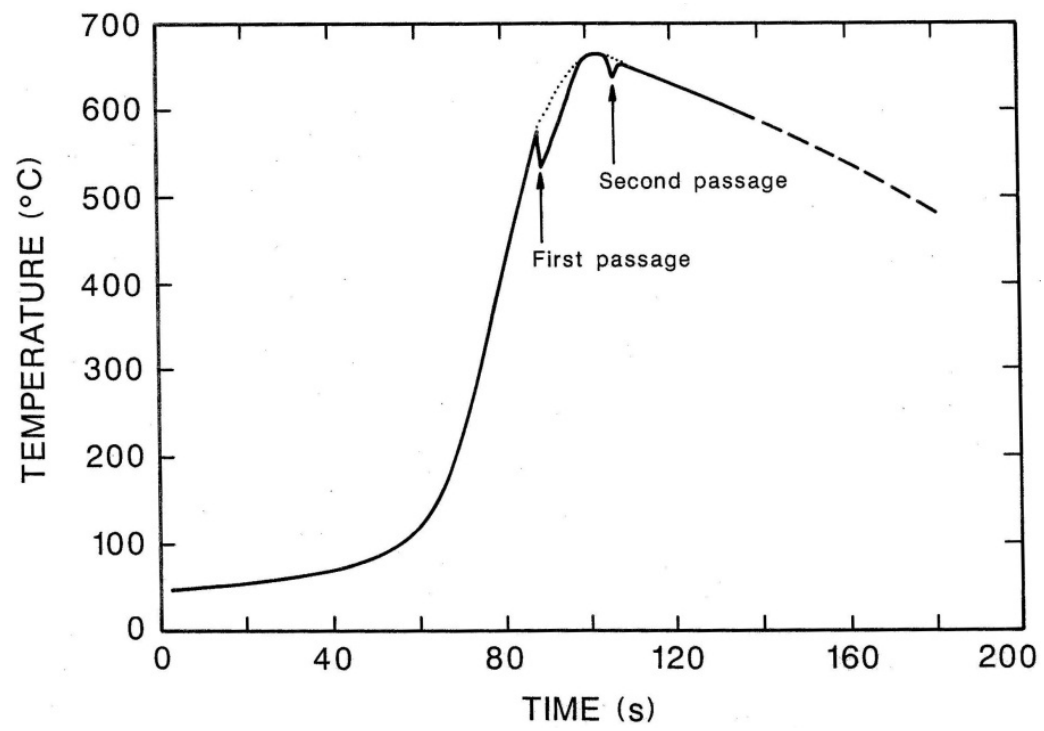

Figure 14. Thermocouple temperature profile of a free-burning commercial cigarette as the Schmidt-Boelter gauge is scanned over the length. [10]

An example of the heat flux measurements is shown in Figure 15 for six scans during one test within a moderate ignition propensity cigarette (FNHC-25) for the three test configurations considered. The average peak heat flux value for this example was approximately $71 \mathrm{~kW} / \mathrm{m}^{2}$ for the free-burning configuration, $56 \mathrm{~kW} / \mathrm{m}^{2}$ for a cigarette on a horizontal one-cushion mock-up, and $47 \mathrm{~kW} / \mathrm{m}^{2}$ for a cigarette in the crevice of a two-cushion mock-up. As noted above, considering only the estimate of the influence of the gauge and the slit in the cushion on the peak heat flux measurement, these values may have been $25 \%$ to $30 \%$ higher without the presence of the gage. [10]

The peak heat flux was also reported to change with fabric on the one-cushion mock-up. For example, for one type of cigarette (FNHC-25) seven tests on each of three fabrics on FPU foam were conducted. The reported peak heat fluxes were $56 \mathrm{~kW} / \mathrm{m}^{2} \pm 8 \mathrm{~kW} / \mathrm{m}^{2}$ for the California standard fabric, $49 \mathrm{~kW} / \mathrm{m}^{2} \pm 3 \mathrm{~kW} / \mathrm{m}^{2}$ for the denim fabric, and $46 \mathrm{~W} / \mathrm{m}^{2} \pm 5 \mathrm{~kW} / \mathrm{m}^{2}$ for the Splendor fabric. [10]

It was noted that the peak width qualitatively appeared wider, although perhaps not statistically so, for the substrate tests compared to the free-burning configuration. [10] 


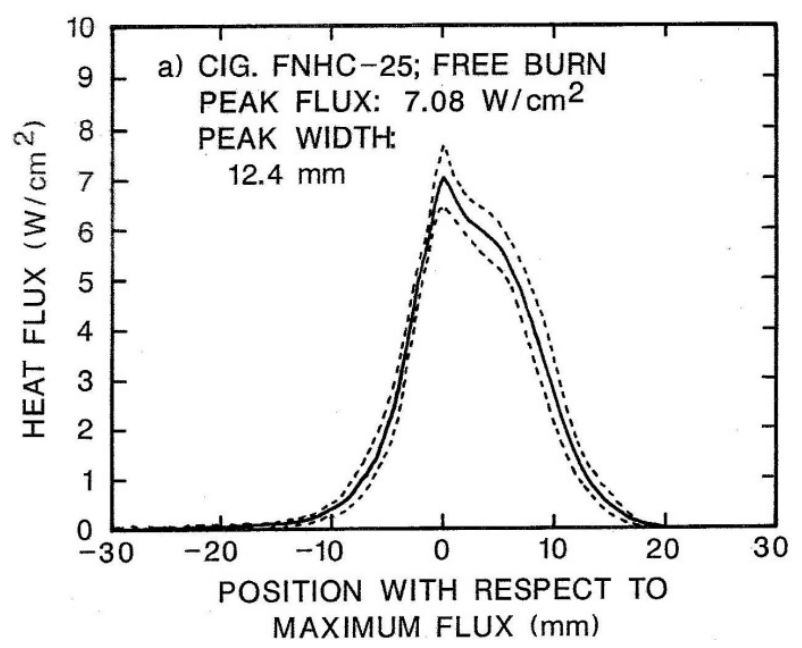

(a)

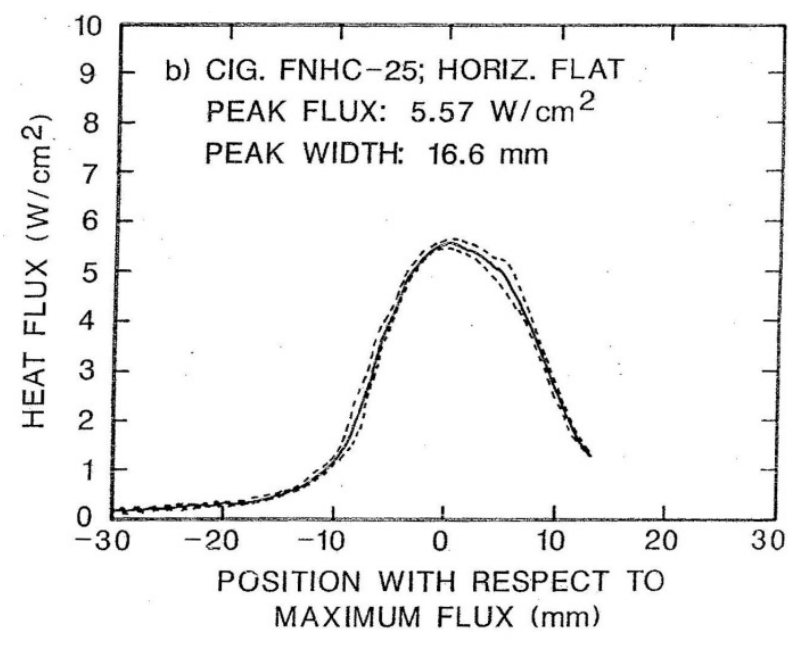

(b)

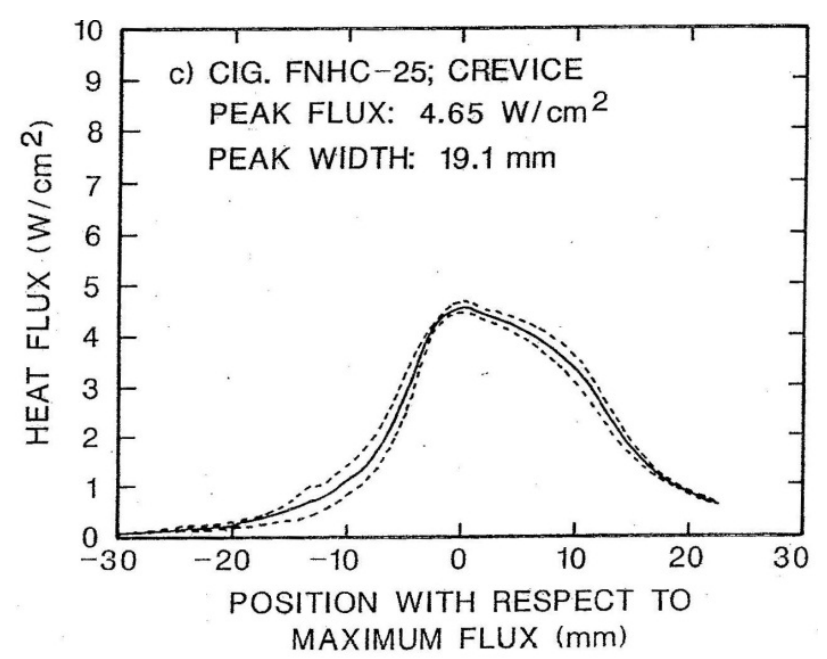

(c)

Figure 15. Example of averaged heat flux gauge measurements for six scans during one test in three test configurations: (a) free-burning, (b) one-cushion mock-up and (c) two-cushion crevice mock-up. [10]

Waymack and co-workers summarized published estimated heat output values for smoldering cigarettes from a range of sources. [88] The heat output for a $25 \mathrm{~mm}$ diameter smoldering cigarette located on a glass slide was estimated to be approximately $5.4 \mathrm{~W}$, based on oxygen calorimetry during smolder and subsequent evolved heat estimations. Other estimates of heat output for a smoldering free-burning cigarette were reported as $4.9 \mathrm{~W}$ to $6.3 \mathrm{~W}$ for mass burn rates of $730 \mathrm{~g} / \mathrm{s}$ to $850 \mathrm{~g} / \mathrm{s}$. Further estimates of heat output for a free-burning cigarette were approximately $5.7 \mathrm{~W} \pm 50 \%$, depending on construction parameters. The components of this $5.7 \mathrm{~W}$ were estimated as $35 \%$ as conduction, $30 \%$ as convection, and $35 \%$ as radiation.

Waymack and co-workers reported that the heat of smoldering combustion for tobacco for a cigarette mounted on a slide was found to be independent of the cigarette construction for 
78 different cigarette designs tested, with the value being approximately $7.1 \mathrm{~kJ} / \mathrm{g}$. [88] The average heat of total combustion of dry tobacco (considering a variety of cut tobacco blend components), using a bomb calorimeter, was measured to be approximately $14.9 \mathrm{~kJ} / \mathrm{g}$. The difference between the heat of complete combustion of the dry tobacco and the heat of smoldering combustion used in the construction of the sample cigarette designs was attributed primarily to incomplete combustion during smoldering, with a small portion due to the evaporation of water content within the tobacco (approximately $0.42 \mathrm{~kJ} / \mathrm{g}$ ). Total heat output and oxygen consumption were reported to be proportional to the mass burn rate of a cigarette smoldering on a slide.

\subsection{Mass Loss RATE}

Krasny and co-workers reported mass loss rates from experiments involving the smoldering of cigarette on a paper substrate. [89] The paper substrate was a single layer of chromatography paper, Standard Reference Material 1006a, cut into $150 \mathrm{~mm}$ x $50 \mathrm{~mm} \times 1.23 \mathrm{~mm}$ pieces. (Assuming that the density of the paper is about $0.6 \mathrm{~g} / \mathrm{cm}^{3}$, the initial mass of the substrate was about $15 \mathrm{~g}$.)

The paper was reported to smolder while the cigarette was observed as smoldering, but did not smolder after the cigarette extinguished. Mass loss rates for the smoldering cigarette/paper system were reported for the four different cigarettes, operators, sheet variations and paper lots. The mass loss rates of the cigarette/paper combinations varied from $38 \mathrm{mg} / \mathrm{min}$ to $55 \mathrm{mg} / \mathrm{min}$. The fact that a single value for the mass loss rate was reported suggests that the smoldering rate of the paper was correlated with the linear smoldering rate of the cigarette. [89]

The mass of a test cigarette, although not given in the report, was likely between $0.5 \mathrm{~g}$ and $1 \mathrm{~g}$, the mass of the paper directly under the cigarette was about $1 \mathrm{~g}$, and the mass of paper within $1 \mathrm{~cm}$ of the test cigarette was about $3 \mathrm{~g}$. Thus, only when the paper smoldering had progressed beyond proximity to the cigarette did the mass loss of the paper become dominant compared to the mass loss of the tobacco column. This made it difficult to separate the mass loss rate of the substrate from the mass loss rate of the system.

The mass loss rate of the substrate was likely a function of (a) the smoldering properties of the substrate itself and (b) the extent and intensity of the substrate combustion at the time the smoldering becomes self-propagating. Characterizing (b) is extremely difficult, and heat losses from the thermally thin substrate would have had a significant contribution to (a).

An alternative approach for obtaining substrate mass loss data involves a heavier substrate. Krasny and co-workers also reported mass loss rates from experiments involving the four types of cigarettes on each of five fabrics over an undescribed piece of FPU foam. [89] The masses of these substrates were almost certainly far larger than the paper substrate. The mass loss rates of the systems were reported to have ranged from $14 \mathrm{mg} / \mathrm{min}$ to $53 \mathrm{mg} / \mathrm{min}$. Smoldering in these substrates was likely to have been three-dimensional, which means that the mass loss rate should have increased with time. The report does not provide information as to how the single mass loss rate value was obtained. 
The Consumer Product Safety Commission has performed research on mass loss rates resulting from lit cigarettes placed in the crevice of a two-cushion mock-up (e.g., References [100] and [101]). This research, using assorted padding materials and cover fabrics, was focused on developing a test for the ignition susceptibility of upholstered furniture. The mass loss was predominantly from the substrate, occurring well after the cigarette burning was complete.

The mass loss rate of the substrate is certainly related to the potential hazard from a smoldering bed or piece of upholstered furniture. It has not been demonstrated whether the mass loss rate is an indicator of the ignition susceptibility of such an item, since most of that mass loss occurs after ignition has been established. This is a research issue, since the degrading substrate interacts with and potentially enhances smoldering of the cigarette. It would be necessary to decouple the interaction and clearly define what part of the test results is to be the focus of replication using a surrogate ignition source.

\subsection{Potential Parameters for Determining Ignition Propensity}

\subsubsection{Premise}

Identification of important parameters and the associated values for the ignition of substrates by cigarettes is central to designing a surrogate smoldering ignition source that is intended to replicate cigarette ignition performance. This is especially true, given that it is likely there could be substantive differences between the surrogate and the cigarette.

For engineering purposes, it would be advantageous if one could predict the ignition propensity of a cigarette (and thus perhaps any replacement ignition source) using one or two property measurements. Gann and co-workers [10] examined this approach as described in the following sections.

\subsubsection{Peak Heat Flux}

The peak heat flux of a cigarette and the number of ignitions in 20 replicate tests is shown in Figure 16 for 19 various cigarette types tested on a one-cushion mock-up. In Figure 16, the dot is the average peak heat flux from the 20 tests, and the width of the horizontal bar for each cigarette type indicates the standard deviation in the 20 values. [10]

The narrow range of peak fluxes for the various cigarettes was expected, given the narrow range of peak coal surface temperatures (Figure 17), despite the variations in the cigarette design parameters. The data in Figure 17 are for 10 of the cigarettes in Figure 17, with each cigarette placed on a one-cushion mock-up consisting of California standard fabric and FPU foam. The average peak temperatures ranged over approximately $50^{\circ} \mathrm{C}$ with standard deviations of $20^{\circ} \mathrm{C}$ to $50{ }^{\circ} \mathrm{C}$, as demonstrated by the example error bars in Figure 17. [10]

There was no trend apparent between the number of substrate ignitions and the peak heat flux from the cigarette. Thus, peak heat flux alone was not the determining factor for ignition of substrates. 


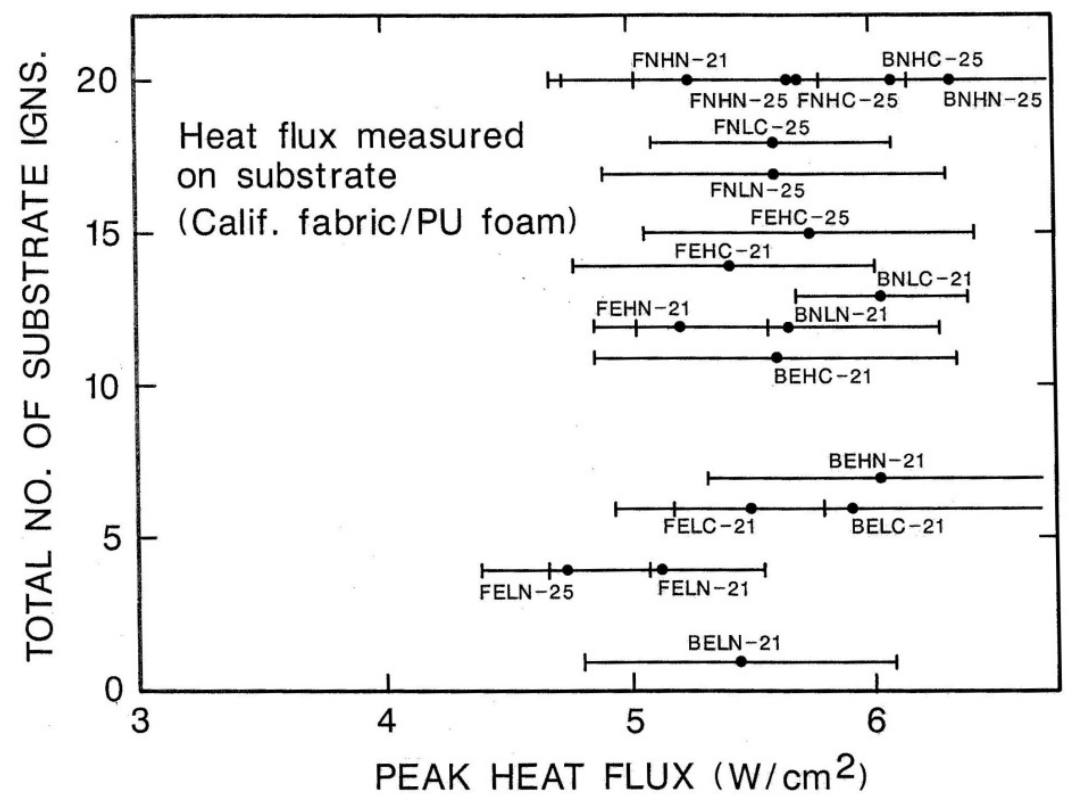

Figure 16. Number of substrate ignitions versus average peak heat flux estimates for various cigarettes on a one-cushion mock-up. [10]

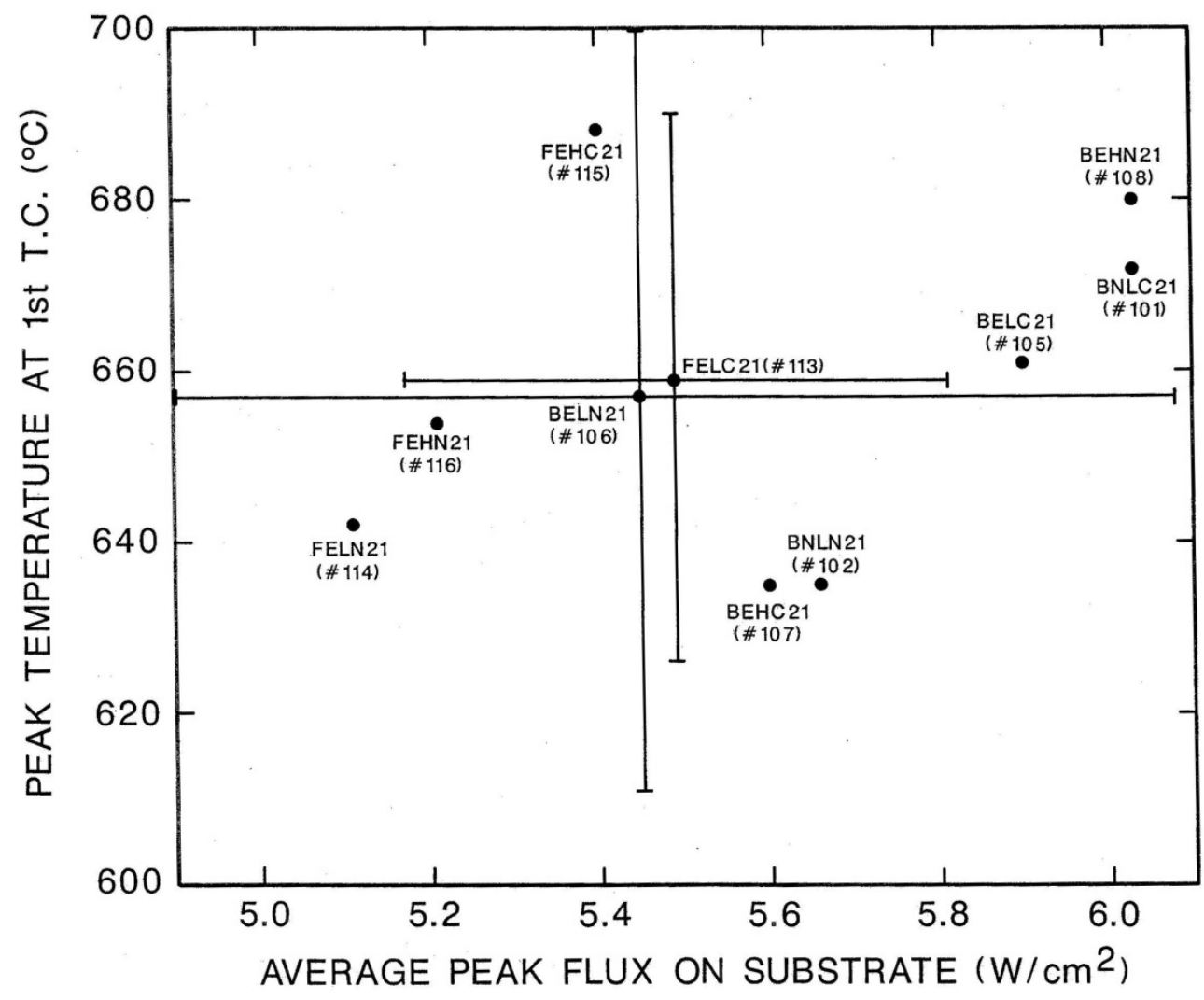

Figure 17. Peak temperature from a peripherally located thermocouple versus average peak flux for a cigarette on a one-cushion mock-up. [10] 


\subsubsection{Coal Hot Spot Area}

The next parameter evaluated as a determinant for ignition propensity was the area of the hot spot produced by the cigarette coal on the substrate. To obtain consistent estimates of the area, the coal was assumed to be conical and thus to impose a "footprint" on the substrate that was one-half the coal length times the diameter of the cigarette. These estimates and the number of ignitions for each cigarette type burning on a one-cushion mock-up using California standard fabric and FPU foam are shown in Figure 18. It appeared that the estimated coal area was a contributing parameter to the number of ignitions, but was not sufficient to separate the results for fewer than 16 ignitions out of 20 total tests. It was suggested that the substrate ignition was influenced more by three-dimensional heat transfer effects in the substrate than either the peak incident flux or total incident heat. [10]

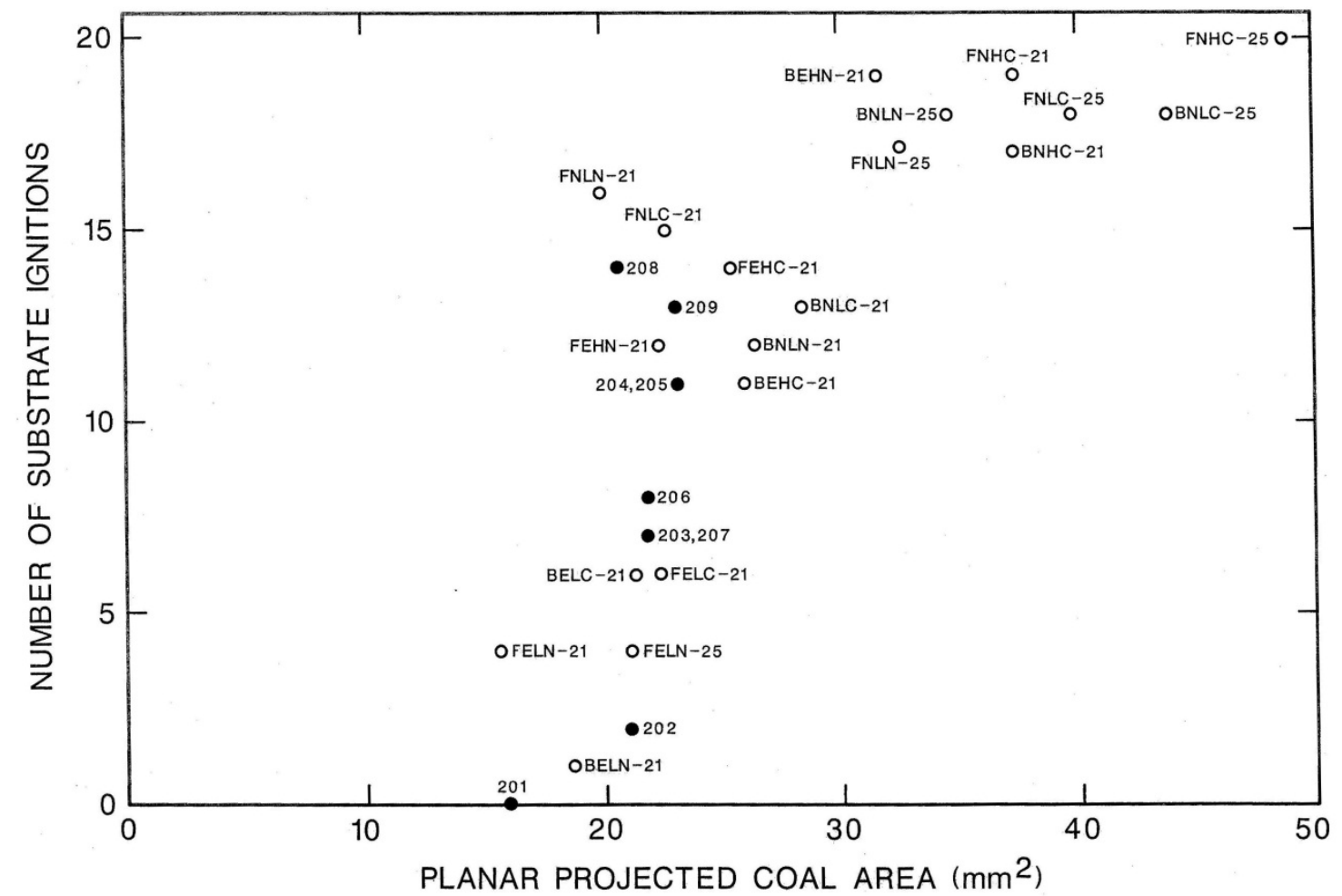

Figure 18. Estimated hot spot area and the number of substrate ignitions from one-cushion mock-up tests performed for various cigarettes. [10]

\subsubsection{Mass Burning Rate}

A reasonable correlation was reported between the mass burning rate and the number of ignitions for the one-cushion mock-up tests (Figure 19). There was a better correlation between these two parameters when results from each type of tobacco were compared separately. [10]

For the cigarettes tested, an approximately linear correlation was reported for the mass burning rates and coal length from the same one-cushion mock-up tests using California standard fabric over FPU (Figure 20). [10] 


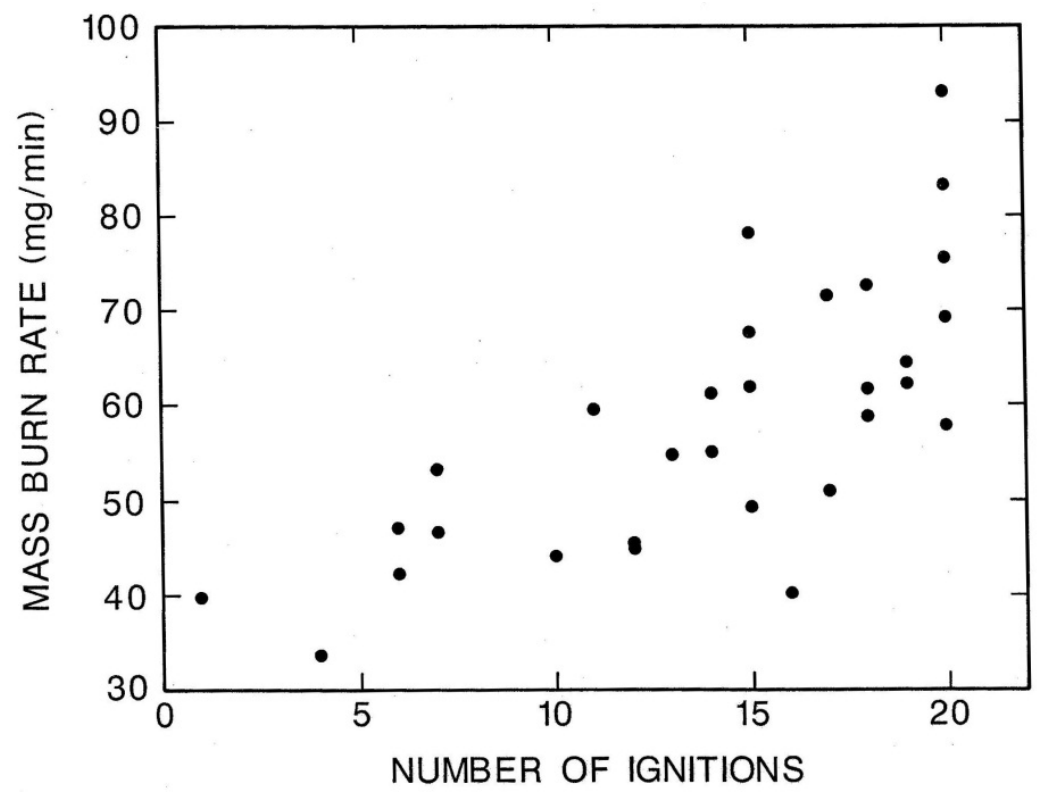

Figure 19. Mass burning rate and number of ignitions from all one-cushion mockup tests. [10]

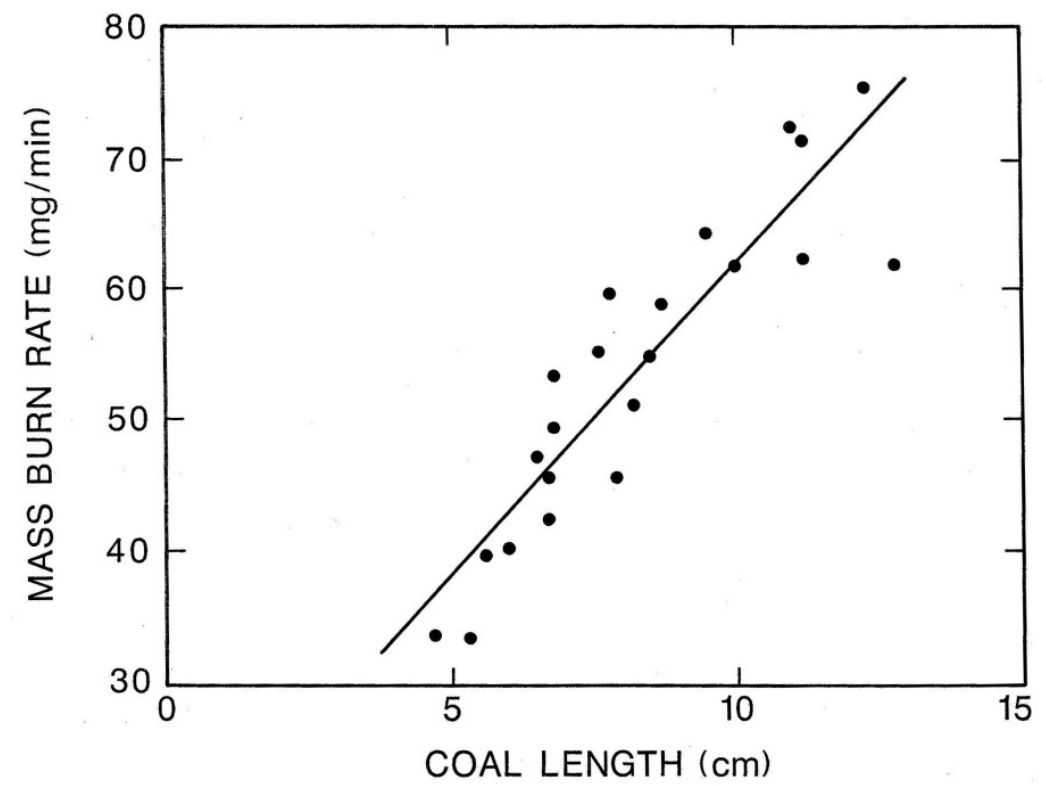

Figure 20. Mass burning rate versus coal length (from one-cushion mock-up tests using California fabric over 2024 polyurethane foam). [10]

\subsubsection{Transient Heat Flux}

It was observed that the heat flux from the cigarette was not always steady and that occasional and inevitable short-lived increases in heat generation occurred during the smoldering of each cigarette. A scanning infrared radiometer was used in preliminary measurement of such transient 
changes in flux of the coal. The results did not show any short-lived changes in the coal surface temperature, as measured along the side length of the cigarette). [10]

\subsubsection{Oxygen Depletion}

Another potential parameter suggested was the oxygen dependence of the oxidation reaction in the substrate. Depending on the reaction rate dependence on oxygen, a small depletion of the oxygen surrounding the cigarette may significantly increase the temperature required to achieve the same reaction rate, or in the situation of interest here ignition. [10]

Experiments were conducted with one-cushion mock-ups of FPU and four different cover fabrics. Gas sampling was under the fabric below the FNHC-25 cigarette. For igniting substrates, the oxygen volume fraction at the time of ignition had decreased from approximately 0.21 to between 0.11 and 0.17 . Replacing the cigarette with an electrical heater led to a decrease in oxygen volume fraction at ignition of about 0.01 . This indicated that the cigarette, rather than the pyrolyzing substrate was likely the cause of the oxygen depletion. It was noted that the $9.5 \mathrm{~mm}$ diameter heater, suspended about $2 \mathrm{~mm}$ above the fabric surface and glowing a dull orange, imposed a heat flux of $23 \mathrm{~kW} / \mathrm{m}^{2}$ to $30 \mathrm{~kW} / \mathrm{m}^{2}$. This low heat flux was sufficient to ignite the substrate at about the same time as did the flux from the cigarette lying on the surface. [10]

The Arrhenius rendition of the rate of heat generation in the substrate which leads to fabric ignition is:

$$
Q=Z\left[O_{2}\right]^{a}\left[\rho_{\text {char }}\right]^{b} 10^{-E / R T}
$$

Where $Q$ is the heat released per unit mass of fabric char oxidized, $Z$ is the effective frequency factor, $\left[\mathrm{O}_{2}\right]$ is the local mass concentration of oxygen, $\rho_{\text {char }}$ is the local mass concentration of fabric char, $E$ is the effective activation energy of the oxidation process, $R$ is the universal gas constant, and T is the local temperature. $E$ was determined to be between $33 \mathrm{kcal} / \mathrm{mole}$ and $36 \mathrm{kcal} / \mathrm{mole}$ for the fabrics in these substrates, Muramatsu found $a$ to be $1 / 2$. If the ignition temperature is $500{ }^{\circ} \mathrm{C}$ in the absence of oxygen depletion, then oxygen depletion by half (the worst case for the tested cigarettes) requires an increase in $6{ }^{\circ} \mathrm{C}$ to $8{ }^{\circ} \mathrm{C}$ to maintain a rate of heat release the same as if no oxygen depletion occurred. Even for a weak heat source such as a cigarette, such a demand is quite small. Thus, differences in oxygen depletion are not likely a prime determinant of ignition probability. [10]

Identification of important parameters and the associated values for the ignition of substrates is of interest when both designing a potential surrogate smoldering ignition source and designing the testing of the appropriateness of candidates. Conversely, since potential surrogate ignition sources will focus on selected parameters, this type of investigation will in turn contribute to a more thorough understanding of the original cigarette-substrate system. For example, a potential surrogate ignition source (such as a heater or heated inert object) that provides heat but does not use a chemical reaction may assist in the investigation of the influence of oxygen depletion on substrate ignition. Similarly, a potential surrogate ignition source that utilizes a controlled heating device may assist in the investigation of the influence of heating rates, etc. 


\subsection{Mathematical Models}

It is apparent from the experiments and calculations in Reference [10] that variations in any one of the five individual parameters could not account for the measured differences in ignition propensity of the tested cigarettes. Thus, a construct is needed, in some form of mathematical model, to combine the effects of multiple parameters.

Moussa and co-workers suggested the radiant coal power as a potential parameter for use in establishing an extinguishment threshold that could be used as a design parameter for low propensity ignition cigarettes. [102]

Models for a smoldering cigarette and heat transfer within a substrate were developed independently by Gann and co-workers [10]. The cigarette sub-model was reported to produce realistic temperature profiles, oxygen concentration profiles and velocities for the thermal wave, etc. The influence of the parameters included in the sub-models was also reported to produce realistic trends in the model results. The key variables identified pertained to oxygen transport. These included the permeability of the paper to oxygen, the temperature at which the paper burns and the diffusion coefficient in the tobacco column. [10]

An attempt to model the interaction between a cigarette and a substrate that used independent models for the cigarette and for the substrate was developed by Mitler and Walton. [39] For a simulation, the cigarette model predicted that the cigarette subjected to the thermal sink of the substrate would extinguish after a few seconds, whereas the substrate model predicted the heat flux from the cigarette would ignite the substrate in approximately $22 \mathrm{~s}$.

A mathematical model of cigarette smoldering that included the situation of the cigarette lying on a substrate was developed by Eitzinger and Pirker. [103] The model relied on the same inputs for free burning cigarette and the cigarette lying on a substrate. The input values were based on properties of the unlit cigarette. The difference between the two cigarette positions was included in the model as differences in boundary conditions. The substrate was modeled as a semi-infinite slab, with the same physical properties as the cigarette paper but assumed to be chemically inert. The model was implemented using FLUENT ${ }^{\mathrm{TM}}$. Difficulties in computation duration were found because the selected computational grid was not optimized for the three-dimensional simulation. Therefore the amount of time modeled for the cigarette smoldering on the horizontal substrate was short. The authors suggested that the model approach could not be used with high predictive confidence, because many of the model parameter values were estimates with low confidence. However, the authors suggested that the model was useful for investigating the influence of parameter value selection and the trends associated with such changes. [103]

\subsection{SUMMARY}

Since this project is the first formal effort to develop a replacement for the cigarette as an ignition source for testing the susceptibility of soft furnishings to smoldering ignition, it is not surprising that there is a paucity of direct information on the subject. 
- Data regarding the thermal properties of lit SRM 1196 cigarettes remain to be developed.

- For other cigarettes, no single parameter has been shown to predict smoldering ignition propensity.

- There are no reported studies of the degree of equivalence of moving hot spots and stationary hot spots.

- Computational models, which would include the combined contributions of multiple cigarette parameters, have not yet evolved to enable the prediction of smoldering ignition propensity on a standard substrate or on multiple, realistic substrates.

Nonetheless, there is some information on the thermal behavior of lit cigarettes to guide the development of a standard ignition source (SIS).

- There is a reasonable set of thermal properties of lit cigarettes from which to identify those that should be considered in designing an SIS.

- There are published descriptions of measurement methods for the thermal properties of lit cigarettes. Some of these include sources and the degree of uncertainty in the measurements.

- There are data regarding the magnitude (length and temperature) of the cigarette coal for a range of cigarettes.

- There are data regarding the linear burning rate of a range of cigarettes on various substrates. This determines the residence time of the hot coal over a particular site on the substrate surface. 


\section{Thermal Response of a Substrate}

\subsection{GenERAL}

\subsubsection{Topics Reviewed}

The following measurements of a substrate subjected to a potential smoldering ignition source have been reported and are summarized in this section:

- temperatures within the substrate,

- temperature profiles on the surface of the substrate, and

- variability among the thermal responses of substrates that were expected to be similar (e.g., as a result of inter-bolt fabric variability).

Details of experiments and the results associated with these aspects are included where such information would guide determinations of the similarity of alternate ignition sources and would identify potential experimental difficulties in ascertaining the equivalence of those ignition sources to SRM 1196. Literature pertaining to experiments where the only result reported was the number of ignitions is not included in this review, as it does not provide such information.

In all the studies reviewed, the padding material in the substrate was a FPU foam, unless otherwise noted. There was insufficient information in the publications to assess the degree of similarity of the foams with regard to ignition susceptibility.

\subsubsection{Indicators of Ignition and Test-end}

In general, indication of ignition and end of test has been determined by observation of a glowing region, e.g., as discussed by Kellogg and coworkers. [26] However, other methods have also been used.

Watkins and Jones suggested that the heat transport at the leading edge of the thermal front was the key variable that determines if and when a substrate material reaches the threshold temperatures for volatilization, pyrolysis and combustion. [104] An experimental technique was used to characterize the heat diffusion within several substrate materials. Details of the work are not included here, since only the abstract for this presentation has been published.

Ohlemiller investigated potential markers for the ignition of the substrate and end of test criteria for possible reduced-scale versions of 16 CFR 1632. [99] Of the potential markers considered, the width of the charred area had the most consistent association with the ignition of the substrate. The width of the charred area never exceeded $38 \mathrm{~mm}$, and typically did not exceed $25 \mathrm{~mm}$, for the substrates that did not ignite. For tests in which ignition occurred, the char width grew to exceed $50 \mathrm{~mm}$. Chars of this width occurred between $15 \mathrm{~min}$ and $30 \mathrm{~min}$ from the start of a test. Ohlemiller also noted that the smolder zone, and subsequently the char length and width, could be affected by cross quilt seams. Therefore, the location of the initial smoldering ignition source may influence the results of variables potentially selected to estimate the extent 
of combustion within a substrate or the end of test. The cigarette used in these tests was the commercial cigarette routinely used for testing mattresses for cigarette ignition resistance. (This is the Pall Mall cigarette which SRM 1196 was designed to replicate.) The time reported for the full length burn of a cigarette on the various substrates (for tests in which ignition did not occur and the cigarette was covered by cotton sheeting) varied from approximately $22 \mathrm{~min}$ to $30 \mathrm{~min}$.

CPSC has for several years been performing research to determine an appropriate smoldering ignition test method and performance criteria for cigarette ignition resistance of upholstered furniture. As part of this program, Tao examined the response of a large variety of furniture composites upon which a lit CTC had been placed. [100] The L-shaped test mock-up consisted of a horizontal and vertical piece of wood, joined orthogonally along one horizontal edge. The layered test materials were placed on both surfaces; the lit cigarette was placed in the crevice. The materials in the test plan included 38 cover fabrics, 11 foam padding materials, and 14 interliners. The measured parameters were the char length in six directions (vertical up and down, horizontal into the foam and away from the crevice, and left and right of the cigarette location) and the mass loss of the foam. Scott performed similar tests of ten loose fill materials. [101] The test results provide significant guidance for selecting diverse, yet appropriate substrate materials for evaluating candidate ignition sources for equivalence to SRM 1196 cigarettes. The test results did not favor that the use of an ignition criterion based on fabric char length in a single direction. Rather, an average foam mass loss of no more than $10 \%$ during a $30 \mathrm{~min}$ test duration is a reasonable candidate as a criterion for the smolder resistance of upholstered furniture materials. The data obtained in developing this criterion provide some background for selecting metrics for determining the equivalence of ignition sources for a given combination of substrate materials.

\subsection{Cigarette ON A Mock-Up Cushion}

\subsubsection{Temperatures within the Padding Material}

Salig reported temperatures from thermocouples located in the foam in lines at $25 \mathrm{~mm}$ and $50 \mathrm{~mm}$ directly below the centerline of a smoldering cigarette that was located on the center of a FPU foam and fabric cushion, as shown in Figure 8. [30] The smoldering ignition source was either a single cigarette $80 \mathrm{~mm}$ long or two such cigarettes placed end-to-end, in effect creating a single double-length cigarette. The cigarette was covered with a square of fabric.

A set of results for a substrate consisting of Doblin fabric over FPU foam is included as Figure 21 and Figure 22. The peak temperatures at $25 \mathrm{~mm}$ below the surface were approximately $470{ }^{\circ} \mathrm{C}$ to $550{ }^{\circ} \mathrm{C}$. At $50 \mathrm{~mm}$ below the surface, the peak temperatures were approximately $360{ }^{\circ} \mathrm{C}$ to $500{ }^{\circ} \mathrm{C}$. A second set of results for a substrate consisting of greige duck fabric over FPU foam is included as Figure 23 and Figure 24. The peak temperatures at $25 \mathrm{~mm}$ below the surface were approximately $340{ }^{\circ} \mathrm{C}$ to $400{ }^{\circ} \mathrm{C}$. At $50 \mathrm{~mm}$ below the surface, the peak temperatures were approximately $140{ }^{\circ} \mathrm{C}$ to $220^{\circ} \mathrm{C}$. A third set of results for a substrate consisting of duck dyed blue fabric over the FPU foam is included as Figure 25 and Figure 26 . The peak temperatures at $25 \mathrm{~mm}$ below the surface were approximately $70{ }^{\circ} \mathrm{C}$ to $100{ }^{\circ} \mathrm{C}$. At $50 \mathrm{~mm}$ below the surface, the peak temperatures were approximately ambient. A fourth set of results for a substrate consisting of printcloth fabric over the FPU foam is included as Figure 27 
and Figure 28. The peak temperatures at $25 \mathrm{~mm}$ below the surface were approximately $70{ }^{\circ} \mathrm{C}$ to $110^{\circ} \mathrm{C}$. At $50 \mathrm{~mm}$ below the surface, the peak temperatures were approximately ambient.

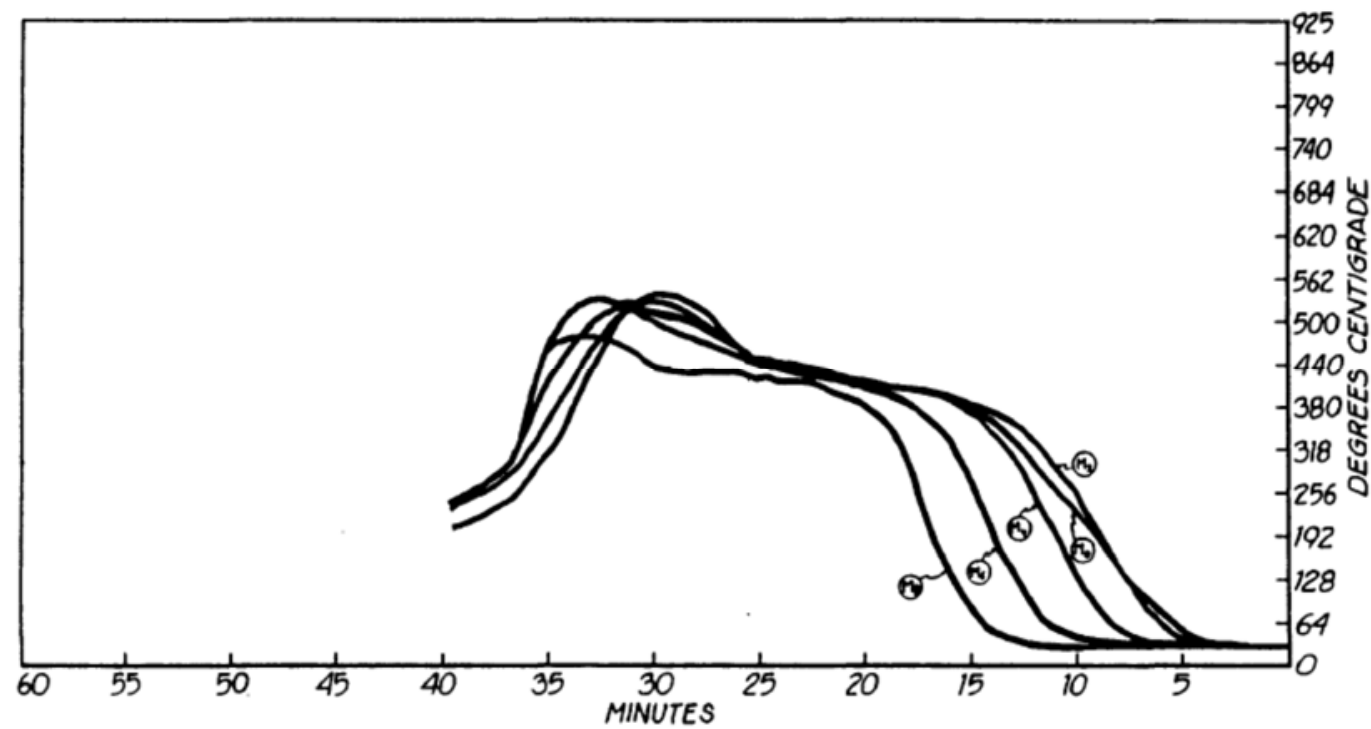

(a)

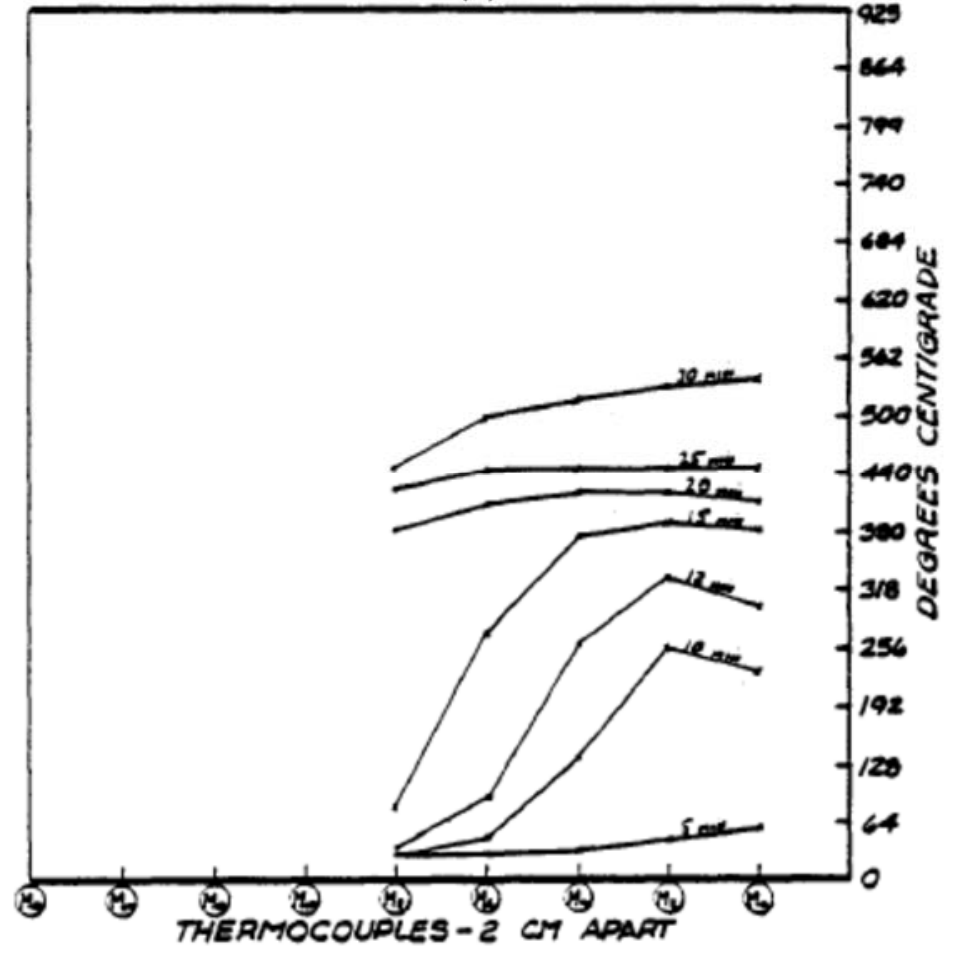

(b)

Figure 21. Thermocouple temperatures versus (a) time and (b) location for TCs located in the foam at $25 \mathrm{~mm}$ directly below a covered $80 \mathrm{~mm}$ cigarette that is located on the substrate of Doblin fabric over a FPU foam. [30] 


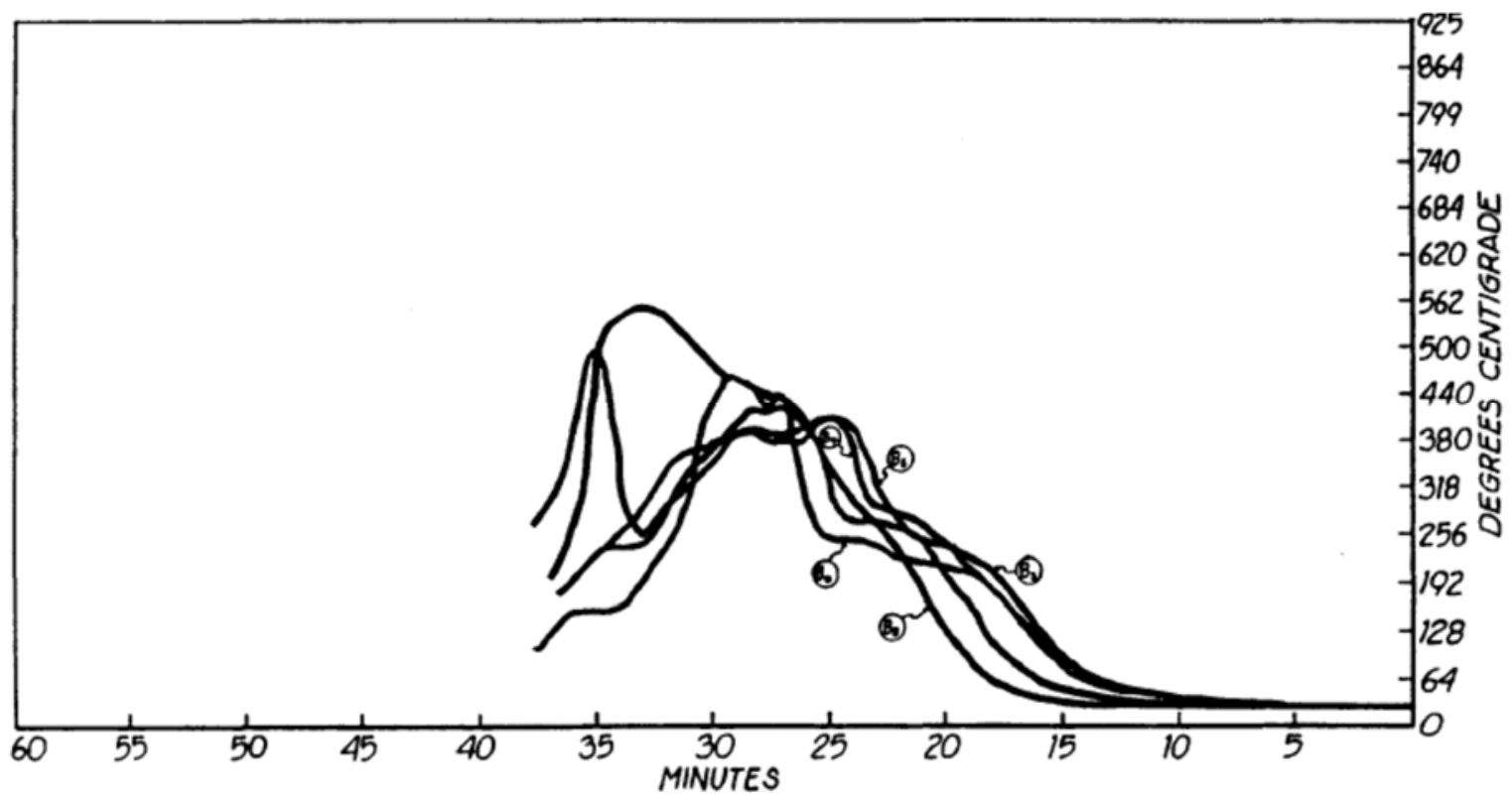

(a)

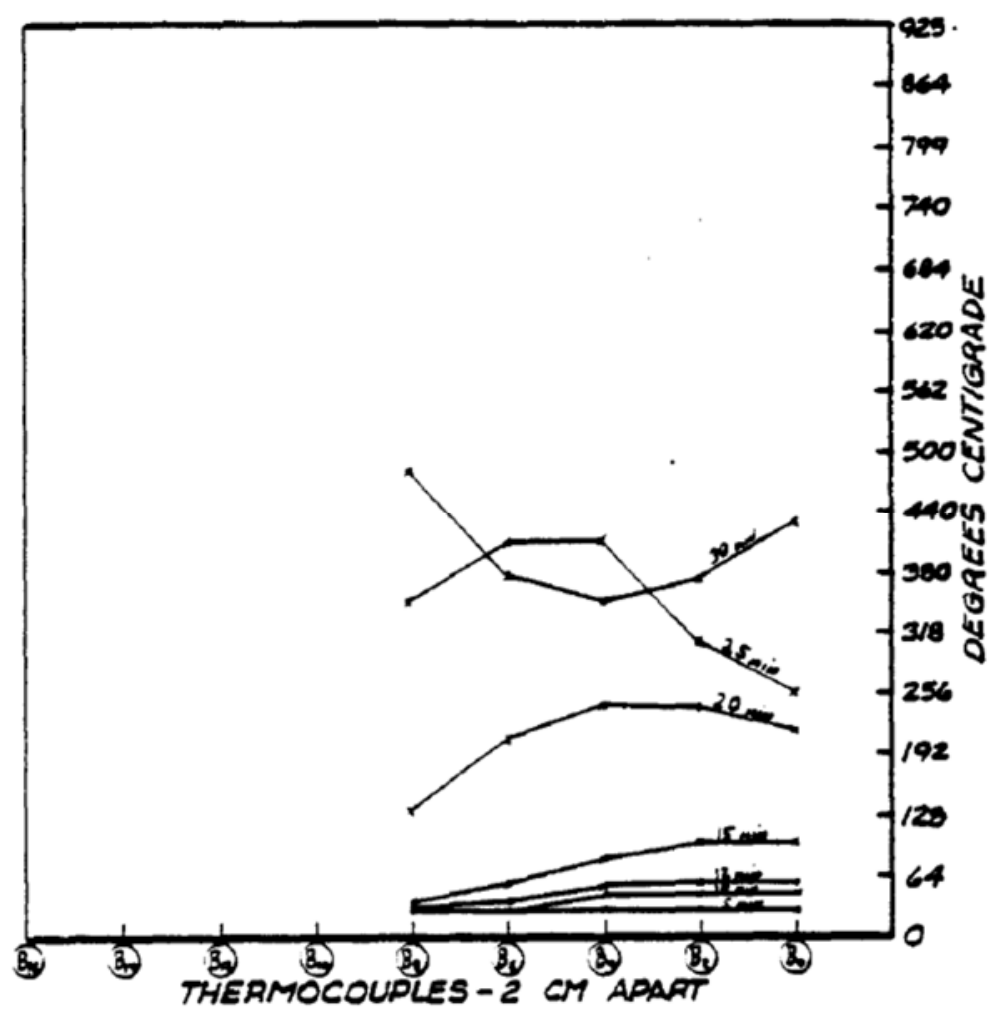

(b)

Figure 22. Thermocouple temperatures versus (a) time and (b) location for TCs located in the foam at $50 \mathrm{~mm}$ directly below a covered $80 \mathrm{~mm}$ cigarette that is located on the substrate of Doblin fabric over a FPU foam. [30] 


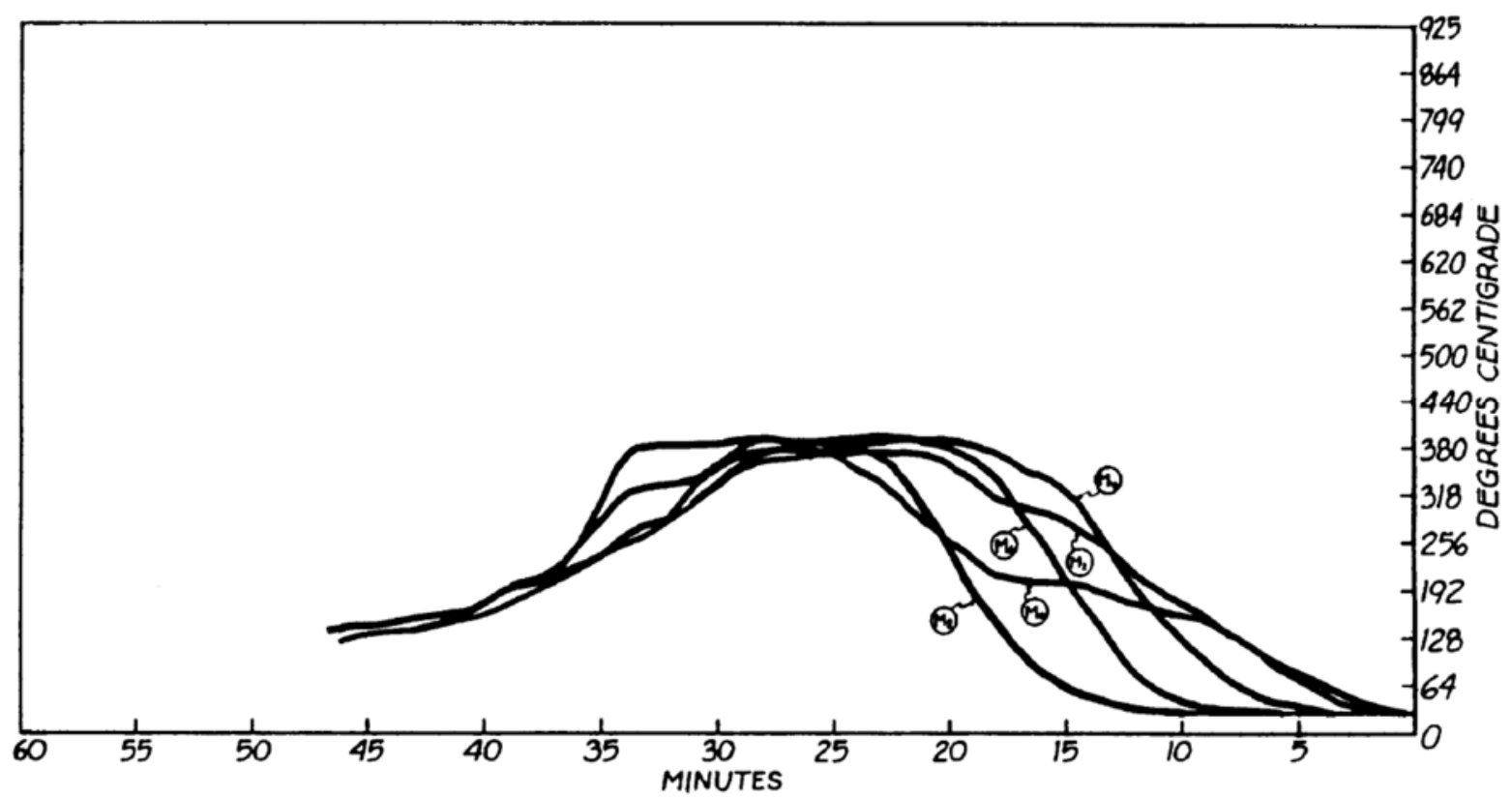

(a)

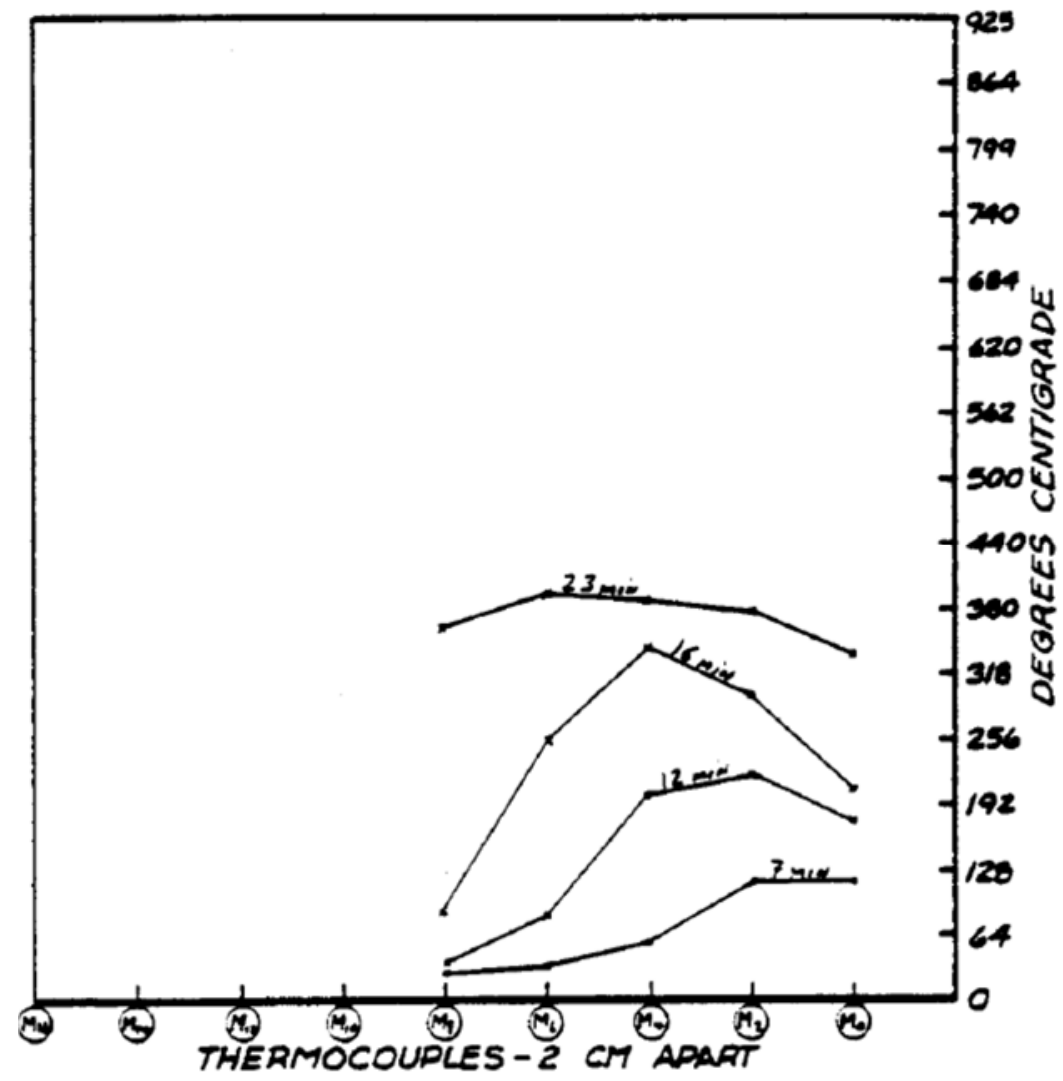

(b)

Figure 23. Thermocouple temperatures versus (a) time and (b) location located in the foam $25 \mathrm{~mm}$ directly below a covered $80 \mathrm{~mm}$ cigarette that is located on the substrate of greige duck fabric over a FPU foam. [30] 


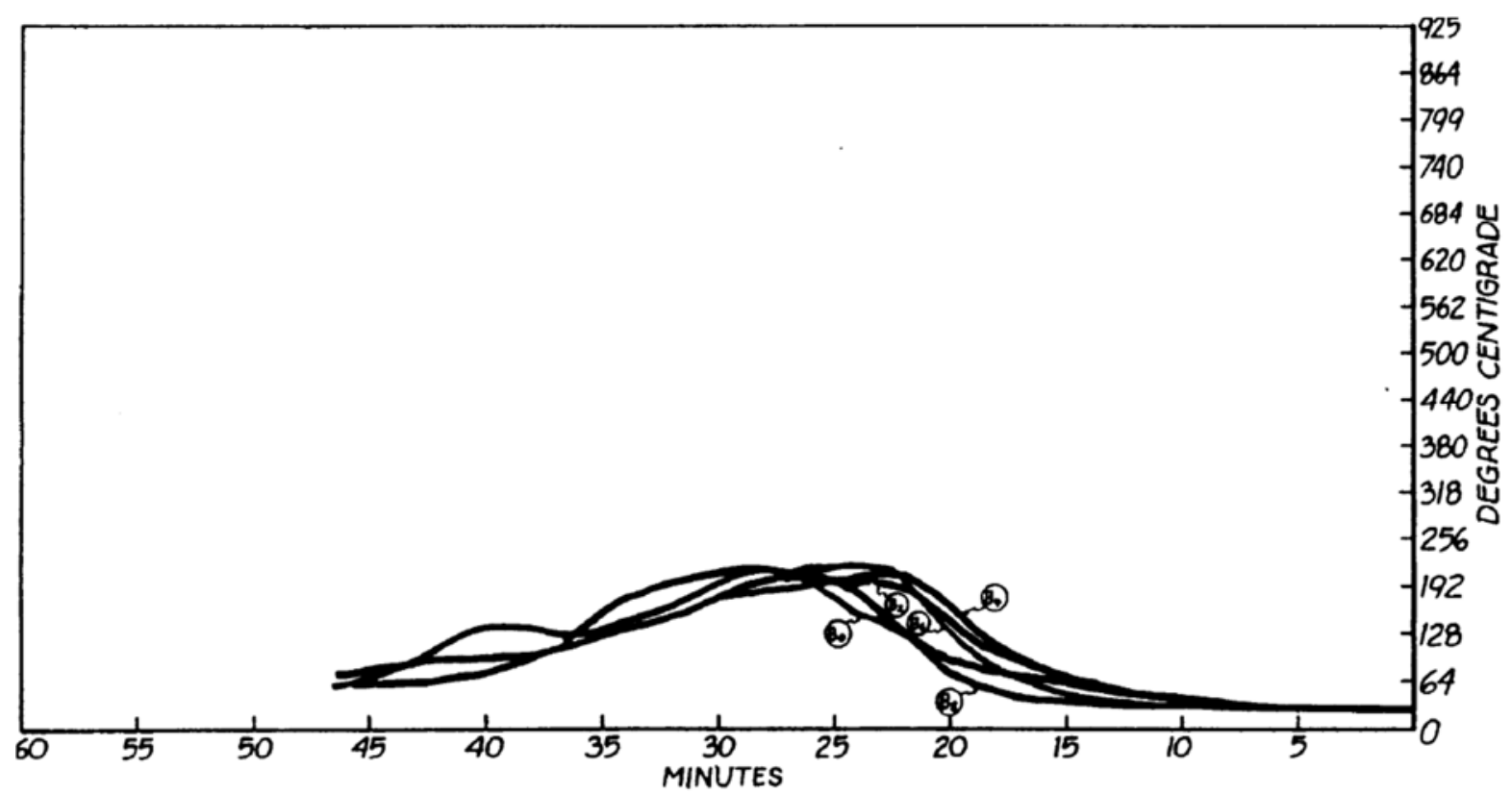

(a)

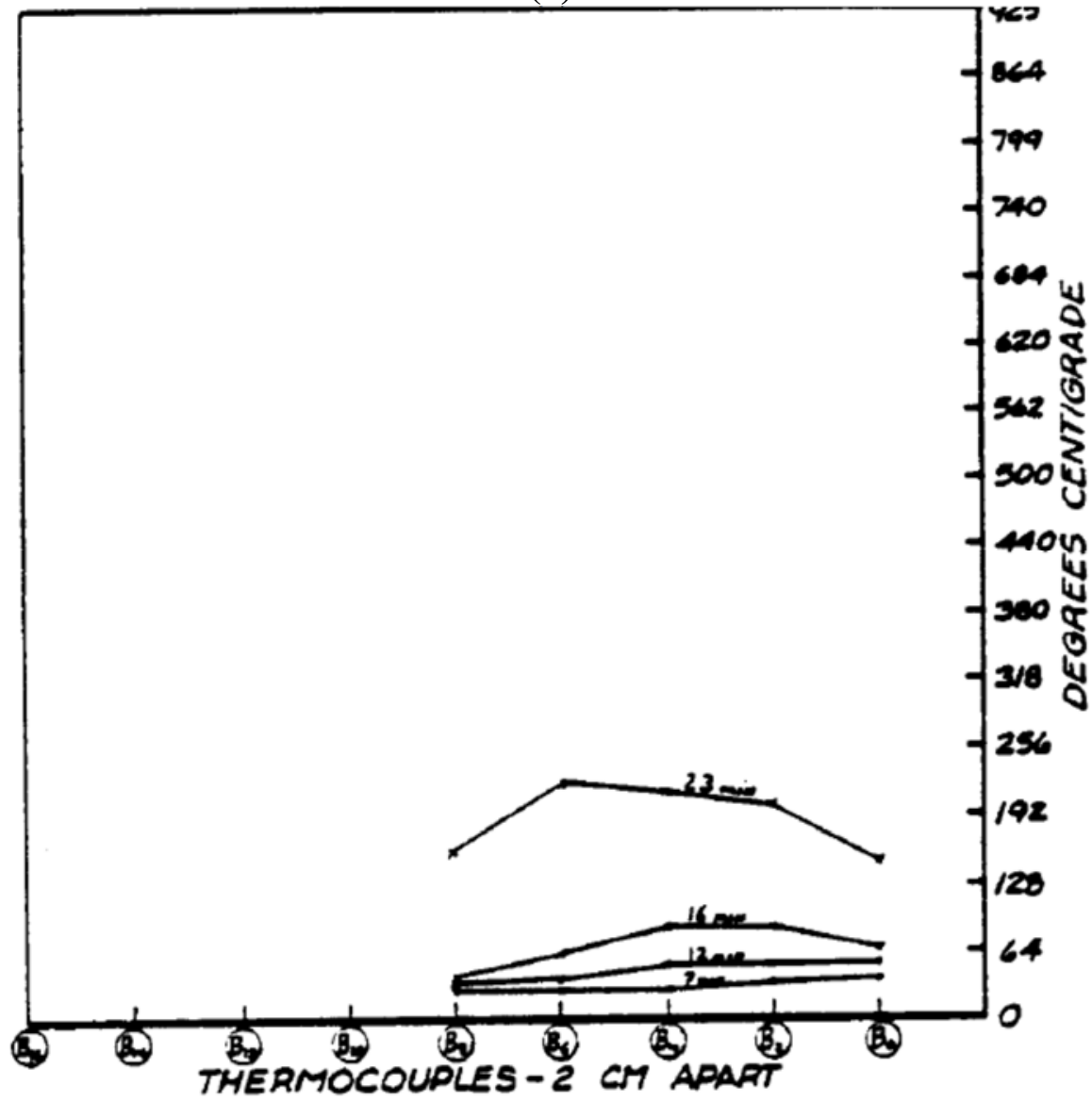

(b)

Figure 24. Thermocouple temperatures versus (a) time and (b) location located in the foam $50 \mathrm{~mm}$ directly below a covered $80 \mathrm{~mm}$ cigarette that is located on the substrate of greige duck fabric over a FPU foam. [30] 


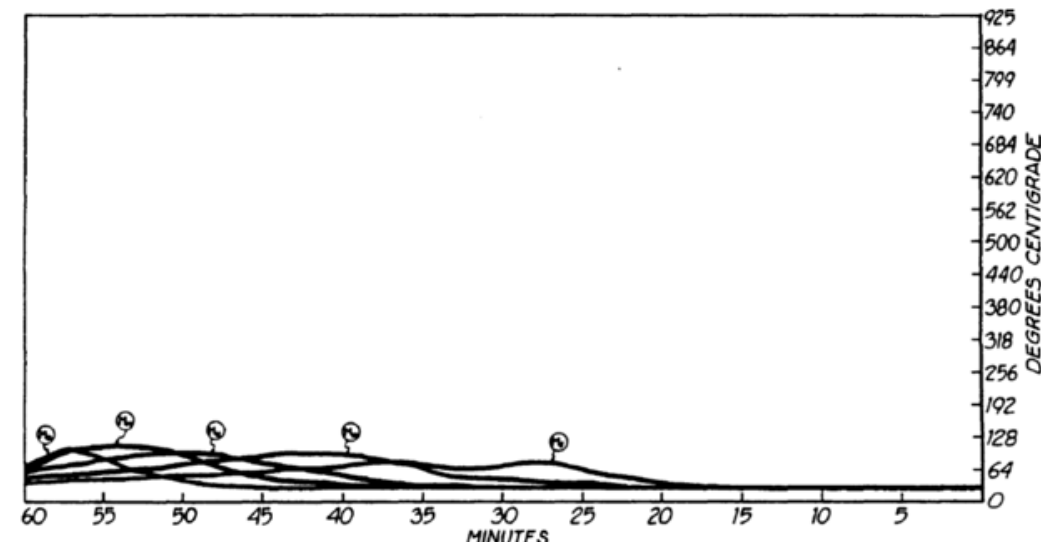

(a)

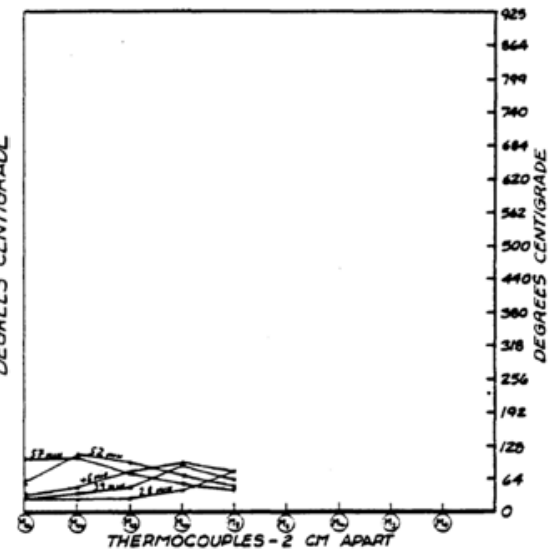

(b)

Figure 25. Thermocouple temperatures versus (a) time and (b) location located in the foam $25 \mathrm{~mm}$ directly below a covered $80 \mathrm{~mm}$ cigarette that is located on the substrate of duck dyed blue fabric over a FPU foam. [30]

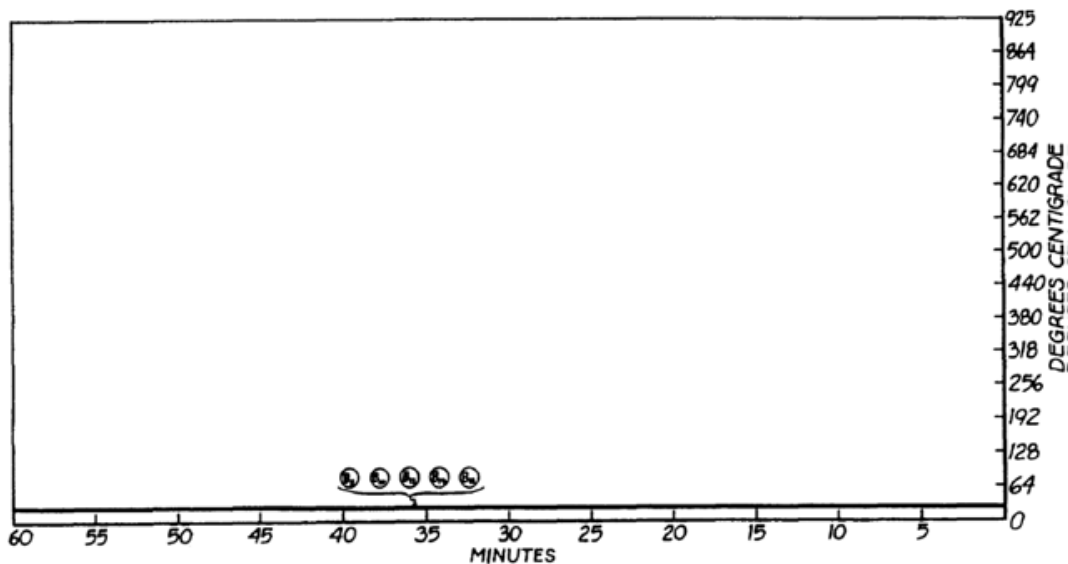

(a)

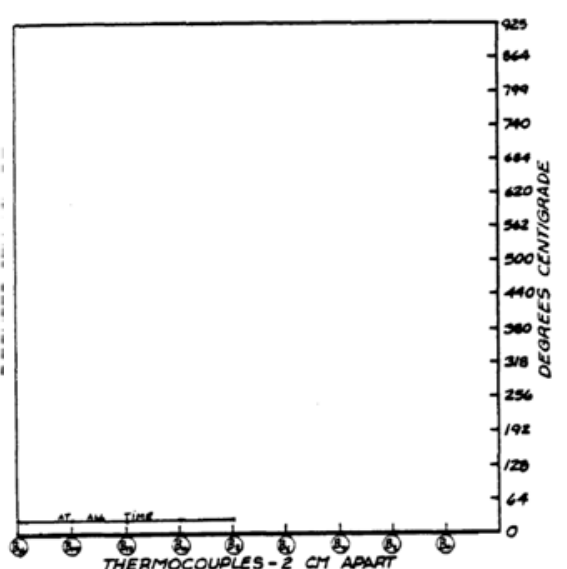

(b)

Figure 26. Thermocouple temperatures versus (a) time and (b) location located in the foam $50 \mathrm{~mm}$ directly below a covered $80 \mathrm{~mm}$ cigarette that is located on the substrate of duck dyed blue fabric over a FPU foam. [30] 


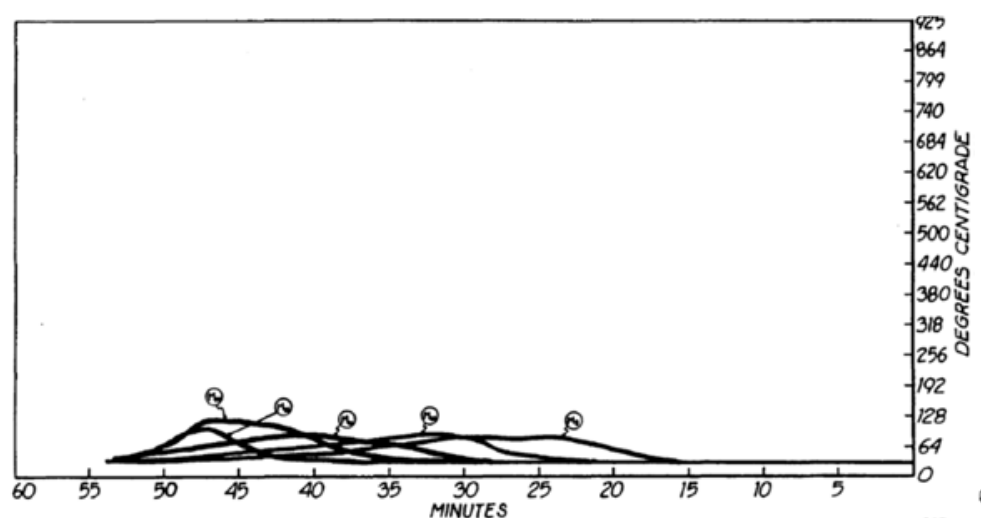

(a)

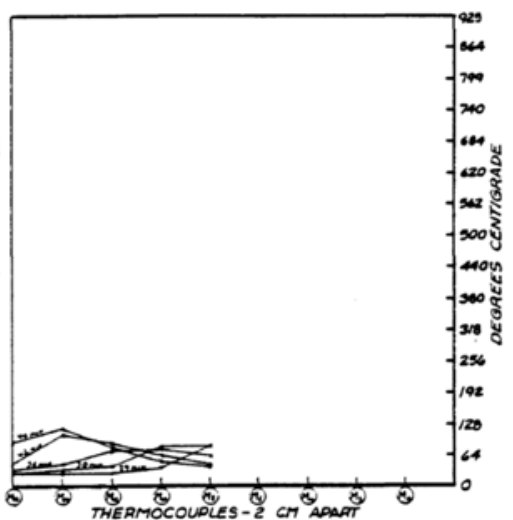

(b)

Figure 27. Thermocouple temperatures versus (a) time and (b) location located in the foam $25 \mathrm{~mm}$ directly below a covered $80 \mathrm{~mm}$ cigarette that is located on the substrate of printcloth fabric over a FPU foam. [30]

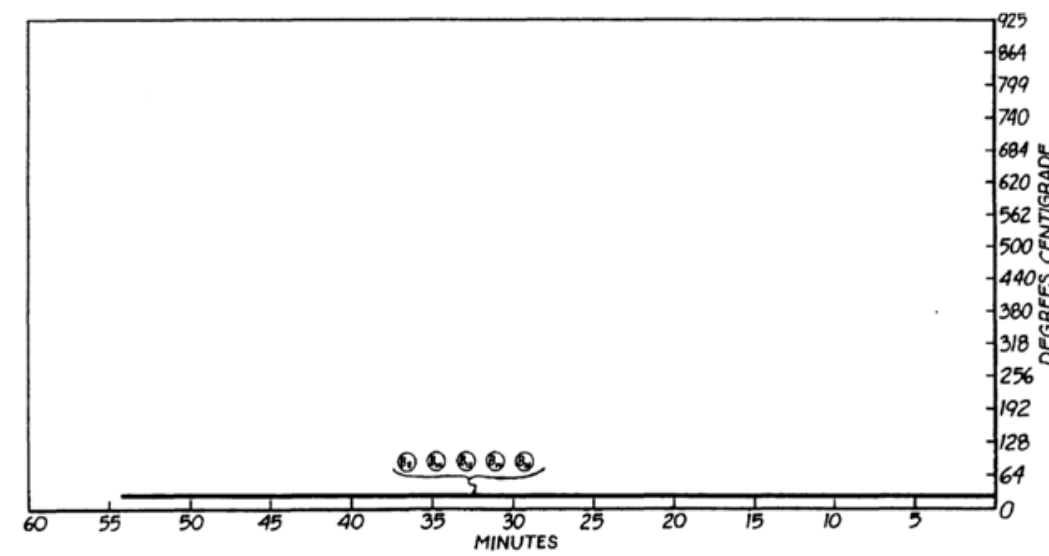

(a)

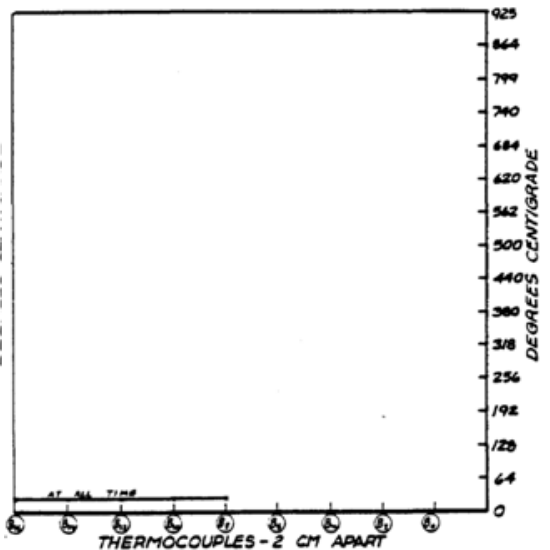

(b)

Figure 28. Thermocouple temperatures versus (a) time and (b) location located in the foam $50 \mathrm{~mm}$ directly below a covered $80 \mathrm{~mm}$ cigarette that is located on the substrate of printcloth fabric over a FPU foam. [30]

While not involving experiments of lit cigarettes on padding material, an investigation by Ohlemiller of the smoldering combustion of padding materials provides data on the conditions for ignition. [99] He inserted a heater (94 $\mathrm{mm}$ long, $19 \mathrm{~mm}$ diameter) into the center of blocks of FPU foam, obtaining information on heating rates and foam response that are useful in potential ignition source design, design of the test matrix to evaluate potential devices, and analysis of test results. One-hour tests with constant heater temperatures were used to determine the heater temperature associated with the onset of smoldering. New foam samples were used for each test, and the heater temperature was incrementally increased by $10^{\circ} \mathrm{C}$ until smoldering was observed. The occurrence of ignition was established by observation of the char area extending on the top surface of the foam or via post-test sectioning of the foam sample to measure the cross-sectional char area.

Tests were also performed at two heating rates, $6{ }^{\circ} \mathrm{C} / \mathrm{min}$ and $14{ }^{\circ} \mathrm{C} / \mathrm{min}$, both lower than the 
approximately $20^{\circ} \mathrm{C} / \mathrm{min}$ that would be expected from a cigarette coal smoldering on top of an upholstered item or cushion. The slower heating rates were used to encourage smolder in the sample, if it could occur. The estimated minimum temperatures for smoldering combustion of the samples were reported as $315^{\circ} \mathrm{C}$ to greater than $360^{\circ} \mathrm{C}$ for various FPU foams, $260{ }^{\circ} \mathrm{C}$ to $270{ }^{\circ} \mathrm{C}$ for latex foam samples, and $330^{\circ} \mathrm{C}$ to $340^{\circ} \mathrm{C}$ for cotton batting with no fire retardant treatment. [99]

A cigarette is a much smaller sized ignition source than the heater used in this test series. Thus, Ohlemiller hypothesized that the minimum ignition temperature that a cigarette must impose on a substrate material to cause an ignition might be higher than those temperatures reported for the fixed temperature cartridge heater tests. [99]

\subsubsection{Temperatures on the Surface of the Substrate}

Gann and co-workers [10] used an Inframetrics Model 525 scanning infrared radiometer to estimate the temperatures on a substrate resulting from a lit cigarette. Obtaining these estimates was difficult because:

1. Being much hotter than the substrate surface, the cigarette dominated the infrared emission. Shielding the detector from the cigarette did not remove the problem of infrared radiation from the cigarette leaking around the shield to the surrounding surfaces. Thus, the cigarette was rapidly removed from the substrate surface, and the infrared data following this were used to estimate the surface temperature profile.

2. Upon removal of the cigarette, the substrate surface cooled rapidly. The cooling rates were estimated to be from $150{ }^{\circ} \mathrm{C} / \mathrm{s}$ to $250^{\circ} \mathrm{C} / \mathrm{s}$.

3. There was sufficient noise in the recorded video that several frames had to be averaged to obtain usable information.

Temperature fields were obtained at about one-eighth second and one-quarter second after the removal of the cigarette. The decaying temperatures at selected spatial locations were extrapolated back to the time of cigarette removal using an exponential decay function. Even then, there were a number of factors that limited the accuracy of the peak surface temperatures to $\pm 25^{\circ} \mathrm{C}$ to $\pm 40^{\circ} \mathrm{C}$.

Examples of isotherms on the top surface of a one-cushion mock-up consisting of California standard fabric and FPU foam are shown in Figure 29 for two types of cigarettes. The cigarettes used in these examples had shown different ignition tendencies for one-cushion mock-ups for four combinations of fabric, batting and foams. One cigarette, BELN-21, had one ignition out of the total 20 one-cushion mock-up tests. The isothermal contours for this relatively low ignition propensity cigarette after burning $20 \mathrm{~mm}$ on the substrate and then being removed are shown in Figure 29(a). The second cigarette, FNHC-25, had 20 ignitions out of the total 20 one-cushion mock-up tests. The isothermal contours for this relatively high ignition propensity cigarette after burning $20 \mathrm{~mm}$ on the substrate and then being removed are shown in Figure 29(b). [10]

The substrate surface area enclosed by the $400{ }^{\circ} \mathrm{C}$ isotherm for the higher propensity cigarette (FNHC-25) was approximately 40 times larger than for the lower propensity cigarette 
(BELN-21). There was also a substantial area enclosed by the $450^{\circ} \mathrm{C}$ isotherm for the higher propensity cigarette and none for the lower propensity cigarette, since the peak temperature reported was approximately $424{ }^{\circ} \mathrm{C}$. It was suggested these results were expected based on the incident flux from these cigarettes. [10]

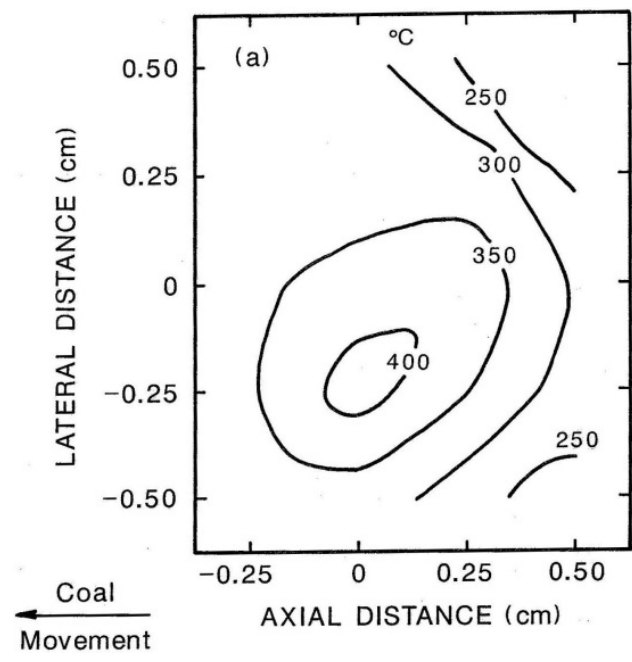

(a)

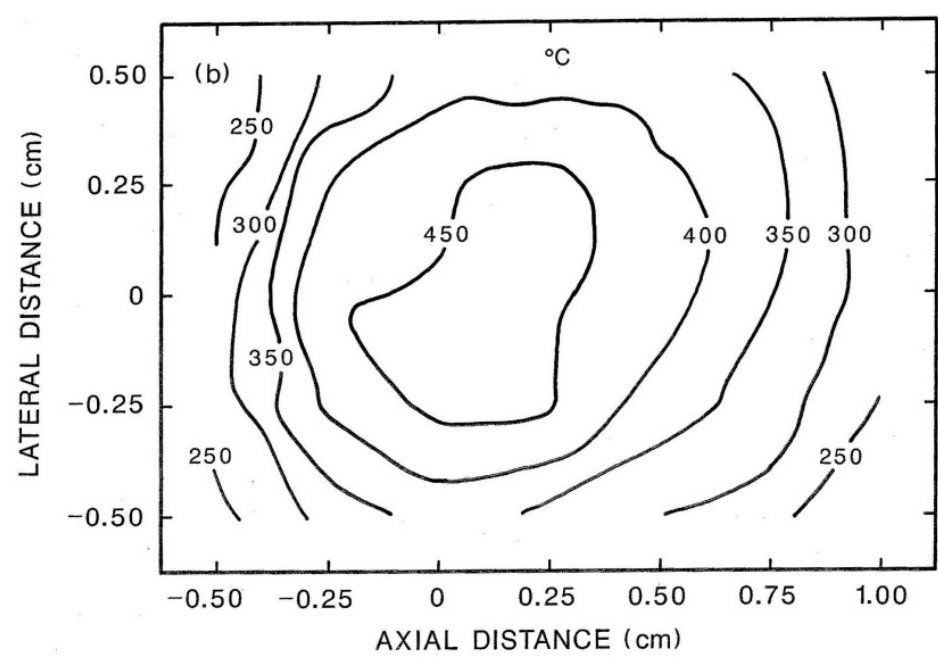

(b)

Figure 29. Isothermal contours on the top surface of a one-cushion mock-up after the cigarette had burnt $\mathbf{2 0} \mathbf{~ m m}$ for (a) a relatively low ignition propensity cigarette, and (b) a relatively high ignition propensity cigarette. [10]

Putzeys and co-workers [25, 69] investigated piloted transition from smoldering to flaming for various FPU foams. Sample blocks (50 $\mathrm{mm}$ x $50 \mathrm{~mm}$ by $125 \mathrm{~mm}$ long) of both non-fire retarded (NFR) FPU foam and fire retarded (FR) FPU foam (Pyrell®) were used. The samples were located vertically in a wall of the test chamber, where the air velocity was upward, past the free surface of the sample, through the chamber. The sample was located in a thin brass walled sample holder that was insulated on the back face. The outer surfaces of the back and side walls of the sample holder were maintained at $200^{\circ} \mathrm{C}$, using guard heaters. [25]

The free surface of the sample was exposed to a radiant heat flux (perpendicular to the freesurface) from an infrared radiant strip heater. For the NFR foam, the applied radiant heat flux was varied between $7.25 \mathrm{~kW} / \mathrm{m}^{2}$ and $8.75 \mathrm{~kW} / \mathrm{m}^{2}$. For the FR foam, the applied radiant heat flux was varied between $4.5 \mathrm{~kW} / \mathrm{m}^{2}$ and $5.5 \mathrm{~kW} / \mathrm{m}^{2}$. The upper limit of the heat flux applied to each type of foam was determined by the minimum heat flux required to cause pyrolysis on the free surface of the samples. The lower limit of the range of heat fluxes applied to each type of foam was associated with the minimum heat flux at which a sustained smolder reaction had been observed. The samples were ignited at the bottom end of the sample that was in contact with a $50 \mathrm{~mm}$ x $50 \mathrm{~mm}$ ceramic honeycomb heater. The ceramic heater was set to a constant power to achieve smoldering ignition for each type of foam tested. For the NFR foam the power of the ceramic igniter was set to $23 \mathrm{~W}$. For the FR foam, the power of the ceramic igniter was set to $115 \mathrm{~W}$. The oxygen concentration of the local atmosphere was varied between tests, from a mole fraction of 0.15 to 0.35 . The upward air velocity was $0.5 \mathrm{~m} / \mathrm{s}$ during the testing of the NFR foam and $0.15 \mathrm{~m} / \mathrm{s}$ during the FR foam tests. [25] 
The smolder velocity and peak smolder temperature were found to increase with oxygen mole fraction and applied heat flux. Oxygen concentration and applied heat flux were suggested to be the primary parameters needed to identify the transition between smoldering and flaming. [25]

\subsubsection{Inter-Bolt Fabric Variability}

The types and mix of fibers used in a cover fabric comprise a key factor in the susceptibility of upholstered items to ignition by a cigarette. [105-109] Variation in ignition results has been demonstrated among different types of fabrics (e.g., varying with areal mass) [26, 110-112] and also for different types of cigarettes. [112] Variations in test results between apparently similar materials have also been reported [26, 108, 111, 113-116], indicating the need for careful control of the substrate materials used in developing alternates to SRM 1196.

Jupe and co-workers [117] investigated inter-bolt variability using two bolts of Duck \#4 that met military specifications when tested using two types of experimental cigarettes. Based on 48 tests of each combination of bolt and type of cigarette, the difference in measured ignition propensity for the two bolts was larger than the variability observed between different laboratories' results in the round robin.

Similarly, Wanna and co-workers [118] also investigated the inter-bolt variability for four bolts of Duck \#6 and two types of experimental cigarettes. The results for each of the cigarettes were also reported to have a statistically significant dependence on the bolt used in the mock-up. Percentages of ignition from 48 tests with four different bolts of Duck \#6 varied from $0 \%$ to $79 \%$ for one type of cigarette (BEHC-21) and from $15 \%$ to $100 \%$ for another type of cigarette (BEHN-25). The relative rankings of the four bolts were similar for these two cigarettes. All controllable variables, such as environmental conditions, were tightly controlled throughout the testing.

\subsection{SUBSTRATES EXPOSED TO AN IGNITION SOURCE}

Behnke was reported to have presented results for temperatures at which an undefined cotton fabric was observed to ignite when exposed to various heat sources to the ASTM D.13 committee in 1969 [87]:

- in a heated vessel at $385^{\circ} \mathrm{C}$

- on a hot plate at $465^{\circ} \mathrm{C}$

- in contact with a hot wire at $518^{\circ} \mathrm{C}$, and

- when exposed to a radiant heat flux of $28 \mathrm{~kW} / \mathrm{m}^{2}$ for $30 \mathrm{~s}$.

Gandhi and co-workers used calibrated thermal imaging to investigate temperature fields and smoldering ignition on thin $100 \mathrm{~mm}$ by $150 \mathrm{~mm}$ horizontal upholstery fabric samples, when exposed to a heat source. [119] The heat source was a glowing $6 \mathrm{~mm}$ diameter, $15 \mathrm{~mm}$ long diesel glow plug that was used to provide localized, low energy radiation energy, with a peak of $75 \mathrm{~kW} / \mathrm{m}^{2}$. The source was chosen to be in general agreement with the peak heat output of a 
smoldering cigarette. The heated element was held parallel to, and in contact with, the upper surface of the horizontal sample. The heat source was applied to each fabric sample for three minutes.

The infrared camera used to measure surface temperatures was calibrated at $600{ }^{\circ} \mathrm{C}$. The chosen calibration temperature influences the resolution of the temperatures in the subsequent images. The subsequent images were collected at $30 \mathrm{~s}$ intervals. The images were grey scale, with 256 levels of gray representing the temperature range of approximately $300{ }^{\circ} \mathrm{C}$ to $550{ }^{\circ} \mathrm{C}$. In addition, the emissivity of the fabric samples was estimated using a $0.05 \mathrm{~mm}$ diameter $\mathrm{K}$ Type thermocouple inserted into the top layer of fabric at three locations. In each test, the first 10 images were collected at $2 \mathrm{~s}$ intervals. The images were also post-processed using filters to smooth temperature gradients, using a center weighted mean filter. The resolution was $0.625 \mathrm{~mm}^{2}$ of sample per pixel. The upholstery fabric samples used in the investigation were three $100 \%$ cotton duck fabrics with various weights, from approximately $510 \mathrm{~g} / \mathrm{m}^{2}$ to $770 \mathrm{~g} / \mathrm{m}^{2}$. Ignition of the samples was observed as the appearance of a glowing char that started to move away from the heating element, leaving a hole in the fabric. This was observed around $400{ }^{\circ} \mathrm{C}$ to $450{ }^{\circ} \mathrm{C}$. Ignition of the fabric samples was observed for the Duck \#6 at $30 \mathrm{~s}$ and for the Duck \#10 at $8 \mathrm{~s}$ to $10 \mathrm{~s}$ after application of the $7.5 \mathrm{~W} / \mathrm{m}^{2}$ heat source. The peak temperatures for samples of Duck \#6 and Duck \#10 were approximately $550^{\circ} \mathrm{C}$. The shapes of the smoldering zones, as evidenced by isotherms, were similar for the two weights of Duck while the heat source was being applied. A difference was observed after the heat source was switched off. The lighter material (Duck \#10) was observed to have a faster moving smolder front than the heavier weight fabric (Duck \#6). [119]

Gandhi and co-workers [120] continued their investigations with an altered equipment setup, in which the infrared camera was still located above the sample, but the heat source was located under the sample (instead of on top as in Reference [119]). The camera was again calibrated to $600{ }^{\circ} \mathrm{C}$, and the spatial resolution of the image was again $0.625 \mathrm{~mm}^{2}$ per pixel. The heating element was again $6 \mathrm{~mm}$ in diameter and $15 \mathrm{~mm}$ long. The igniter was controlled using variable voltage to achieve a peak heat flux of $75 \mathrm{~kW} / \mathrm{m}^{2}$, as measured using a Schmidt-Boelter heat flux gage. The peak heat flux was selected in the range of previously reported cigarette heat flux estimates and to ensure smoldering ignition of the test fabrics.

Five types of fabric samples were tested; three were cotton duck fabrics (numbers 4, 6 and 10) and two were $100 \%$ cotton residential upholstery fabrics that were commercially available. The test fabrics were examined for areal density, thickness, porosity and ionic content. The image thermal scene range was $200{ }^{\circ} \mathrm{C}$ to $650{ }^{\circ} \mathrm{C}$. The thermocouple and infrared camera temperatures were within $2{ }^{\circ} \mathrm{C}$ to $5^{\circ} \mathrm{C}$, after accounting for time delays associated with the infrared camera measurements. The surface temperature distribution at $90 \mathrm{~s}$ after application of the $75 \mathrm{~kW} / \mathrm{m}^{2}$ heating element on a sample of cotton duck fabric and a sample of $100 \%$ cotton residential upholstery fabric that was commercially available were similar in magnitude. Only small differences $\left(<50^{\circ} \mathrm{C}\right)$ were found in the peak surface temperatures were for each type of fabric with and without washing. [120] 


\subsection{EXPERIMENTAL CONSIDERATIONS}

\subsubsection{Introduction}

Researchers performing experiments related to the testing of cigarettes on potentially ignitable substrates identified several features of such testing that need to be considered in a justifiable test protocol. These are enumerated in this section.

\subsubsection{Conditioning of Test Materials}

Test results, especially for smoldering combustion, are sensitive to the temperature and relative humidity history of the test materials. Thus, standard bench-scale test methods such as ASTM E 1352 and ASTM E 2187 include requirements for conditioning of materials prior to testing. They also include requirements for quickness of test initiation if the test environment is not the same as the conditioning environment.

Lack of conditioning of larger-scale upholstered items before testing has been suggested as a potential cause for variations in test results. [10] This importance is recognized in the standards for full-scale testing of mattresses, 16 CFR 1632 and 16 CFR 1633, by the inclusion of temperature and relative humidity conditioning requirements. The need for substantial conditioned storage space is a significant factor in using small test specimens in the search for alternative ignition sources.

\subsubsection{Air Drafts}

For experiments involving smoldering combustion, variability in the air flow around the test specimen can lead to a high degree of scatter in the test results. Small-scale testing can be designed to be conducted within enclosures to reduce or control the air flow around the specimen and eliminate the influence of general drafts in the laboratory or testing space, e.g., References [10] and [99]. Typically, it is difficult or not possible to control air drafts in large-scale testing, e.g., References [10] and [121]. Characterization of the direction and speed of air currents is needed in order to develop a basis for comparing the results between small-scale and large-scale tests.

\subsubsection{Influence of Substrate on Cigarette Burning}

There are wide variations in test results for various substrates, e.g., References [10] and [30]. Therefore, it is important that the substrate be fully defined in order to reduce the number of uncontrolled variables and subsequently to assist with the usability of test results for analysis and comparison of different ignition sources. The sources of these variations range from variability among bolts of the same type of fabric $[117,118]$ to the effect of incipient substrate decomposition and/or smoldering. [10] 


\subsubsection{Determination of Time to Ignition}

In tests of upholstered items or mock-up cushions, the metric is whether ignition has occurred. This is typically determined, after the test specimen has cooled, by the dimension of charring of the specimen materials. [106, 108, 109, 114-116, 122, 123]

It may also be useful to record the time to ignition of the substrate as a more sensitive means for comparison of results for various ignition sources. Visual determination of ignition time has proven problematic. Ignition may have occurred below the surface, and a successful initiation is not known until the surface char passes the $50 \mathrm{~mm}$ mark. Discerning a unique relationship between the char spread on the surface fabric and the linear smoldering rate of the padding material(s) is difficult since the latter varies with the test specimen materials.

Silcock and Shields [124] suggested a flux-time product as a parameter to assist in determining the time taken for the sample to ignite. Although components used in upholstered items may be tested using a cone calorimeter, e.g., References [41], [125], and [126], this is not typical for mock-up cushions or full-scale items. Methods for determining time to ignition involving upholstered items ignited by a cigarette have generally been based on observations that are later correlated to recorded thermocouple temperatures, e.g., Reference [30]. 


\section{SUMmary OF ReVIeW}

\subsection{Alternate Ignition Sources}

- Aside from the CPSC examination of alternate ignition sources and the documentation of the NIST development of SRM 1196, there have been no reported efforts to identify new ignition sources for testing soft furnishings for cigarette ignition resistance.

- A variety of thermal sources have been used to study the smoldering ignition of susceptible materials. These sources were mainly cartridge heaters and heated wires. Some work has involved radiative heaters and hot slugs. In none of the testing involving these sources was the source intentionally moved to simulate the movement of a burning cigarette coal.

- There are exothermic reactive materials that might be considered as smoldering ignition sources, although there were no published reports of intent for this use. Such materials include formed cellulosics (e.g., cotton rope, rolled paper, punk), intumescent materials, charcoal, methenamine, and chemicals undergoing a phase change (e.g., sodium acetate).

\subsection{SUBSTRATES STUdIED}

- There have been studies of the smoldering ignition of susceptible materials (including FPU foams, latex foams, cellulosic insulation, and cotton batting) and furniture-like assemblies of materials.

- In these studies that involved cigarettes, the description of the substrate materials is generally insufficient to enable determination of those properties that affected the cigarette's ignition performance.

\subsection{METRICS FOR SMOLDERING IGNITION}

- The initiation of smoldering involves heating a susceptible material to an elevated temperature for some time interval. Heat losses from the potential ignition site, the quality of the thermal contact of the source with the material, and the degree of oxygen depletion near the possible ignition front affect whether and when ignition occurs.

- Smoldering ignition is deemed to be self-sustaining when the smoldering front has advanced far enough that it is no longer heated by the ignition source. For fabric/padding substrates, there is significant evidence that this occurs at a separation distance of approximately $50 \mathrm{~mm}$. If the smoldering progresses along the fabric surface, then char length is a valid indicator of ignition. Should the smoldering progress be below the substrate surface, increasing substrate mass loss is a viable indication of ignition.

- There are many combinations of the thermal processes in the first bullet that can lead to smoldering ignition. To ensure that two dissimilar sources (e.g., a cigarette and a hot slug) are igniting a substrate in the same manner, thermal measurements within the substrate are essential. Measurement of the temperature profile within the substrate and 
the temperature(s) of the ignition source are good starting points.

- Many of the published studies were performed during the evolution of the standard for less fire-prone cigarettes, and the sole metric was the propensity for substrate ignition. This limitation provided minimal guidance for developing a standard ignition source.

- There are sets of experiments for which thorough characterization of the ignition source and the substrate has been documented. Cigarettes (other than SRM 1196) were used in some of these test series, and measurements of the temperatures inside and at the perimeter of the cigarettes, linear burn rates, coal length, etc. have been reported. Appropriate measurements for SRM 1196 cigarettes are needed in order to identify the appropriate temperature ranges to be chosen for non-cigarette ignition sources.

\subsection{OTHER CONSIDERATIONS For IDENTIFYING AND QUalifying Alternate STANDARD IGNITION SOURCES}

- Baseline set of data for SRM 1196. This needs to be accomplished for the selected substrates under the selected test conditions. Specific issues to be considered are:

0 Is enhanced burning (where thermal feedback between the cigarette and the substrate occurs) of the cigarette observed for all substrates that ignite? If not, for what types of substrates is this observed and for what types is it not?

o If enhanced burning of the cigarette is observed for any substrates that do not ignite, for what types of substrates is this observed and for what types is it not?

o For the substrates that do ignite and enhanced burning of the cigarette is also observed, would the substrates ignite without the enhanced burning of the cigarette?

o What is the difference in the thermal characteristics of the ignition source when the smoldering cigarette is covered with a piece of fabric compared to the uncovered test configuration?

- Substrate selection. Some screening of substrates will be necessary. Although there may be a range of possible commercial substrates, the efficient development of an alternate ignition source will require testing on a select few whose ignition performance is reflective of the broader marketplace.

- Tests with a covered ignition source. The sheeting specimens used in some of the testing in 16 CFR 1632 [127] and in 16 CFR 1634 (proposed) [128] can change the oxygen access to the smoldering front and can partially obscure observation of the progress or cessation of smoldering. A precise and repeatable specification and use protocol is important.

- Substrate material variability. Several studies have indicated that inconsistent ignition performance resulted both from non-uniformity of the substrate materials and from unevenness in the assembly of the substrate. Thus, characterization of the materials for test substrates and their variability is important.

- Substrate deformation. Because of its low mass, a test cigarette rests atop the fibers of 
the cover fabric. A heavier candidate SIS might create a channel-shaped depression in the top surface of the substrate. This could significantly affect the nature and the magnitude of the heat transfer from the ignition source to the substrate.

- Ignition source-substrate interaction. For a reactive ignition source such as a cigarette, there can be thermal interaction with the substrate, resulting in acceleration of the ignition process. There will be some thermal interaction for a non-reactive source, but it is likely to be different in character. This difference needs to be determined empirically in order to relate ignition performance among ignition sources on a variety of substrates.

- Control of the test environment. Smoldering ignition is sensitive to the local air velocity and relative humidity. These can be maintained within narrow ranges for testing small specimens, but can be problematic for testing large specimens.

- Ignition temperature sensitivity.

o Prior research has characterized the onset of ignition by an ignition temperature. These studies indicate that this value depends not only on the substrate materials, but on the magnitude of the ignition source and the device used to measure the temperature. Early selection of standard test substrates is thus important, as is use of proper instrumentation.

o The rate of temperature increase has previously been reported to be influential on the ignition of foams, with higher rates potentially leading to the melting of the foam away from the heated area or ignition to flaming. Therefore, the rate of temperature increase is an important parameter to determine the ignition sensitivity for intended test substrates.

o Surface temperature measurements can be made with thermocouples and infrared cameras. The former are used for subsurface measurements. Each type of device has sources of error that need to be minimized. In particular, thermocouples can act as inadvertent heat sinks, lowering the local temperature and perturbing the ignition process.

o Time-based measurements provide more useful information than average or peak values. The temporal and spatial resolution and equipment response time and accuracy need to be considered during the design phase of the test procedure and well understood during analysis of data sets.

o When considering active ignition devices, results for temperature control versus power control may be useful in determining the extent of igniter-substrate thermal interaction.

- Time to ignition sensitivity. There is an effect of ambient air velocity that likely depends on the nature of the ignition source and the composition of the substrate. A set of standard test conditions is needed that relates to the room-scale performance of the tested furnishings.

- Mass loss and mass loss rate measurement. If these are deemed important for characterizing the onset or result of smoldering ignition, the substrate mass consumed needs to be measurable in the presence of a heavier test apparatus and electrical leads to 
thermocouples.

- Precision.

0 The degree of agreement in ignition performance between a candidate ignition source and SRM 1196 needs to be established before testing begins. This criterion would reflect the variability in test materials, operator consistency, etc.

o The larger the number of replicate tests, the greater the confidence in the ability to discern agreement and disagreement among ignition sources. However, the larger the number of tests, the less likely that the substrate materials will be uniform, due to inter-batch variability. 


\section{References}

[1] Clarke, F. B. I., and Ottoson, J., 1976, "Fire Death Scenarios and Fire Safety Planning," Fire Journal, 70(3), pp. 117-118.

[2] 1972, "America Burning: the Report of the National Commission on Fire Prevention and Control," U.S. Government Printing Office, Washington, D.C.

[3] Hall, J., J.R., 2010, "The Smoking-Material Fire Problem," National Fire Protection Association, Quincy, MA.

[4] 1972, "Standard for the Flammability of Mattresses and Mattress Pads," 16 Code of Federal Regulations, Part 1632.

[5] 2009, "Standard for the Flammability of Residential Upholstered Furniture (Proposed)," 16 Code of Federal Regulations, Part 1634.

[6] 2000, "Requirements, Test Procedure, and Apparatus for Testing the Flame and Smolder Resistance of Upholstered Furniture," Technical Bulletin 117, Bureau of Home Furnishings and Thermal Insulation, State of California, North Highlands, CA.

[7] 2009, "Standard Methods of Tests and Classification System for Cigarette Ignition Resistance of Components of Upholstered Furniture," NFPA 260, National Fire Protection Association, Quincy, MA.

[8] 2002, "Standard Test Method for Cigarette Ignition Resistance of Components of Upholstered Furniture," ASTM E 1353, ASTM International, West Conshohocken, PA.

[9] 2009, "Standard Method of Test for Determining Resistance of Mock-Up Upholstered Furniture Material Assemblies to Ignition by Smoldering Cigarettes," NFPA 261, National Fire Protection Association, Quincy, MA.

[10] Gann, R. G., Harris, J., R.H., Krasny, J. F., Levine, R. S., Mitler, H. E., and Ohlemiller, T. J., 1987, "The Effect of Cigarette Characteristics on the Ignition of Soft Furnishings," Volume 3 Technical Study Group Cigarette Safety Act of 1984, NBS TN 1241, National Bureau of Standards, Gaithersburg, MD.

[11] Loftus, J. J., 1971, "Results of Temperature Measurements Made on Burning Cigarettes and Their Use as a Standard Ignition Source for Mattress Testing," NBS Memo Report, June 18, 1971, National Bureau of Standards, Gaithersburg, MD.

[12] Loftus, J. J., 1978, "Back-Up Report for the Proposed Standard for the Flammability (Cigarette Ignition Resistance) of Upholstered Furniture," PFF 6-76, NISTIR 78-1438, National 
Bureau of Standards, Gaithersburg, MD.

[13] 2000, "New York Legislation and Fire Safety Standard for Cigarettes, Chapter 284," Laws of New York, United States of America.

[14] Alpert, H. R., Carpenter, C., Connolly, G. N., Rees, V., and Wayne, G. F., 2005, "'Fire Safer" Cigarettes: The Effect of the New York State Cigarette Fire Safety Standard on Ignition Propensity, Smoke Toxicity, and the Consumer Market - A Preliminary Report," Harvard School of Public Health, Boston, MA.

[15] NIST, 2010, "Standard Reference Materials, Material Measurement Laboratory," https://www-s.nist.gov/srmors/quickSearch.cfm.

[16] Gann, R. G., and Hnetkovsky, E. J., 2009, "Modification of ASTM E 2187 for Measuring the Ignition Propensity of Conventional Cigarettes," NIST TN 1627, National Institute of Standards and Technology, Gaithersburg, MD.

[17] Cleary, T., 2009, "Results from a Full-Scale Smoke Alarm Sensitivity Study," Suppression and Detection Research Application: A Technical Working Conference, 13th Annual. SUPDET 2009. Proceedings, Fire Protection Research Foundation, Orlando, FL.

[18] Cleary, T., 2010, "Results from a Full-Scale Smoke Alarm Sensitivity Study," Fire Technology, published online.

[19] Owrutsky, J. C., Steinhurst, D. A., Minor, C. P., Rose-Pehrsson, S. L., Williams, F. W., and Gottuck, D. T., 2006, "Long Wavelength Video Detection of Fire in Ship Compartments," Fire Safety Journal, 41, pp. 315-320.

[20] Steinhurst, D. A., Minor, C. P., Owrutsky, J. C., Rose-Pehrsson, S. L., Gottuk, D. T., Williams, F. W., and Farley, J. P., 2003, "Long Wavelength Video-Based Event Detection Preliminary Results from the CVNX and VS1 Test Series, ex-USS SHADWELL 7-25 April 2003," NRL/MM-MR/6110--03-8733, Naval Resarch Laboratory, Washington, D.C.

[21] Lynch, J. A., Gottuk, D. T., Rose-Pehrsson, S. L., Steinhurst, D. A., Minor, C. P., Wales, S. C., Williams, F. W., and Parley, J. P., 2004, "Volume Sensor Development Test Series 2 Lighting Conditions, Camera Settings, and Spectral and Acoustic Signatures," NRL/MRMM/6180--04-8843, Naval Research Laboratory, Washington, D.C.

[22] Tao, W., 2002, "Memorandum regarding the Development of a Surrogate for the Standard Cigarette Ignition Source - Status Report, April 2002, Consumer Product Safety Commission," Recipient: Neily, M., U.S. Consumer Product Safety Commission, Washington, D.C. 
[23] Pitts, W. M., 2007, "Ignition of Cellulosic Fuels by Heated and Radiative Surfaces," NIST Technical Note 1481, National Institute of Standards and Technology, Gaithersburg, MD.

[24] Hagen, B. C., Frette, V., Kleppe, G., and Arntzen, B. J., 2011, "Smoldering in Cotton: Effects of Density," Fire Safety Journal, 46(3), pp. 73-80.

[25] Putzeys, O. M., Fernandez-Pello, A. C., Rein, G., and Urban, D. L., 2008, "The Piloted Transition to Flaming in Smoldering and Fire Retarded and Non-Fire Retarded Polyurethane Foam," Fire and Materials, 32, pp. 485-499.

[26] Kellogg, D. S., Waymack, B. E., Mcrae, D. D., Chen, P., and Dwyer, R. W., 1998, "The Initiation of Smoldering Combustion in Cellulosic Fabrics," Journal of Fire Sciences, 16(2), pp. 90-104.

[27] Querol, E., Torrent, J. G., Bennett, D., Gummer, J., and Fritze, J.-P., 2006, "Ignition Tests for Electrical and Mechanical Equipment Subjected to Hot Surfaces," Journal of Loss Prevention in the Process Industries, 19, pp. 639-644.

[28] Ohlemiller, T. J., and Rogers, F. E., 1980, "Cellulosic Insulation Material II, Effect of Additives on Some Smolder Characteristics," Combustion Science and Technology, 24(3-4), pp. 139-152.

[29] Ohlemiller, T. J., 1981, "Cellulosic Insulation Material III, Effects of Heat Flow Geometry on Smolder Initiation," Combustion Science and Technology, 26(3-4), pp. 89-105.

[30] Salig, R., 1982, "Smoldering Behavior of Upholstered Polyurethane Cushioning and Its Relevance to Home Furnishings Fires," Master of Science and Engineering, Massachusetts Institute of Technology, Cambridge, MA.

[31] Beyler, C. L., Fay, T., Gratkowski, M., Campbell, B., and Hartman, J. R., 2006, "Ignition Studies of Cerium Nitrate Treated Towels," Fire and Materials, 30, pp. 223-240.

[32] Suuberg, E. M., Milosavljevic, I., and Lilly, W. D., 1994, "Behavior of Charring Materials in Simulated Fire Environments," NSIT-GCR-94-645, National Institute of Standards and Technology, Gaithersburg, MD.

[33] Bukowski, R. W., Peacock, R. D., Averill, J. D., Cleary, T. G., Bryner, N. P., Walton, W. D., Reneke, P. A., and Kuligowski, E. D., 2008, "Performance of Home Smoke Alarms, Analysis of the Response of Several Available Technologies in Residential Fire Settings," TN 1455-1, National Institute of Standards and Technology, Gaithersburg, MD.

[34] Collier, P. C. R., 2011, "Personal Communication: Unsuccessful upholstery mockup ignition device using Nichrome ${ }^{\mathrm{TM}}$ wire," BRANZ Ltd, Judgeford, New Zealand. 
[35] Grishin, A. M., Dolgov, A. A., Zima, V. P., Kryuchokov, D. A., Reino, V. V., Subbotin, A. N., and Tsvyk, R. S., 1998, "Ignition of a Layer of Combustible Forest Materials," Combustion, Explosion and Shock Waves, 34(6), pp. 613-620.

[36] Walther, D. C., Anthenien, R. A., and Fernandez-Pello, A. C., 2000, "Smolder Ignition of Polyurethane Foam: Effect of Oxygen Concentration," Fire Safety Journal, 34(4), pp. 343-359.

[37] Eckhoff, R. K., 1996, "Prevention and Mitigation of Dust Explosions in the Process Industries: A Survey of Recent Research and Development," Journal of Loss Prevention in the Process Industries, 9(1), pp. 3-20.

[38] Olson, S. L., Baum, H. R., and Kashiwagi, T., 1998, "Finger-Like Smoldering Over Thin Cellulosic Sheets in Microgravity," Twenty-seventh International Symposium on Combustion, The Combustion Institute, pp. 2525-2533.

[39] Mitler, H. E., and Walton, G. N., 1993, "Modeling the Ignition of Soft Furnishings by a Cigarette," NIST Special Publication 851, Vol. 3, National Institute of Standards and Technology, Gaithersburg, MD.

[40] Mitler, H. E., and Walton, G., 1992, "A Computer Model of the Smoldering Ignition of Furniture," NISTIR 4973, National Institute of Standards and Technology, Gaithersburg, MD.

[41] Anderson, M. K., Sleight, R. T., and Torero, J. L., 2000, "Downward Smolder of Polyurethane Foam: Ignition Signatures," Fire Safety Journal, 35(2), pp. 131-147.

[42] Daikoku, M., Venkatesh, S., and Saito, K., 1994, "The Use of Cellulose Sample for Material's Flammability and Pyrolysis Tests," Journal of Fire Sciences, 12(5), pp. 424-441.

[43] Gratkowski, M. T., Dembsey, N. A., and Beyler, C. L., 2006, "Radiant Smoldering Ignition of Plywood," Fire Safety Journal, 41, pp. 527-543.

[44] Bilbao, R., Mastral, J. F., Aldea, M. E., Ceamanos, J., Betran, M., and Lana, J. A., 2001, "Experimental and Theoretical Study of the Ignition and Smoldering of Wood including Convective Effects," Combustion and Flame, 126, pp. 1363-1372.

[45] Schaffer, E. L., 1980, "Smoldering Initiation in Cellulosics under Prolonged Low-Level Heating," Fire Technology, 16(1), pp. 22-28.

[46] Kashiwagi, T., 1979, "Experimental Observation of Radiative Ignition Mechanisms," Combustion and Flame, 34, pp. 231-244.

[47] 1987, "Method of Determination of the Effects of a Small Source of Ignition on Textile Floor Coverings (Hot Metal Nut Method)," BS 4790, British Standards Institution, London, UK. 
[48] Ortiz Molina, M. G., 1976, "Experimental Investigation of Smoldering Combustion of Cellulosic Materials," Master of Science and Mechanical Engineering, Massachusetts Institute of Technology, Cambridge, MA.

[49] Kinbara, T., Endo, H., and Sega, S., 1966, "Combustion Propagation through Solid Materials I - Downward Propagation Along a Thin Vertical Sheet of Paper," Combustion and Flame, 10(1), pp. 29-36.

[50] Kinbara, T., Endo, H., and Sega, S., 1967, "Downward Propagation of Smoldering Combustion through Solid Material," Symposium (International) on Combustion, pp. 525-531.

[51] Collier, P. C. R., and Whiting, P. N., 2008, "Timeline for Incipient Fire Development," Study Report No. 194, BRANZ Ltd, Judgeford, New Zealand.

[52] White, N., Dowling, V. P., and Barnett, J. R., "Full-Scale Fire Experiment on a Typical Passenger Train," Proc. Fire Safety Science, Proceedings of the Eigth International Symposium, International Association for Fire Safety Science, pp. 1157-1168.

[53] Ohlemiller, T. J., and Villa, K., 1992, "Characterization of the California Technical Bulletin 133 Ignition Source and a Comparable Gas Burner," Fire Safety Journal, 18(4), pp. 325-354.

[54] Zicherman, J. B., and Allard, D. L., 1988, "Compartment Tests of Polyurethane Foam Seating Assembiles," Fire Technology, 24(2), pp. 128-137.

[55] Mukunda, H. S., Basani, J., Shravan, H. M., and Binoy, P., 2007, "Combustion of "Incense" Sticks: Experiments and Modeling," Combustion Science and Technology, 179(4-6), pp. 11131129 .

[56] Lin, T. C., Yang, C. R., and Chang, F. H., 2007, "Burning Characteristics and Emission Products Related to Metallic Content in Incense," Journal of Hazardous Materials, 140, pp. 165172.

[57] Anderson, M. K., Sleight, R. T., and Torero, J. L., 2000, "Igintion Signatures of a Downward Smolder Reaction," Experimental Thermal and Fluid Science, 21, pp. 33-40.

[58] Anthenien, R. A., and Fernandez-Pello, A. C., 1998, "A Study of Forward Smolder Ignition of Polyurethane Foam," Symposium (International) on Combustion, 27(2), pp. 2683-2690.

[59] Chao, C. Y. H., and Wang, J. H., 2001, "Transition from Smoldering to Flaming Combustion of Horizontally Oriented Flexible Polyurethane Foam with Natural Convection," Combustion and Flame, 127(4), pp. 2252-2264. 
[60] Camino, G., and Costa, L., 1988, "Performance and Mechanisms of Fire Retardants in Polymers - A Review," Polymer Degradation and Stability, 20, pp. 271-294.

[61] Ohlemiller, T. J., 1985, "Modeling of Smoldering Combustion Propagation," Progress in Energy and Combustion Science, 11(4), pp. 277-310.

[62] Babrauskas, V., 1985, "Pillow Burning Rates," Fire Safety Journal, 8(3), pp. 199-200.

[63] Krasny, J., Rockett, J. A., and Huang, D., 1988, "Protecting Fire Fighters Exposed in Room Fires: Comparison of Results of Bench Scale Test for Thermal Protection and Conditions during Room Flashover," Fire Technology, 24(1), pp. 5-19.

[64] Stoliarov, S. I., Crowley, S., Walters, R. N., and Lyon, R. E., 2010, "Prediction of the Burning Rates of Charring Polymers," Combustion and Flame, 157(11), pp. 3024-3034.

[65] 2006, "Standard Test Method for Ignition Characteristics of Finished Textile Floor Covering Materials," ASTM D 2859, ASTM International, West Conshohoken, PA.

[66] Damant, G., 1971, "Progress Report on Flammability Studies," Laboratory Report Number SP-71-2, State of California, Department of Consumer Affairs, Bureau of Furniture and Bedding Inspection.

[67] Gann, R. G., 2002, "Concept paper: Development of a Standard Ignition Source for Testing Mattresses and Upholstered Furniture " Presented to a Meeting of Manufacturers and Regulators, U.S. Consumer Product Safety Commission, June 19, 2002.

[68] Rogers, F. E., and Ohlemiller, T. J., 1980, "Cellulosic Insulation Material I. Overall Degradation Kinetics and Reaction Heats," Combustion Science and Technology, 24(3-4), pp. 129-137.

[69] Bar-Ilan, A., Putzeys, O. M., Rein, G., Fernandez-Pello, A. C., and Urban, D. L., 2005, "Transition from Forward Smoldering to Flaming in Small Polyurethane Foam Samples," Proceedings of the Combustion Institute, 30(2), pp. 2295-2302.

[70] 2009, "Mechanical Properties of Corrosion-Restistant Stainless Steel Fasteners, Part 2: Nuts," BS/EN/ISO 3506, International Organization for Standardization, Geneva, Switzerland.

[71] 1981, "Specification for Corrosion-Resistant Stainless Steel Fasteners," BS 6105, British Standards Institution, London, UK.

[72] 2001, "ISO Metric Precision Hexagon Bolts, Screws and Nuts - Specification," BS 3692, British Standards Institution, London, UK. 
[73] 2010, "Square and Hex Nuts," ANSI/ASME B18.2.2, American Society of Mechanical Engineers.

[74] Collier, P. C. R., 2007, "Fire Properties of Floor Coverings: New Fire Test Methods and Acceptable Solutions," Study Report No. 181, BRANZ Ltd, Judgeford, New Zealand.

[75] Tao, W., 2006, Consumer Product Safety Commission, Personal Communication to Gann, R.G.

[76] UFAC, 1990, "Fabric Classification Test Method," Upholstered Furniture Action Council.

[77] Mowrer, F. W., 1999, "Fire Safe Student Housing: A Guide for Campus Housing Administrators," United States Fire Administration, Emmitsburg, MD.

[78] Ahrens, M., 2008, "Fires and Burns Involving Home Medical Oxygen," National Fire Protection Association, Quincy, MA.

[79] Cagliostro, D. E., Riccitello, S. R., Clark, K. L., and Shimizu, A. B., 1975, "Intumescent Coating Modeling (for Thermal Protection)," Journal of Fire and Flammability, 6, pp. 205-221.

[80] Di Blasi, C., 2004, "Modeling the Effects of High Radiative Heat Fluxes on Intumescent Material Decomposition," Journal of Analytical and Applied Pyrolysis, 71, pp. 721-737.

[81] Camino, G., Costa, L., and Luda di Cortemiglia, M. P., 1991, "Overview of Fire Retardant Mechanisms," Polymer Degradation and Stability, 33, pp. 131-154.

[82] Zumdahl, S. S., and Zumdahl, S. A., 2010, Chemistry, Brooks Cole, Belmont, CA.

[83] Helmestine, A. M., 2011, "Black Snakes or Glow Worms: Make Your Own Fireworks," http://chemistry.about.com/od/chemistryhowtoguide/a/blacksnakes.htm.

[84] 2000, "Standard for the Surface Flammability of Carpets and Rugs," FF 1-70, U.S. Consumer Product Safety Commission, Bethesda, MD.

[85] Wikipedia, 2011, "Hand warmer," http://en.wikipedia.org/wiki/Hand_warmer.

[86] Ohlemiller, T. J., 2008, "Smoldering Combustion, Chapter 9, Section 2," SFPE Handbook of Fire Protection Engineering, P. J. DiNenno, D. Drysdale, C. L. Beyler, and W. D. Walton, eds., Society of Fire Protection Engineers, Bethesda, MD, pp. 2/229-240.

[87] Krasny, J. F., 1987, "Cigarette Ignition of Soft Furnishings—A Literature Review with Commentary, Report No. 2," NBSIR 87-3509, US National Bureau of Standards, Gaithersburg, 
MD.

[88] Waymack, B. E., Kellogg, D. S., McRae, D. D., and Dwyer, R. W., 1997, "Watts in a Cigarette: Thermophysical Properties of Smoldering Cigarettes," Tobacco Science, 41, pp. 7481 .

[89] Krasny, J. F., Allen, P. J., Maldonado, A., and Juarez, N., 1981, "Development of a Candidate Test Method for the Measuremnet of the Propensity of Cigarettes to Cause Smoldering Ignition of Upholstered Furniture and Mattresses," NISTIR 81-2363, National Bureau of Standards, Gaithersburg, MD.

[90] Laszlo, T. S., and Watson, F. M., 1974, "A Scanning Infrared Technique for Cigarette Coal Peak Temperature Measurements," Beitraege zur Tabakforschung, 7(5), pp. 269-275.

[91] Lam, J., 1955, "Measuring Temperature during Combustion in Cigarettes, Cigarillos, Cigars and Pipes," Acta Pathologica Microbiologica Scandinavica, 36(6), pp. 503-510.

[92] Sherwood, T. S., Issac, J. C., and Jones, J. S., 2006, "Semi-Empirical Model using Radian Coal Power to Predict Cigarette Ignition Strength as Measured by Extinction Test," Fire Technology, 42(3), pp. 233-251.

[93] Liu, C., and Woodcock, D., 2002, "Observing the Peripheral Burning of Cigarettes by an Infrared Technique," Beitraege zur Tabakforschung International/ Contributions to Tobacco Research, 20(4), pp. 257-264.

[94] Holleyhead, R., 1999, "Ignition of Solid Materials and Furniture by Lighted Cigarettes. A Review," Science \& Justice, 39(2), pp. 75-102.

[95] Lendvay, A. T., and Laszlo, T. S., 1974, "Cigarette Peak Coal Temperature Measurements," Beitrage zur Tabakforschung, 7(5), pp. 276-281.

[96] Baker, R. R., 1975, "Temperature Variation Within a Cigarette Combustion Coal during the Smoking Cycle," High Temperature Science, 7, pp. 236-247.

[97] Egerton, A., Gugan, K., and Weinberg, F. J., 1963, "Mechanism of Smoldering in Cigarettes," Combustion and Flame, 7(1), pp. 63-78.

[98] Justice, A., 2011, "A Review of the Smouldering Characteristics of Cigarettes, and the Likely Ignition of Cellulose Materials from Hand-Rolled Cigarettes," Masters of Science Degree in Applied Science - Fire Investigation, Anglia Ruskin University, Cambridge, UK.

[99] Ohlemiller, T. J., 2008, "On the Criteria for Smoldering Ignition in the CFR 1632 Cigarette Test for Mattresses," NIST TN 1601, National Institute of Standards and Technology, 
Gaithersburg, MD.

[100] Tao, W., 2005, "Memorandum regarding Evaluation of Test Method and Performance Criteria for Cigarette Ignition (Smoldering) Resistance of Upholstered Furniture Materials, May 12 2005, U.S. Consumer Product Safety Commission," Recipient: Ray, D., http://www.cpsc.gov/LIBRARY/FOIA/FOIA05/os/uff2.pdf, U.S. Consumer Product Safety Commission, Bethesda, MD.

[101] Scott, L. L., 2005, "Memorandum regarding Smoldering and Small Open Flame Ignition Performance of Upholstered 'Furniture Loose Fill Materials', May 31 2005, U.S. Consumer Product Safety Commission," Recipient: Ray, D., http://www.cpsc.gov/LIBRARY/FOIA/FOIA05/os/uff5.pdf, U.S. Consumer Product Safety Commission,Bethesda, MD.

[102] Moussa, N. A., Toong, T. Y., and Garris, C. A., 1977, "Mechanism of Smoldering of Cellulosic Materials," 16(1), pp. 1447-1457.

[103] Eitzinger, B., and Pirker, S., 2005, "Numerical Simulation of a Cigarette during Smoking," Contributions to Tobacco Research, 21(7), pp. 402-416.

[104] Watkins, M. L., and Jones, J. S., "Characterization of the Heat Transfer for Cigarette Ignition Propensity Substrates using Transient Thermal Analysis," Proc. CORESTA Smoke and Technology Groups Meeting.

[105] Damant, G. H., 1995, "Cigarette Ignition of Upholstered Furniture," Journal of Fire Sciences, 13(5), pp. 337-349.

[106] Damant, G. H., Williams, S. S., and McCormack, J. A., 1983, "The Role of Fabric in the Cigarette Ignition of Upholstered Furniture," Journal of Fire Sciences, 1(5), pp. 309-321.

[107] Ohlemiller, T. J., Villa, K. M., Braun, E., Eberhardt, K. R., Harris, J., R.H., Lawson, J. R., and Gann, R. G., 1995, "Quantifying the Ignition Propensity of Cigarettes," Fire and Materials, 19, pp. 155-169.

[108] Ohlemiller, T. J., Villa, K. M., Braun, E., Eberhardt, K. R., Harris, J., R.H., Lawson, J. R., and Gann, R. G., 1993, "Test Methods for Quantifying the Propensity of Cigarettes to Ignite Soft Furnishings," Report No. 2, Technical Advisory Group, Fire Safe Cigarette Act of 1990 and NIST Special Publication 851, National Institute of Standards and Technology, Gaithersburg, MD.

[109] Damant, G. H., McCormack, J. A., and Claire, B., 1987, "Tests of Smoldering Ignition of Chairs and Reduced-Scale Mock-Ups by Various Cigarettes," Report No. 7, Technical Study Group on Cigarette and Little Cigar Fire Safety, Cigarette Safety Act of 1984, U. S. Consumer 
Product Safety Commission, Washington, D.C.

[110] Greear, L. C., Hudson, W. Z., Jupe, R., Pinion, D. O., and Wanna, J. T., 1996, "Ignition Responses of Fifty Upholstdery Fabrics to Commercial Cigarettes," Journal of Fire Sciences, 14(6), pp. 413-425.

[111] Donaldson, D. J., Yeadon, D. A., and Harper, R. J. J., 1983, "Smoldering Phenomenon Associated with Cotton," Textile Research Journal, 53(3), pp. 160-164.

[112] Kellogg, D. S., Waymack, B. E., Mcrae, D. D., and Dwyer, R. W., 1997, "Smolder Rates of Thin Cellulosic Materials," Journal of Fire Sciences, 15(5), pp. 390-403.

[113] Wakelyn, P. J., Adair, P. K., and Barker, R. H., 2005, "Do Open Flame Ignition Resistance Treatments for Cellulosic and Cellulosic Blend Fabrics also Reduce Cigarette Ignitions?," Fire and Materials, 29, pp. 15-26.

[114] Dwyer, R. W., Fournier, L. G., Lewis, L. S., Furin, D., Ihrig, A. M., Smith, S., Hudson, W. Z., Honeycutt, R. H., and Bunch, J. E., 1994, "The Effects of Upholstery Fabric Properties on Fabric Ignitabilities by Smoldering Cigarettes," Journal of Fire Sciences, 12(3), pp. 268-283.

[115] Hirschler, M. M., 1997, "Comparison of the Propensity of Cigarettes to Ignite Upholstered Furniture Fabrics and Cotton Ducks (500-Fabric Study)," Fire and Materials, 21(3), pp. 123141.

[116] Paul, K. T., 2000, "Assessment of Cigarettes of Reduced Ignition Power and their Role to Reduce Fire Risks of Upholstered Seating, Mattresses, and Bed Assemblies," Journal of Fire Sciences, 18(1), pp. 28-73.

[117] Jupe, R., Shipley, D. K., Hudson, W. Z., Wanna, J. T., and Greear, L. C., 1995, "Inter-Bolt Variability of Cotton Duck \#4 on Cigarette Ignition Propensity Test Outcome," Journal of Fire Sciences, 13(2), pp. 127-140.

[118] Wanna, J. T., Jupe, R., Chen, P. L., and Greear, L. C., 1996, "Effect of Cotton Duck \#6 Inter-Bolt Variability on Cigarette Ignition Propensity Test Outcome," Journal of Fire Sciences, 14(4), pp. 313-324.

[119] Gandhi, S., Spivak, S. M., and Pourdeyhimi, B., 1995, "Computer Aided Infrared Imagery for Fabric Surface Temperautre Fields under Simulated Cigarette Exposure," Journal of Fire Protection Engineering, 7(4), pp. 107-123.

[120] Gandhi, S., Spivak, S. M., and Pourdeyhimi, B., 1998, "A Study of Smoldering Conditions in Upholstery Fabrics using Thermal Imaging," Textile Research Journal, 68(9), pp. 687-696. 
[121] Paul, K. T., and King, D. A., 1990, "The Burning Behaviour of Domestic Upholstered Chairs Containing Different Types of Polyurethane Foams," Fire Safety Journal, 16(5), pp. 389410 .

[122] McCormack, J. A., Damant, G. H., and Williams, S. S., 1986, "Cigarette Evaluation of 450 Pieces of Residential Upholstered Furniture," Journal of Fire Sciences, 4, pp. 135-147.

[123] Eberhardt, K. R., Levenson, M. S., and Gann, R. G., 1997, "Fabrics for Testing the Ignition Propensity of Cigarettes," Fire and Materials, 21, pp. 259-264.

[124] Silcock, G. W. H., and Shields, T. J., 1995, "A Protocol for Analysis of Time-to-Ignition Data from Bench Scale Tests," Fire Safety Journal, 24(1), pp. 75-95.

[125] Hilado, C. J., and Brauer, D. P., 1979, "Ignition Testing of Fabrics and Fabric/Cushion Systems," Fire Technology, 15(3), pp. 216-228.

[126] Babrauskas, V., and Wetterlund, I., 1998, "Testing of Furniture Composites in the Cone Calorimeter: A New Specimen Preparation Method and Round Robin Results," Fire Safety Journal, 30(2), pp. 179-194.

[127] CPSC, 1972, "16 CFR 1632 Standard for the Flammability of Mattresses and Mattress Pads (FF 4-72, Amended)," Consumer Product Safety Commission, Washington, D.C.

[128] CPSC, 2008, "16 CRF 1634 Standard for the Flammability of Residential Upholstered Furniture, Proposed Rule," Federal Register, Vol. 73, No. 43, Consumer Product Safety Commission, Washington, D.C. 